\title{
Sistema de Segurança Distribuído: Integração de Firewalls com Sistemas de Detecção de Intrusão
}

\author{
José Maurício Bonifácio Júnior
}

Orientador: Prof. Dr. Edson dos Santos Moreira

Dissertação apresentada ao Instituto de Ciências Matemáticas e de Computação - USP, como parte dos requisitos para obtenção do título de Mestre em Ciências - Área de Ciências de Computação e Matemática Computacional

USP - São Carlos

Dezembro de 1998 
Aos meus pais, Maurício e Regina 


\section{Agradecimentos}

À minha família, principalmente meus pais e avós, pelo constante apoio, carinho e dedicação, sem os quais nunca teria chegado até aqui.

Ao Prof. Dr. Edson dos Santos Moreira, um grande amigo e orientador, pelo constante apoio e incentivo desde a graduação e (como não poderia deixar de ser) paciência.

Ao Prof. Dr. André C. P. L. F. de Carvalho, meu orientador em Iniciação Científica e que teve uma importância fundamental neste mestrado.

Aos colegas de república, Taboca, Gustavo e Roger.

Aos grandes amigos, especialmente à Samantha, Elder, Pissioli, Mac, Claudia, Roberto, Humberto, Elaine, Tanão, Matite, Araxá, Vidigal, Laura, Kutova, Dilvan pela convivência, risadas e pelas pequenas (e grandes) ajudas, sem mencionar as barcas.

A todo o pessoal do ICMC, da seção de pós (Beth, Laura e Marília), da secretaria, Paulinho, Cabral, Eduardo, Frans, e tantos outros, pela prestatividade e amizade que encontrei neles.

À FAPESP e CNPq, pelo apoio financeiro durante a graduação e pós. 


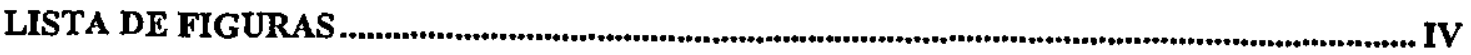

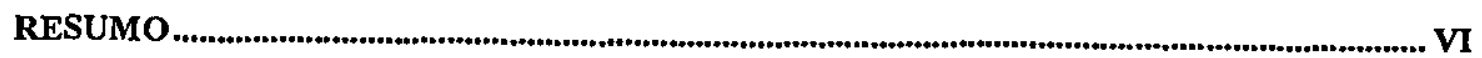

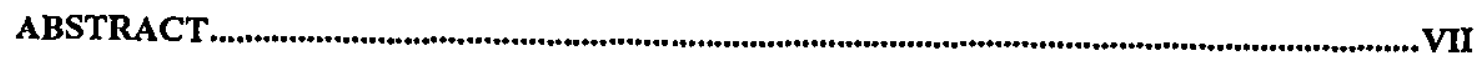

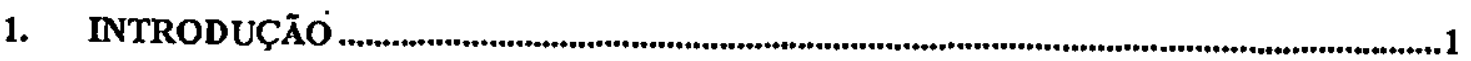

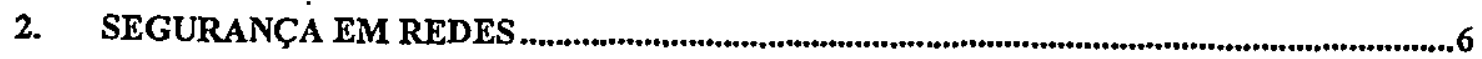

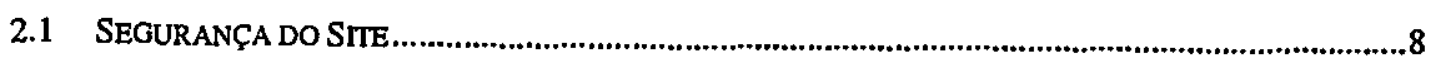

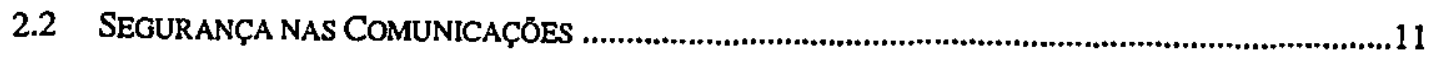

3. FERRAMENTAS PARA SEGURANÇA DE REDES .......................................................16

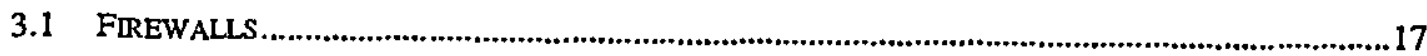

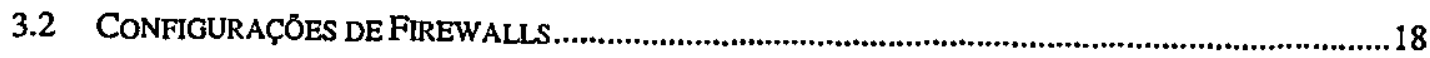

3.2.1 Firewall com Filtragem de Pacotes......................................................................22

3.2.2 Dual-Homed Gateway............................................................................................21

3.2.3 Screened Host Firewall.........................................................................................22

3.2.4 Screened Subnet Firewall ........................................................................................23.

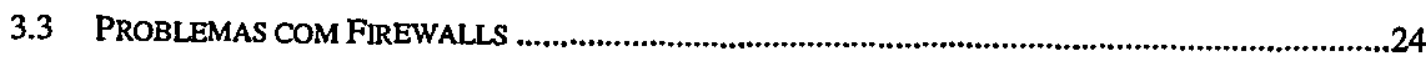

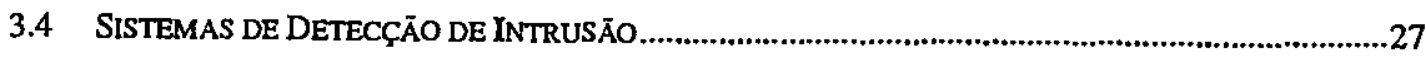

3.5 O SISTEMA DE DETECÇĀO DE INTRUSĀO DO ICMSC ..............................................................28

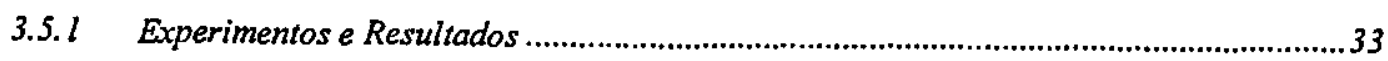

3.6 EXEMPLOS DE PROJETOS DE INTEGRAÇĀO ..............................................................................37

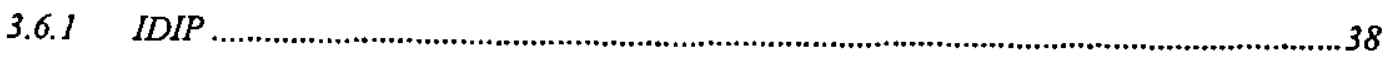

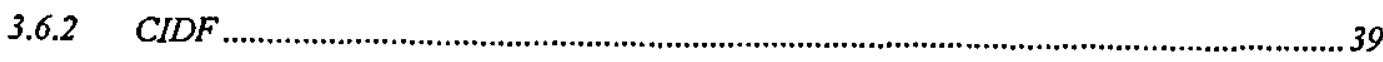

4. SISTEMA DE SEGURANÇA DISTRIBUIDO.............................................................40

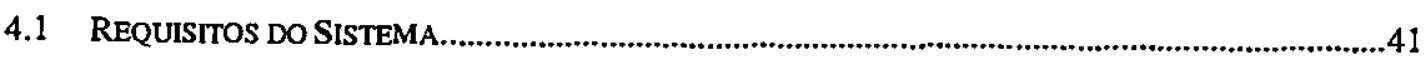

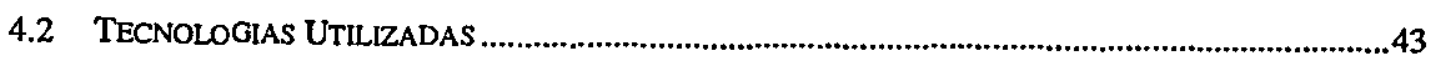

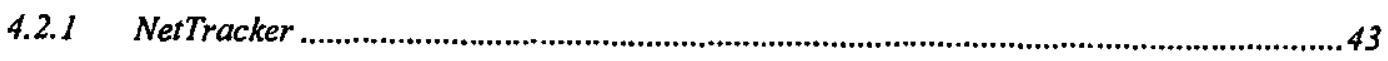

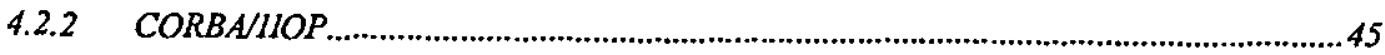

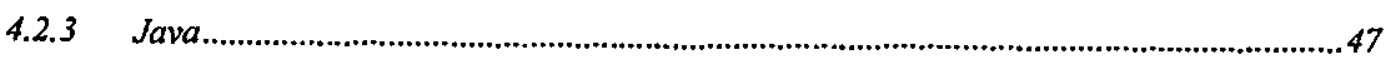

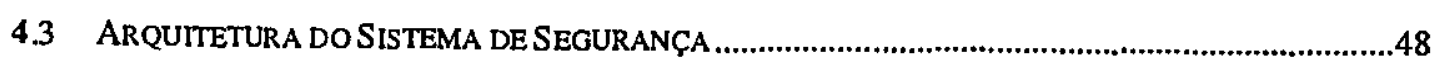

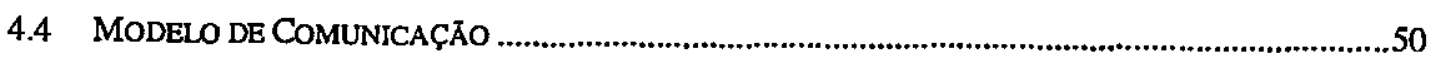

4.5 INTEGRAÇÃo DO FIREWALL E DO ACME! COM O SISTEMA DE SEGURANÇA ..............................52

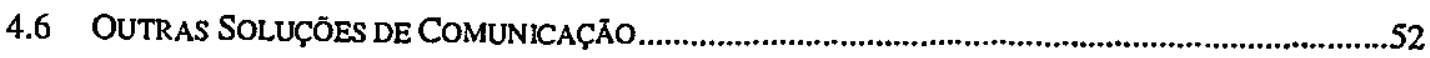

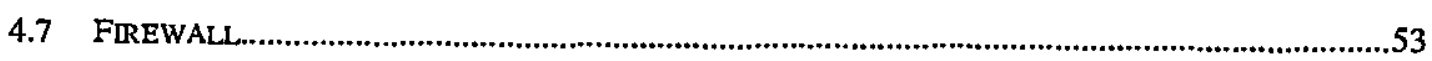

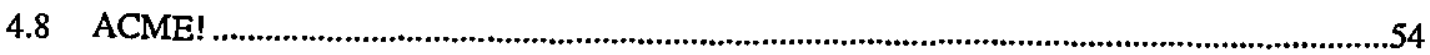

4.8.1 Melhoria dos resultados da rede neural .................................................................55 


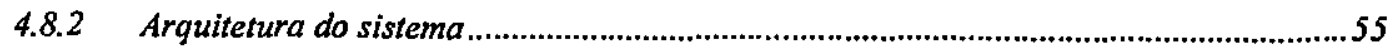

4.8.3 Módulo Semântico/Neural .........................................................................................57

4.8.4 Implementação e Análise da Rede Neural em C..........................................................61

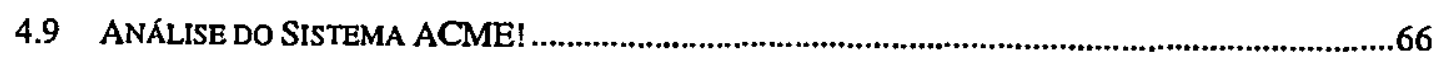

4.9.1 Uso do ACME! em Ambientes Baseados em Switch ......................................................66

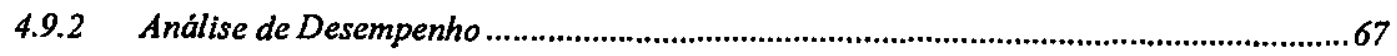

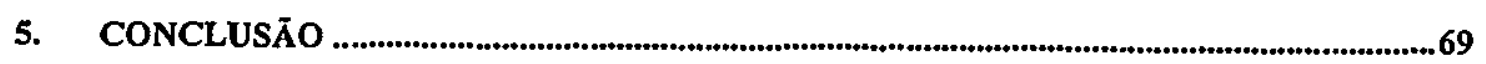

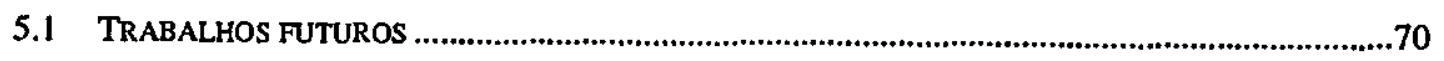

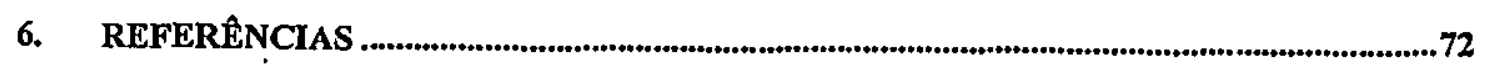

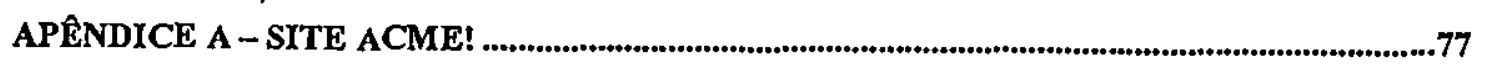

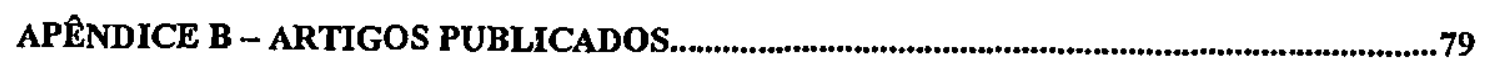




\section{Lista de Figuras}

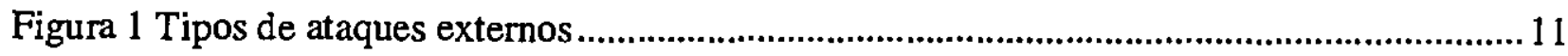

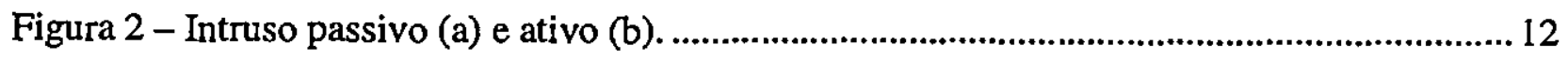

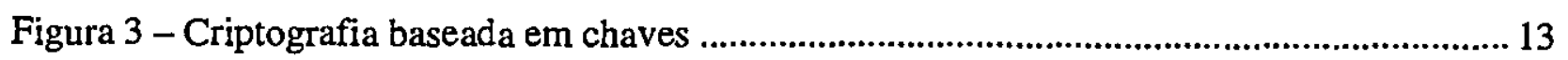

Figura 4 - Comunicação passando pelo gateway de aplicação ................................................... 20

Figura 5- Firewall com filtragem de pacotes ....................................................................21

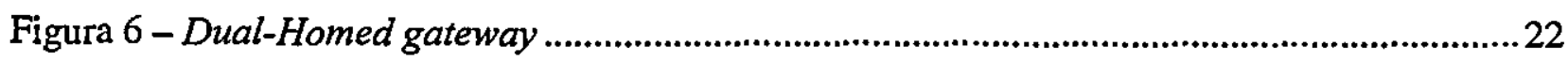

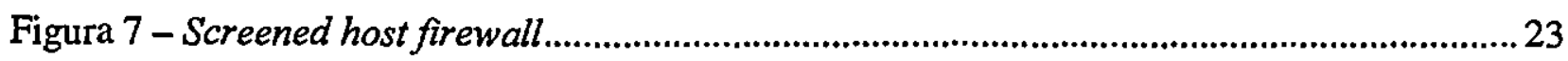

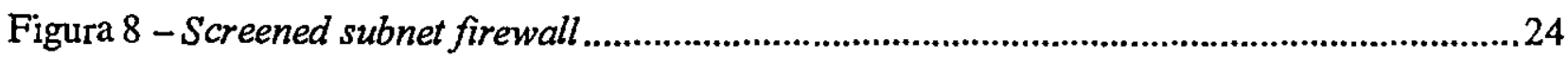

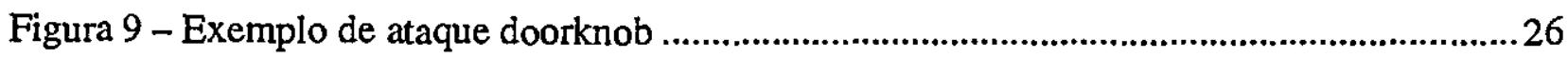

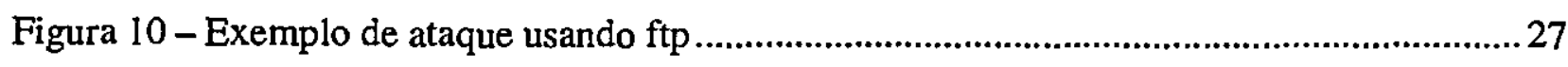

Figura 11 - Estrutura modular do sistema de detecção de intrusão............................................229

Figura 12 - Exemplo de ataque ao SendMail ........................................................................ 31

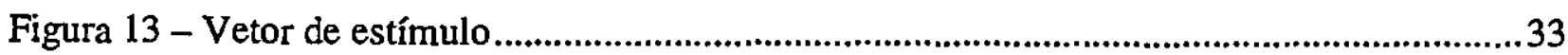

Figura 14 - Vetores de estímulo gerados pela técnica de janelas ........................................... 33

Figura 15 - Resultados do al goritmo Backpropagation .......................................................... 35

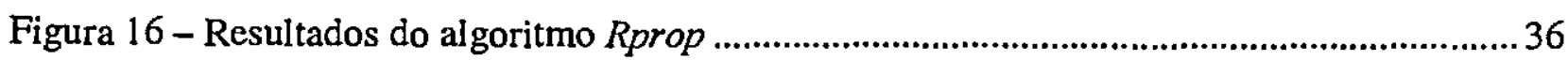

Figura 17 - Resultados do algoritmo QuickProp ..................................................................36

Figura 18 - Relacionamento de comunicação intramódulos .....................................................4 43

Figura 19 - Arquitetura do sistema NetTracker......................................................................4 44

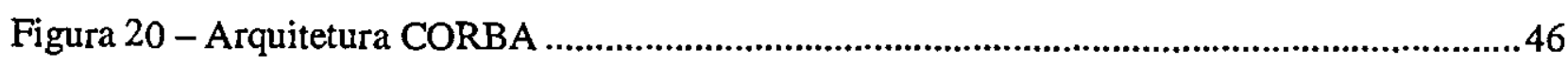

Figura 21 - Arquitetura do sistema de segurança distribuído..................................................4 49

Figura 22 - Modelo de comunicação do sistema de segurança ................................................51

Figura 23 - Arquitetura de arquivos e comunicação do ACME!................................................56

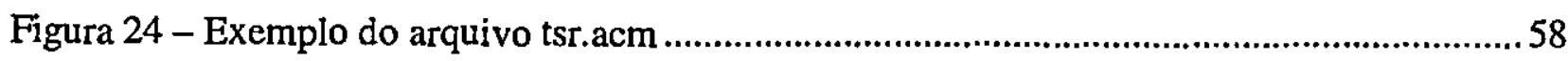

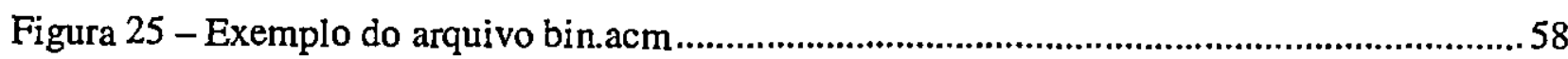

Figura 26 - Estrutura de dados Separate Chaining .................................................................61

Figura 27 - Janela indicando a diminuição do erro da rede neural ............................................62

Figura 28 - Arquivo nnet.h mostrando a função que implementa a rede neual.......................... 63

Figura 29 - Visualização gráfica da rede neural no SNNS......................................................6 65 


\section{Lista de Tabelas}

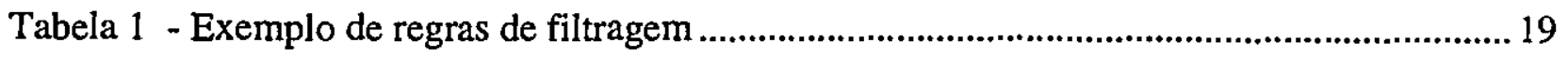

Tabela 2 - Vetor de estímulo produzido pelo analisador semântico..............................................32

Tabela 3 - Algoritmos de treinamento e parâmetros .............................................................. 35 
Atualmente, segurança de redes é um assunto de vital importância nas mais diversas áreas. $\mathrm{O}$ crescimento e popularização da Internet fizeram com que diversos serviços essenciais fossem realizados através da rede e cada vez mais redes privadas se conectassem para desfrutar de todos os benefícios oferecidos. Por outro lado, atos de pirataria e ataques aos computadores tem causado enormes prejuízos e danos. Este cenário exige mecanismos altamente eficazes para se aumentar a segurança das redes conectadas à Internet. Atualmente, a solução mais utilizada é o firewall, porém, sob diversas circunstâncias ele não é capaz de impedir um ataque. Sistemas de detecção de intrusão podem se tornar uma ferramenta altamente útil trabalhando em conjunto com firewalls. Este trabalho propõe que o uso conjunto de um firewall e um sistema de deteç̧ão de intrusão adaptativo baseado em redes neurais pode fornecer um alto grau de segurança à uma rede privada na medida em que une características complementares dos dois sistemas, além de permitir respostas rápidas e automáticas frente a uma invasão em andamento. Esta integração se dará com base em um sistema de segurança distribuído com as seguintes características: modularidade, escalabilidade, gerenciamento remoto, comunicação segura entre os diversos módulos e portabilidade. 
Abstract

Currently, security of networks is a subject of vital importance in diverse areas. The growth of the Internet has allowed that essential jobs be carried out through the network, and more networks have been connected to enjoy all the resulted benefits. On the other hand, acts of piracy and attacks to the computers have caused enormous damages. This scene demands highly efficient mechanisms to increase the security of the networks connected to the Internet. Currently, the most used solution is firewall-based, however, under diverse circumstances it is not capable to hinder an attack. Intrusion detection systems might be a highly useful tool working with firewalls. This work considers that the joint use of a firewall and an adaptive neural network based intrusion detection system can supply a high degree of security to the private network. The integration matches features of the two systems, whereas allowing for fast and automatic front of counter measures to an in-progress invasion. This integration will be done over a distributed security system with the following features: modularity, scalability, remote management, safe communication between the diverse modules and portability 


\title{
1. Introdução
}

\begin{abstract}
"Contra os experts em ataque, um inimigo não sabe onde se defender. Contra os experts em defesa, o inimigo não sabe onde atacar." - Sun Tzu (A arte da guerra)
\end{abstract}

Uma das principais características da sociedade moderna é o reconhecimento de que o poder é derivado da posse de informações. Como resultado, a aquisição, manuseio e a manutenção da informação têm se tornado um aspecto de crucial importância para a sociedade em geral. Paralelamente, é observada uma crescente expansão do armazenamento e da distribuição, através de redes de computadores, de informações sensíveis.

Por outro lado, atos de pirataria, tentativas de ataque e invasões consumadas tem se tornado freqüentes (Howard, 1997). e envolvem um número crescente de computadores destinando-se geralmente, ao roubo, destruição ou alteração das informações. Frequientemente ocorrem situações onde os intrusos facilmente superam os mecanismos de proteção existentes. Além disso, uma quantidade cada vez maior de atividades essenciais é realizada por intermédio das redes (principalmente através da Internet), e seu funcionamento correto e confiável torna-se de vital importância. Este cenário mostra a necessidade de técnicas especiais de segurança nos sistemas de computação modernos; técnicas que vão além da tradicional prática "locking-up-thedoors".

Em 2 de novembro de 1988, Robert Morris, a partir do MTT, lançou um Worm (Spafford, 1988), depois conhecido como o Internet Worm. Um Worm se assemelha a um vírus, porém não tem intenção explícita de se manter escondido. Em poucas horas, milhares de computadores de escolas, hospitais, universidades e órgãos militares foram atingidos. Por um descuido de Morris, o Worm, explorando um furo do deamon de finger, se multiplicou mais do que o previsto deixando os computadores atacados inoperantes. Os prejuízos foram calculados entre U $\$ 200,00$ e U\$ 53.000,00 por computador atingido. Morris foi identificado e preso, condenado por violação às leis de fraude e uso abusivo de computadores, a três anos de detenção, 400h de trabalhos comunitários e multa de US $\$ 10.050,00$. 
Em 1997, o CERT (Computer Emergency Reponse Team) ${ }^{1}$, órgão criado para responder e auxiliar em casos de ataques a redes de computadores, registrou um total de 2134 notificações de ataque. Este número representa uma pequena parcela dos ataques efetivamente ocorridos uma vez que muitas empresas e organizações preferem não divulgar tais informações com receio de abrir possibilidade a novos ataques ou de ter sua imagem denegrida.

O estudo da segurança em redes de computadores é uma área de crescente interesse uma vez que a rede é o meio pelo qual a maioria dos ataques ou intrusões em sistemas computacionais são realizados. Existem diversas tecnologias para se abordar este problema, dentre elas, firewalls e sistemas de detecção de intrusấo (IDS) ${ }^{2}$. O uso destas tecnologias parte do princípio de que trocar toda a gigantesca infra-estrutura de redes e computadores inseguros é impraticável e financeiramente inviável (Snapp, 1991). Diante disto, deve-se procurar meios de se aumentar a segurança de toda a infra-estrutura já existente através do uso conjunto de diversas tecnologias no sentido de proporcionar soluções altamente eficazes. Tais soluções devem ser transparentes o bastante aos usuários, não provocar grandes interferências no ambiente e fornecer mecanismos eficazes de monitoração e controle.

A tecnologia de segurança de redes mais largamente utilizada é o firewall (Wack, 1997; Ranum, 1992, 1993). Estes sistemas previnem o uso não autorizado usando mecanismos de controle de acesso. Porém não existe nenhum sistema que garanta o estado-da-arte em matéria de proteção e que forneça um elevado grau de segurança enquanto permite uma certa flexibilidade e liberdade no uso dos recursos computacionais.

Existem fatores que tornam muito difícil impedir que atacantes eventualmente tenham acesso ao sistema. A maioria dos computadores possui algum tipo de furo de segurança que permite atacantes externos (ou ainda usuários legítimos) de terem acesso a informações confidenciais. Mesmo um sistema supostamente seguro pode ser vulnerável a usuários internos abusando de seus privilégios ou ser comprometido por práticas impróprias. Em vista disto, uma vez que um ataque pode ser considerado inevitável, existe uma óbvia necessidade por

I O site do CERT pode ser encontrado em http://www.cert.org

${ }^{2}$ Do inglês: Intrusion Detection System 
mecanismos que possam detectar atacantes tentando penetrar no sistema ou usuários legítimos fazendo mau uso de seus privilegios.

Um exemplo de deficiência de firewalls ocorre quando um usuário legítimo, ou um atacante que tenha conseguido acesso, executa operações que explorem furos de segurança na rede interna ao firewall. Como estas conexões serão legítimas para o firewall, ele não terá como identificar o ataque. Neste caso seria necessário o uso conjunto de um sistema de deteç̧ão de intrusão, que tenha acesso aos dados da conexão e que possa inferir sobre seu comportamento, distinguindo conexões normais de conexões que representem um possível de ataque.

Sistemas de deteç̧ão de intrusão (Mukherjee 1994; Snapp 1991; Vaccaro \& Liepins, 1989) podem ser divididos em dois tipos básicos: os baseados em host e os baseados em redes. Os sistemas baseados em host usam audit trails (geralmente deamons rodando nas máquinas) para detectar um comportamento suspeito baseado nas ações que ocorrem na máquina, enquanto que os baseados em rede constróem seu próprio conjunto de informações usando o tráfego da rede capturado diretamente do meio de comunicação.

Um sistema de detecção de intrusão (ACME!) ${ }^{3}$ baseado em rede foi desenvolvido no ICMSC-USP (Cansian et al., 1997a., 1997b, 1997c; Cansian 1997). Tal sistema faz uso de redes neurais para identificar um comportamento intrusivo nas conexões estabelecidas. $O$ uso de redes neurais é uma proposta inovadora na medida que permite um alto grau de adaptabilidade ao sistema. Novas técnicas de intrusão podem ser facilmente adicionadas ao sistema retreinando-se a rede neural com os novos padrões de ataque. Outra característica deste sistema é a capacidade de generalização da rede neural que pode identificar um padrão intrusivo mesmo que nunca tenha tido contato com este tipo de ataque. Os resultados provenientes de um protótipo implementado mostraram que uma solução deste tipo pode conseguir uma taxa de erros em torno de 5 a 6\% (Bonifácio et al., 1998a, 1998c).

O uso conjunto de diversas tecnologias, visando-se aumentar a segurança, acarreta em alguns problemas de cunho gerencial. A administração do firewall e do sistema de detecção de intrusão requerem cuidados especiais, uma vez que tais sistemas devem ser considerados de alta prioridade. O funcionamento correto destes sistemas deve ser a principal preocupação do

\footnotetext{
${ }^{3} \mathrm{O}$ site do ACME! pode ser encontrado em http://www.intermidia.icmc.sc.usp.br/acme
} 
administrador de segurança da rede, pois falhas irão afetar diretamente a rede sob sua proteção. Uma falha no firewall pode deixar a rede sem conexão com a Internet, o que em diversos casos pode significar grandes perdas monetárias. Outro fator a se levar em conta, considerando-se uma possível falha no sistema de deteç̧ão de intrusão, é a possibilidade de se ter toda a rede a mercê de possíveis intrusões, cujos prejufzos podem ser ainda mais desastrosos.

Nem sempre é possível a permanência constante de um administrador junto aos sistemas de segurança, o que leva a necessidade por mecanismos que permitam o gerenciamento remoto do sistema. Tais mecanismos visam facilitar o trabalho do (ou da equipe do) administrador de forma que, a partir de qualquer ponto da rede, ou ainda através da Internet, ele tenha acesso às configurações e informações coletadas pelos sistemas de segurança. Ataques podem se dar de forma extremamente rápida e facilidades como esta visam diminuir o tempo de resposta frente a um ataque identificado.

Não apenas preocupações com relação ao gerenciamento devem ser feitas; é ainda preciso que se garanta o funcionamento dos sistemas de segurança mesmo em situações de invasões consumadas. Neste cenário, a principal preocupação deve ser em garantir a não existência de pontos críticos nos sistemas de segurança, a partir dos quais, um ataque direcionado poderia comprometer o funcionamento de todo o sistema. Deve haver redundância e mecanismos de recuperação de falhas suficientes para que um intruso não consiga desativar os sistemas de segurança e executar suas ações sem ser detectado.

A proposta deste trabalho é de que o uso conjunto de um sistema de proteção, como um firewall, com um sistema de deteç̧ão de intrusão pode prover um alto nível de proteção a um sistema computacional uma vez que os dois sistemas possuem características complementares, permitindo também respostas mais rápidas ao se detectar uma conexão suspeita. Tal integração se dará através de um sistema de segurança distribuído (Bonifácio et al., 1998b). Este sistema deverá ainda ter características como modularidade, escalabilidade, tolerância à falhas, gerenciamento remoto, comunicação segura entre os diversos módulos, portabilidade, etc.

A construção deste sistema de segurança visa dar continuidade a dois projetos desenvolvidos no ICMSC-USP: o NetTracker (Mouro, 1997; Mouro, Morishita \& Moreira, 1997), uma ferramenta de gerenciamento de redes, e o sistema de deteç̧ão de intrusão ACME! baseado em redes neurais. 
No Capítulo 2 são abordados os principais conceitos sobre segurança de redes, abordando conceitos de segurança do site e das comunicações. No capítulo 3 serão descritas algumas tecnologias e ferramentas de segurança de redes, será mostrado o sistema de deteç̧ão de intrusão ACME! e um protocolo para integração de diversos elementos de segurança de uma rede. $O$ capítulo 4 descreve os requisitos e a implementação do sistema de segurança distribuído e os desenvolvimentos necessários para desenvolver e integrar os módulos do ACME! de forma a poder ser executado independentemente de intervenção humana e faz uma análise deste sistema. Por fim, no capítulo 5, é apresentada a conclusão e uma proposta para trabalhos futuros. 


\section{Segurança Em Redes}

"Súbito e insubstancial, o expert não deixa tracos; divinamente misterioso, ele é inaudivel" - Sun Tzu

Segurança de redes (Garfinkel \& Spafford, 1996; Pabrai \& Gurbani, 1996) é notadamente uma área de crescente interesse e preocupação na Internet, atingindo desde administradores preocupados com a segurança e o bom funcionamento de seus sites até hackers e vândalos buscando novos métodos e técnicas de ataque. O termo hacker deriva da década de 70/80, quando designava pessoas que possuíam um profundo conhecimento sobre computadores, sistemas operacionais e softwares, não tendo nenhuma ligação com o atual significado no que se refere a atacantes e intrusos. Geralmente os termos hacker e cracker são usados indiscriminadamente, mas algumas diferenciações são encontradas na literatura.

Hacker é o indivíduo com um profundo conhecimento, mas geralmente sem intenções destrutivas. Seu propósito é unicamente provar que consegue invadir um determinado sistema, e quanto mais protegido for este sistema, maior será seu empenho. De forma oposta, o cracker é aquele cujo único objetivo é destruir, danificar e causar perdas. Um estereótipo típico criado é o de um adolescente em sua casa que, a partir de um computador e um modem, profere ataques aos computadores de grandes organizações.

A segurança de uma rede pode ser comparada à segurança de uma casa. Não importa que grau de segurança exista, não importa que sistemas ou trancas sejam usadas, quando alguém decide com suficiente empenho invadir, provavelmente terá êxito. De modo análogo, todas as medidas no sentido de se aumentar a segurança de uma rede tem como objetivo torná-la tão segura quanto possível, já que nenhum sistema conhecido garante o estado-da-arte em termos de proteção. Geralmente, um atacante irá analisar a relação custo/benefício, ou seja, o quão custoso e complicado será invadir um determinado sistema ponderado aos lucros que ele alcançará com tal invasão. Uma vez que esta proporção se torne inviável, pode-se dizer que foi atingido um bom grau de segurança. 
Ao mesmo tempo em que a Internet é o meio pelo qual a maioria das intrusões e ataques ocorrem, é também através dela que são largamente disponibilizados e veiculados documentos explicando e demonstrando técnicas de hacking, furos de segurança e casos de monitoração de intrusões em andamento (Farmer \& Venema; Cheswick, 1991). E possível encontrar com facilidade documentos do tipo "receita de bolo", que ensinam passo a passo técnicas de intrusão. Ainda que sejam técnicas simples, podem ser altamente destrutivas, tendo-se em vista que a maioria das redes conectadas à Internet negligencia quase que por completo questões relacionadas à segurança.

Existem atualmente diversos sites dedicados exclusivamente a este assunto, contendo documentos que abordam desde técnicas básicas de hacking até conceitos avançados para se aumentar a segurança de uma rede. Exemplos de sites são: www.rootshell.com e www.underground.org. Semanalmente são divulgados relatórios com novos furos de segurança nos mais variados sistemas operacionais e softwares. Como existe uma certa demora no lançamento de patches de segurança e a uma desconsideração destes patches por muitos administradores de rede, tem-se um cenário em que a maioria das redes se coloca num estado altamente vulnerável.

Esta conjuntura de computadores, redes e comunicações inseguras deve-se, em parte, ao modo como a Internet foi projetada. O principal foco do projeto da Internet, e mais basicamente, do protocolo TCP/IP estava muito distante dos atuais usos da Internet. Seu projeto previa inicialmente o uso por instituições militares e de pesquisa. O crescimento e a popularização da Internet, o surgimento de aplicações de comércio eletrônico, a interligação das redes das diversas filiais de uma empresa e muitas outras características e serviços oferecidos pela Internet de hoje não eram sequer supostas pelos seus projetistas e técnicos. O crescimento da Internet levou a uma mudança no foco e no perfil dos usuários e das aplicações da rede. Em vista disto, os protocolos, serviços, sistemas operacionais como o Unix e os softwares que são utilizados na Internet não foram projetados e especificados com as devidas preocupações com relação à segurança. No Unix, as senhas circulam totalmente abertas pela rede, o protocolo TCP/IP não prevê nenhum esquema de criptografia dos dados ou autenticação das máquinas e usuários envolvidos em uma conexão. Os atuais sistemas, como Windows NT, foram criados em cenários com preocupações específicas sobre segurança. Porém ainda não se mostraram soluções 
totalmente confiáveis devido a fatores como pouco tempo para desenvolvimento e testes, o que acarretou em falhas e furos de segurança.

Segurança de redes é um assunto muito vasto e é interessante dividi-lo em duas subáreas: Segurança do site e segurança nas comunicações.

A segurança do site diz respeito à segurança dos recursos computacionais presentes em uma rede privada. Tais recursos são compostos por hosts, roteadores, impressoras, informações armazenadas, servidores de banco de dados e softwares em geral.

Quatro princípios básicos definem a segurança de um site:

- Confidencialidade: Apenas quem tem os direitos de acessar um determinado recurso ou informação poderá efetivamente acessá-los.

- Integridade: Garante que os dados armazenados não serão alterados, tanto como consequência de atos provenientes de uma intrusão quanto a eventos como quedas de energia e falhas nos sistemas.

- Disponibilidade: Garante que os recursos computacionais e os dados presentes neles estarão disponíveis sempre que necessários. Atualmente um número cada vez maior de ataques explora furos que causam falhas na disponibilidade dos sistemas. Tais ataques são geralmente chamados de denial of service.

- Autenticação: Diz respeito à identidade de um usuário, ou seja, garantir se o usuário realmente é quem diz ser.

Uma quebra de segurança pode ser definida como uma ação, ou conjunto de ações, que vão contra a política de segurança vigente. Esta política de segurança é criada com as necessidades particulares de cada local. Desta forma, o que é considerado uma quebra de segurança pode variar conforme o local. A política de segurança irá definir o que pode ou não ser feito, por quem, sob quais circunstâncias, define os procedimentos (Plano de Emergência) a serem tomados frente a uma invasão, quais são os recursos que devem ser prioritariamente 
protegidos, que nível de risco é aceitável, além de resolver questões éticas e polêmicas como, por exemplo, se o administrador ou um chefe tem o direito de ler o e-mail dos funcionários. Uma vez que se tenha tudo definido e que cada usuário e administrador esteja ciente desta política, tem-se um quadro onde é fácil identificar que ações são consideradas como uma quebra de segurança e que medidas podem ser tomadas.

Uma quebra de segurança pode ocorrer onde existir uma falha. Falhas podem ser atribuídas a três causas principais:

-Softwares: Os softwares que rodam nos computadores podem apresentar falhas que podem ser exploradas por atacantes, ou ainda, falhas que podem prejudicar a rede, como por exemplo, um servidor de banco de dados mal projetado que perca informações. Por outro lado, um software, devido à sua procedência duvidosa, pode conter backdoors ou ser um Trojan Horse (Cavalo de Tróia).

Um backdoor é um tipo de ataque muito comum em que um software inserido, ou modificado em uma rede pode, a partir de uma combinação especial de caracteres, ou a um evento de tempo, ter um comportamento diferente do esperado. Um dos rastros deixados por uma invasão geralmente são modificações em programas como o deamon de telnet, em que ele é programado para quando alguém entrar com o login hacker, por exemplo, não seja pedida a senha e o acesso seja liberado. Já o Trojan Horse, outro ataque clássico, consiste em se trocar o processo de login por outro programa, de comportamento idêntico. Este programa pede o username e a senha do usuário, salva-o, exibe uma mensagem de erro de senha e chama o verdadeiro processo de login, a partir do qual tudo transcorre normalmente, a não ser pelo fato de que a senha do usuário foi capturada. Para o usuário, tudo ocorre normalmente, ele apenas pensa que digitou errado sua senha.

O outro problema com softwares, como dito anteriormente, é a demora dos fabricantes em lançar patches de segurança de problemas que tenham sido descobertos.

-Administradores: A menos que se tenha uma pessoa com a função específica de administrador de segurança, este será outro grande problema. Geralmente, administradores não dão a devida importância à segurança da rede, quer seja por falta de informação ou por desinteresse. As falhas mais comuns oriundas de administradores são: não instalam sistemas de 
proteção e auditoria; não aplicam patches de problemas conhecidos; negligenciam procedimentos básicos de segurança; não orientam os usuários e não se mantém atualizados.

-Usuários: Este é outro grande perigo para a segurança de uma rede: usuários mal informados ou mal intencionados podem causar grandes prejuízos. Um ataque se torna muito mais fácil e com muito mais chances de sucesso se proferido por um usuário do próprio sistema com intenções de roubo de informações ou até mesmo vingança contra um colega ou um superior. Usuários comuns podem expor o sistema com senhas fracas, podem fornecer suas senhas para terceiros, utilizar programas de origem duvidosa e muitas outras ações que podem ir contra a política de segurança ou que não estejam previstas, mas que podem colocar a rede sob perigo.

As senhas em sistemas Unix são guardadas no arquivo /etc/passwd encriptadas. Porém o algoritmo usado, chamado de one-way, não permite que a partir da senha encriptada, se obtenha de volta a senha original. Desta forma, o sistema pega a senha do usuário, encripta-a e compara com a que tem guardada. Um intruso, mesmo com acesso ao arquivo de senhas, não tem acesso às senhas originais e, portanto não poderá entrar no sistema. Porém, existe uma técnica chamada de quebra de senha por força bruta na qual o intruso, através de programas chamados cracker de senhas, escolhe palavras em um dicionário, faz combinações com números, maiúsculas e minúsculas e encripta uma por uma e as compara com as senhas encriptadas no arquivo de senhas. Quando ele conseguir uma igual, ele terá descoberto uma senha válida para o sistema. Senhas fracas são senhas que podem ser facilmente quebradas, como nomes de pessoas, palavras comuns ou o próprio username. Se todos os usuários possuírem senhas fortes, a chance de que um ataque baseado na captura do arquivo de senhas tenha sucesso seriam pequenas.

Os ataques externos geralmente se dão de quatro formas diferentes mostradas na Figura 1, podendo partir de um único atacante ou um grande grupo. Um ataque pode ocorrer a partir de uma única máquina atacando outra (a), várias máquinas sendo atacadas a partir de uma única (b), uma máquina atacar diversas outras (c) ou ainda ser um ataque indireto, onde o atacante ataca outras máquinas para então realizar o ataque ao seu alvo principal (d). 


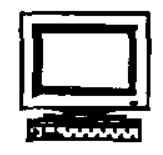

Alvo

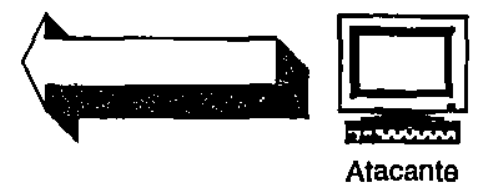

(a)

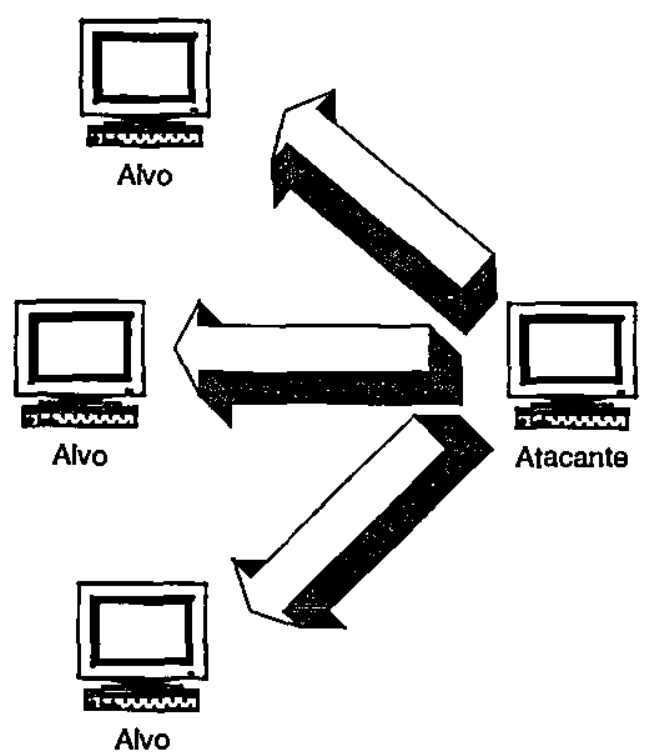

(b)
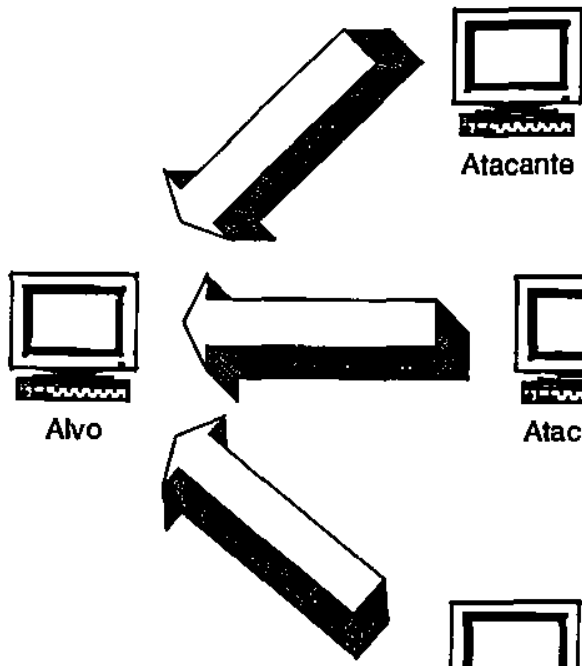

(c)

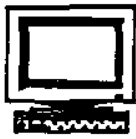

Atacante

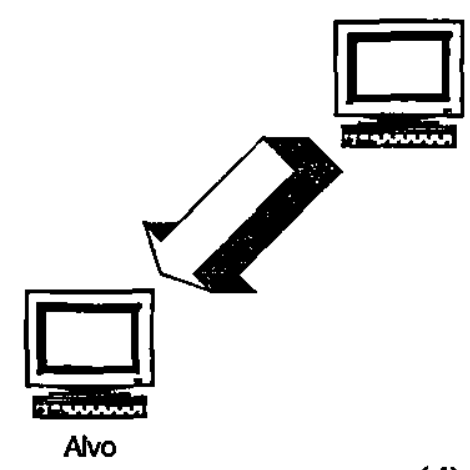

(d)

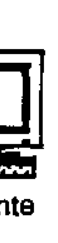

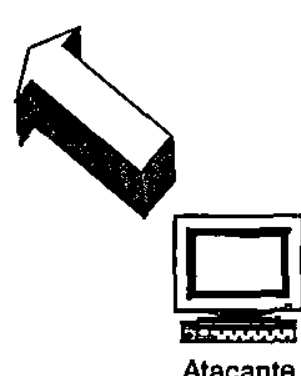

Atacante

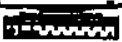

Atacante 
para isso, ter uma interface de rede em modo promíscuo, ou seja, todos os pacotes serão capturados, não importando se são destinados a ela ou não. Esta técnica é chamada de sniffing.

Um intruso pode ser classificado em passivo ou ativo, como mostra a Figura 2 . Um intruso passivo simplesmente monitora a rede em busca de informações como senhas, números de cartões de crédito e, informações confidenciais; enquanto que $o$ intruso ativo atua modificando o conteúdo dos pacotes.

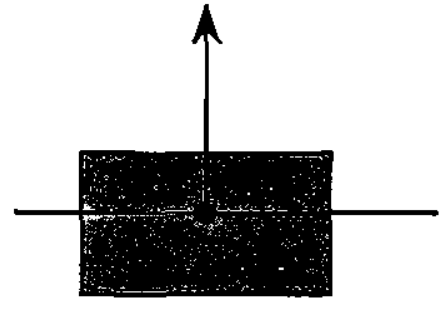

(a)

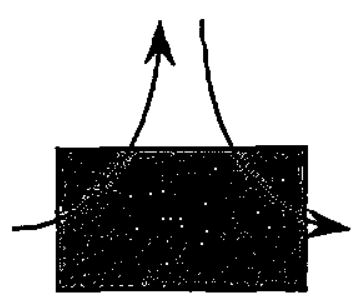

(b)

Figura 2 - Intruso passivo (a) e ativo (b).

Desta forma, é preciso alguns requisitos para se garantir um ambiente em que se tenha segurança nas comunicações:

- Confidencialidade: Apenas as partes envolvidas podem ter acesso ao conteúdo dos dados trafegando. Qualquer ação de monitoração da rede não deve ser capaz de ter acesso aos dados.

- Integridade: Deve-se garantir que a informação transmitida em um ponto é a mesma recebida por outro e que não houve qualquer adulteração dos dados por parte de terceiros ou falhas.

- Autenticidade: As partes envolvidas em uma comunicação devem ter meios de confirmarem mutuamente suas identidades, certificando-se de com quem estão se comunicando.

A principal técnica utilizada nestes casos é a criptografia (Tanenbaum, 1997; Schneider, 1995). Criptografia consiste em técnicas que permitem transformar um texto legível em outro segundo um algoritmo de forma que obtenção do texto original a partir do encriptado seja 
possível apenas usando-se o mesmo algoritmo. Criptografia teve seu grande desenvolvimento durante a segunda guerra mundial e a guerra fria para garantir que o inimigo não tivesse acesso às comunicações.

A técnica mais simples é a transposição de letras, por exemplo, trocando-se cada letra por sua subsequente no alfabeto: HAL $\rightarrow$ IBM. Claro que a criptografia usada nos modernos sistemas utilizam algoritmos muito mais complexos baseados em chaves. $O$ texto a ser encriptado (plaintext) é encriptado e gerado um ciphertext usando-se como parâmetro uma chave mostrado na Figura 3. Existem dois tipos: criptografia com chave simétrica e criptografia com chaves públicas. Como a recuperação da informação original está vinculada ao conhecimento da chave, um processo para se conseguir quebrar o texto encriptado é o mesmo usado com senhas: busca exaustiva. Neste caso, são geradas todas as possíveis combinações de chaves até que se ache a correta. O grande problema desta solução é que o número de chaves possíveis cresce exponencialmente com o tamanho da chave, e as chaves usadas em aplicações militares ou de alta segurança podem levar alguns milhares de anos para serem quebradas com os recursos computacionais disponíveis atualmente.

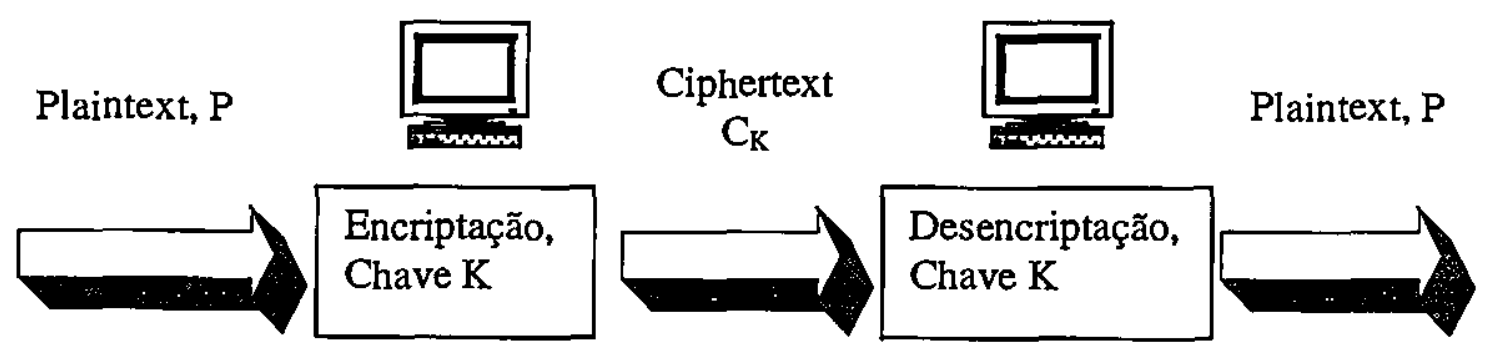

Figura 3 - Criptografia baseada em chaves

$\mathrm{Na}$ criptografia com chaves simétricas, é usada a mesma chave para se encriptar e desencriptar um texto. Neste caso, ambas as partes envolvidas tem de concordar com uma chave antes de iniciar a comunicação, o que pode ser problemático, pois a menos que se conheçam, a escolha da chave deve ser feita usando-se a própria rede insegura. Exemplos de algoritmos de chave simétrica são DES (Data Encryption Standard), Iargamente utilizado no passado pelo govemo americano, TrippleDES e IDEA (International Data Encryption Algorithm). 
A criptografia de chave pública utiliza duas chaves diferentes e complementares. $O$ que é encriptado com uma chave só pode ser desencriptado com a outra e vice-versa. O usuário deixar uma chave de conhecimento público (chave pública) e manter a outra em segredo (chave privada). Este modelo evita as duas partes terem de concordarem em uma única chave, uma vez que cada uma conhece a chave pública da outra, podendo com ela, encriptar os textos que só poderá ser lidos pela chave privada correspondente. Algoritmos de chave pública são o RSA (Rivest, Shamir e Adleman, as inicias dos inventores) e El Gamal, por exemplo.

Com o uso de criptografia, seja por chave simétrica ou pública, pode-se garantir a confidencialidade dos dados que serão enviados em uma conexão. Apesar da criptografia de chave pública ser mais segura que a de chave simétrica, ela é muito lenta para grandes volumes de dados. Atualmente, soluções como o protocolo SSL (Security Socket Layer) (Freier, Karlton \& Kocher, 1996; Wagner \& Shneider, 1996) da Netscape Communications utiliza as duas técnicas em conjunto para se ter segurança e velocidade. O primeiro passo é usar criptografia de chave pública para que as duas partes possam concordar em uma chave que posteriormente será usada na criptografia de chave simétrica durante todo o restante da comunicação.

O uso de criptografia garante apenas a confidencialidade dos dados, mas um simples ataque do tipo man-in-the-middle, onde uma terceira pessoa está posicionada entre as duas partes que querem se comunicar faz com que cada uma delas acredite estar falando com a outra sendo que estão ambas se comunicando com esta terceira pessoa. Ou seja, não há meios de se garantir que uma determinada chave pública pertença realmente a alguém. Para isso, existem os certificados ou assinaturas digitais. Através desta assinatura, um usuário pode confirmar se uma determinada chave pública pertence realmente ao seu dono. Certificados digitais estão sendo largamente usados nos browsers Web (Netscape e Explorer principalmente) e se baseiam no conceito de entidades certificadoras que emitem os certificados baseados em suas chaves pública e privada. Como os browsers já tem a chave pública de um certificador, e no qual ele confia, ele pode verificar a autenticidade do portador de um certificado gerado pelo certificador, garantindose a autenticidade. Em um certificado digital do tipo X.509 utilizado pelo SSL, vão informaçōes como o nome do dono, data de criação, data de validade, versão e a chave pública do dono encriptada através da chave privada do certificador. Desta forma, garante-se que apenas a chave pública do certificador possa desencriptar a chave pública e esta não precisa ser transferida pela rede sem garantias. 
O último requisito, a integridade dos dados, é satisfeito com o uso de algoritmos de Message Digest, que a partir de um texto de tamanho variável, gera uma sequência de bits de tamanho fixo pequeno utilizando-se funções hash one-way. Uma das propriedades necessárias a estes algoritmos é que deva ser praticamente impossível se computar o tex to original a partir do message digest, além de que não deve ser possível dois textos diferentes gerarem o mesmo message digest, que deve ter pelo menos 128 , ou mais. O message digest é então enviado junto com a mensagem, de forma que quem está recebendo possa calcular o message digest da mensagem e comparar com o que foi enviado. Os dois algoritmos mais conhecidos são o MD5 e o SHA (Secure Hash Algorithm).

De forma semelhante à segurança do site, não existe nenhum protocolo ou solução completamente segura. Novos protocolos tem sido propostos e utilizados no intuito de se atingir um alto grau de segurança nas comunicações, protocolos como HTTPS e SSL são voltados a aplicações Web, enquanto que o protocolo SET (Secure Eletronic Transaction), recentemente desenvolvido por grandes empresas como IBM e outras em parceria com a VISA, visam atacar o problema do comércio eletrônico em que existem três partes envolvidas na negociação: o cliente, o vendedor e o banco onde será efetuado o pagamento. 


\section{Ferramentas para Segurança de Redes}

'Podem existir centenas de posturas de combate, mas existe apenas um propósito: vencer" - Heiho Kaden Sho

Para se aumentar a segurança de uma rede, existem diversas ferramentas, cada qual atacando um, ou alguns, problemas específicos. Não existe nenhuma solução que ofereça proteção completa em todos os aspectos. Dentre as diversas ferramentas disponíveis, pode-se citar:

-TCP Wrapper (Venema, 1992): Monitora e filtra as requisições de entrada dos serviços da rede através de pequenos deamons. Estes deamons são disparados quando é feita uma tentativa de se acessar um determinado serviço, realizando rotinas de auditoria e controle de acesso.

-Tiger Scripts: Verifica permissões indevidas de arquivos, arquivos de configuração e realiza a checagem da integridade de arquivos importantes e binários do sistema. Esta checagem é feita gerando-se um message digest, geralmente via MD5, dos arquivos em condições seguras, e conferindo-se regularmente este message digest. Qualquer alteração no arquivo será detectada pela diferença do message digest gerado, podendo constituir um caso de trojan horse, backdoor, ou arquivos de configuração alterados por um intruso.

- Cracker de Senhas: Realiza tentativas de se quebrar as senhas do sistema usando o método de busca exaustiva procurando por senhas fracas. Esta ferramenta, além ser altamente utilizada por atacantes, também é usada por administradores procurando por senhas fracas que possam existir.

-SATAN (Security Administration Tool for Analyzing Networks) ${ }^{4}$ : É um software do tipo scanner. Ele faz uma varredura em todos os computadores da rede procurando por vulnerabilidades conhecidas de segurança ou configurações erradas.

\footnotetext{
${ }^{4} \mathrm{O}$ site do SATAN pode ser encontrado em http://www.cs.purdue.edu/coast/satam.html
} 
-ISS (Internet Security Scanner) ${ }^{5}$ : Ferramenta similar ao Satan.

-Kerberos: Protocolo de autenticação para permitir usuários acessarem recursos computacionais de forma segura.

Além destas ferramentas, existem firewalls e sistemas de detecção de intrusão, que serão melhor detalhadas a seguir.

and

O propósito de um firewall é prevenir o acesso de usuários não autorizados aos recursos computacionais em uma rede privada e a exportação não notificada e não autorizada de informações confidenciais.

Na configuração de um firewall, as principais decisões relacionadas à segurança são frequentemente ditadas pela política da organização ou corporação. Especificamente, as decisões devem ser tomadas pesando-se até que nível a segurança deve ser mais importante que a flexibilidade e facilidade de uso dos recursos computacionais que o firewall se destina a proteger.

Há duas abordagens básicas na configuração de um firewall:

- O que não é expressamente proibido é permitido

- O que não é expressamente permitido é proibido

No primeiro caso, o administrador do sistema tem de prever que tipos de ações os usuários, ou pessoas externas, podem fazer que infringem a política de segurança; e preparar defesas contra elas. No segundo caso, o firewall deve ser projetado para bloquear tudo, os serviços devem ser permitidos caso a caso após um cuidadoso estudo de necessidade e risco. Isto causa impacto imediato nos usuários, que podem ver o firewall como um estorvo. Esta opção é também a mais segura, já que o administrador não precisa conhecer profundamente que portas

\footnotetext{
${ }^{5} \mathrm{O}$ site do ISS pode ser encontrado em http://www.iss.net
} 
TCP são seguras ou que furos de segurança podem existir no kernel do sistema ou nas aplicações. Uma vez que muitos fabricantes demoram em publicar furos de segurança, esta é claramente uma abordagem mais conservadora, com base no fato de que o que você não conhece pode ser perigoso para você. Esta segunda abordagem pode ser bem empregada em empresas com normas bem definidas e rígidas, porém pode-se tornar altamente imprópria em instituições de ensino e pesquisa, uma vez que ela restringe em demasia o uso dos recursos computacionais. A não ser que se tenha uma equipe muito bem preparada e que reconheça a fundo todas as diferentes necessidades dos usuários do sistema e reflitam isto na configuração, o firewall pode ser tornar um inconveniente e mesmo prejudicar o andamento de pesquisas.

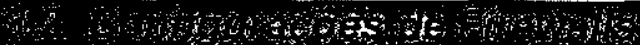

Existem diversas configurações possíveis para se implementar um firewall. A escolha de uma destas configurações reflete diretamente nos custos envolvidos, dificuldade de administração, grau de segurança fornecido, grau de liberdade e flexibilidade permitido aos usuários e em diversos outros fatores. Em (Wack, 1997) e (Chapman, 1992) são discutidos detalhes e analisadas vantagens e desvantagens das diversas configuraçð̄es. Desta forma, a adoção de uma certa configuração é uma tarefa delicada e uma decisão errada pode levar tanto a perdas monetárias como de tempo gasto. De acordo com (Wack, 1997), os componentes básicos da arquitetura de um firewall, independente da configuração usada, são:

-Política da rede: Uma política de operação da rede define quais serviços serão permitidos ou negados na rede interna, como estes serviços poderão ser usados e quais as possíveis exceções. Esta política define que serviços são de vital importância para a operação da rede, quais serviços podem ser desabilitados e quais oferecem perigo, ela deverá seguir uma das duas abordagens básicas discutidas anteriormente.

- Mecanismos de autenticação avançados: Mecanismos como smartcards, tokens de autenticação, e outros, tem a finalidade de se criar sistemas chamados de one-time password systems. Tais sistemas não fazem uso das tradicionais senhas estáticas, eles trabalham com 
senhas geradas cada vez que um usuário acessar o sistema. Este tipo de senha não pode ser reutilizada por um intruso que esteja monitorando a conexão.

-Filtragem de Pacotes: A filtragem dos pacotes com destino a, ou originados da, rede privada, pode ser feita com base nos endereços IPs de origem e destino ou nas portas de origem $\mathrm{e}$ destino envolvidas na conexão. A função do filtro é a de permitir que certos serviços, ou hosts, sejam acessíveis ou não, dependendo da política adotada. Esta filtragem pode ser feita por um roteador com capacidades especiais ou ainda via software por um host atuando como gateway. A filtragem se dá por regras baseadas nos seguintes dados: tipo da conexão (TCP ou UDP), endereço IP origem, endereço IP destino, porta origem, porta destino e ação a ser tomada (permitir ou bloquear). Um exemplo de regras de filtragem poderia ser:

\begin{tabular}{lllllll} 
Tipo & IP origem & IP destino & Porta origem & Porta destino & Ação \\
\hline Tcp & $*$ & & 143.107 .231 .1 & $>1023$ & 25 & permitir \\
Tcp & $*$ & 143.107 .231 .1 & $>1023$ & 23 & permitir \\
$*$ & $*$ & $*$ & $*$ & $*$ & bloquear \\
\hline
\end{tabular}

Tabela 1 - Exemplo de regras de filtragem

Neste exemplo, a primeira regra diz que todas as conexões tcp provenientes de qualquer host usando uma porta de usuário (maior que 1023) com destino ao host 143.107.231.I utilizando a porta 25 (sendmail) serão permitidas. O mesmo ocorre para as conexões na porta 23 (telnet). Todas as demais conexões, não importando sua origem ou destino, terão seu acesso negado com base na terceira regra de filtragem. Este é um exemplo típico de uma abordagem do tipo: “O que não é expressamente permitido é proibido".

- Gateways de Aplicações: Um gateway de aplicações é um host que executa um tipo de serviço chamado proxy. Um proxy é um software que faz repassa e filtra as conexões entre a rede interna e a externa. Estes gateways são geralmente usados em sistemas onde o roteador permitirá conexões, por exemplo, de telnet, apenas para uma máquina, que será o gateway de 
aplicação telnet; e todas as conexões para máquinas internas deverão passar obrigatoriamente por este proxy. Desta forma, o gateway pode analisar, registrar e filtrar as conexões, não havendo tráfego direto entre um host externo e um interno. Estes gateways também são chamados de bastion hosts.

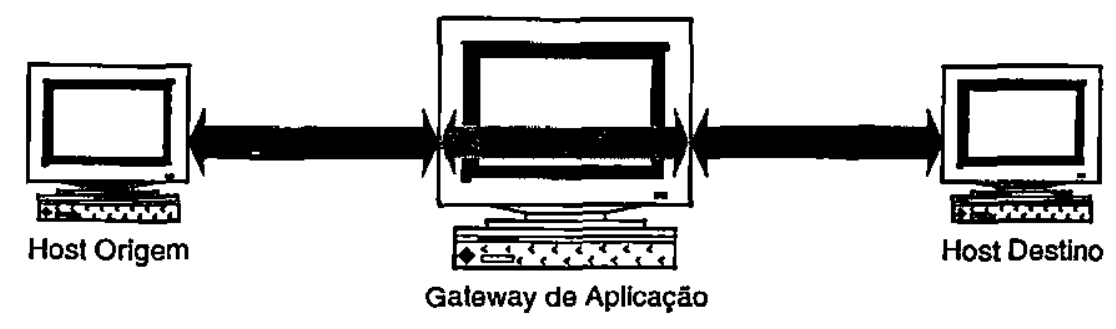

Figura 4 - Comunicação passando pelo gateway de aplicação

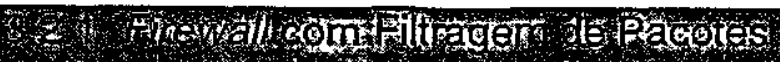

Esta é a mais simples e comum configuração de firewalls, geralmente aplicada em redes pequenas. Basicamente é constituída de um roteador com capacidades de filtragem colocado na conexão da rede privada com a Internet. As regras de filtragem devem seguir a política criada. Por ser uma configuração bastante simples, apresenta algumas desvantagens como pouca ou nenhuma capacidade de auditoria por não usar gateways de aplicação. 


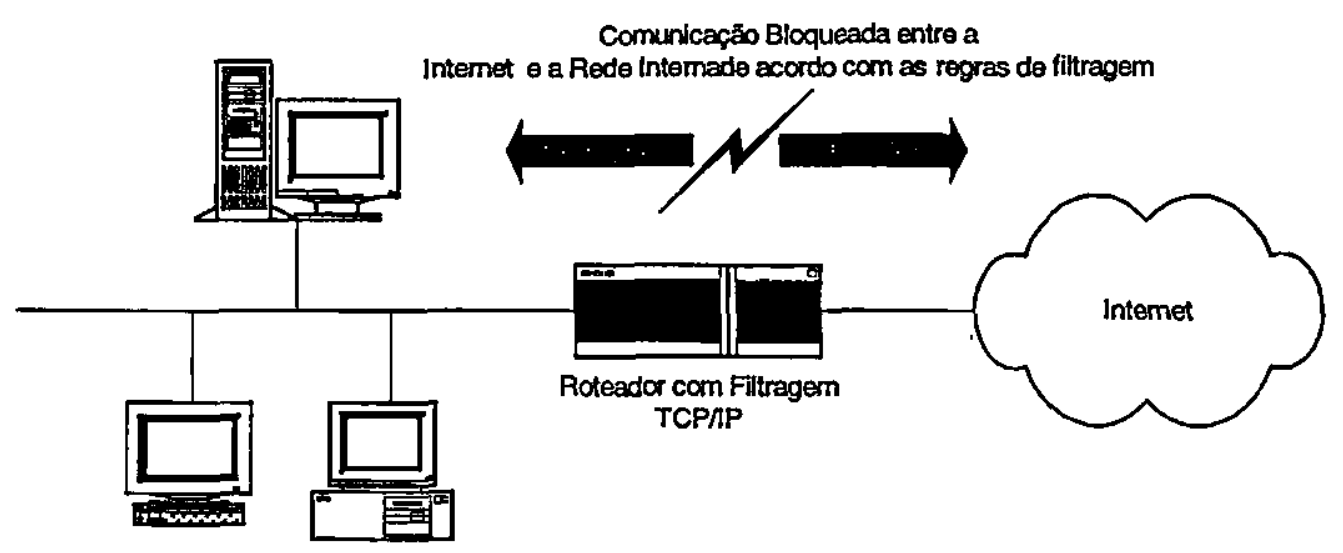

Figura 5- Firewall com filtragem de pacotes

Um dual-homed gateway é um host com duas interfaces de rede e com suas capacidades de IP forwarding desabilitadas, ou seja, o host não tem capacidades de rotear pacotes entre as duas redes conectadas. Adicionalmente, um filtro é utilizado na conexão com a Internet. Nesta configuração, todo o tráfego entre a rede privada e a Internet é bloqueado pelo gateway e as conexões devem ser feitas através de proxies localizados neste gateway. Entre o filtro e o gateway é criada uma sub-rede onde é possível se colocar servidores de informação como servidores Web. Esta configuração implementa, intrinsecamente, a abordagem de negar todos os serviços a não ser os especificamente permitidos. Um dos principais problemas com esta configuração é a necessidade de haver proxies para cada serviço que se deseje permitir. 


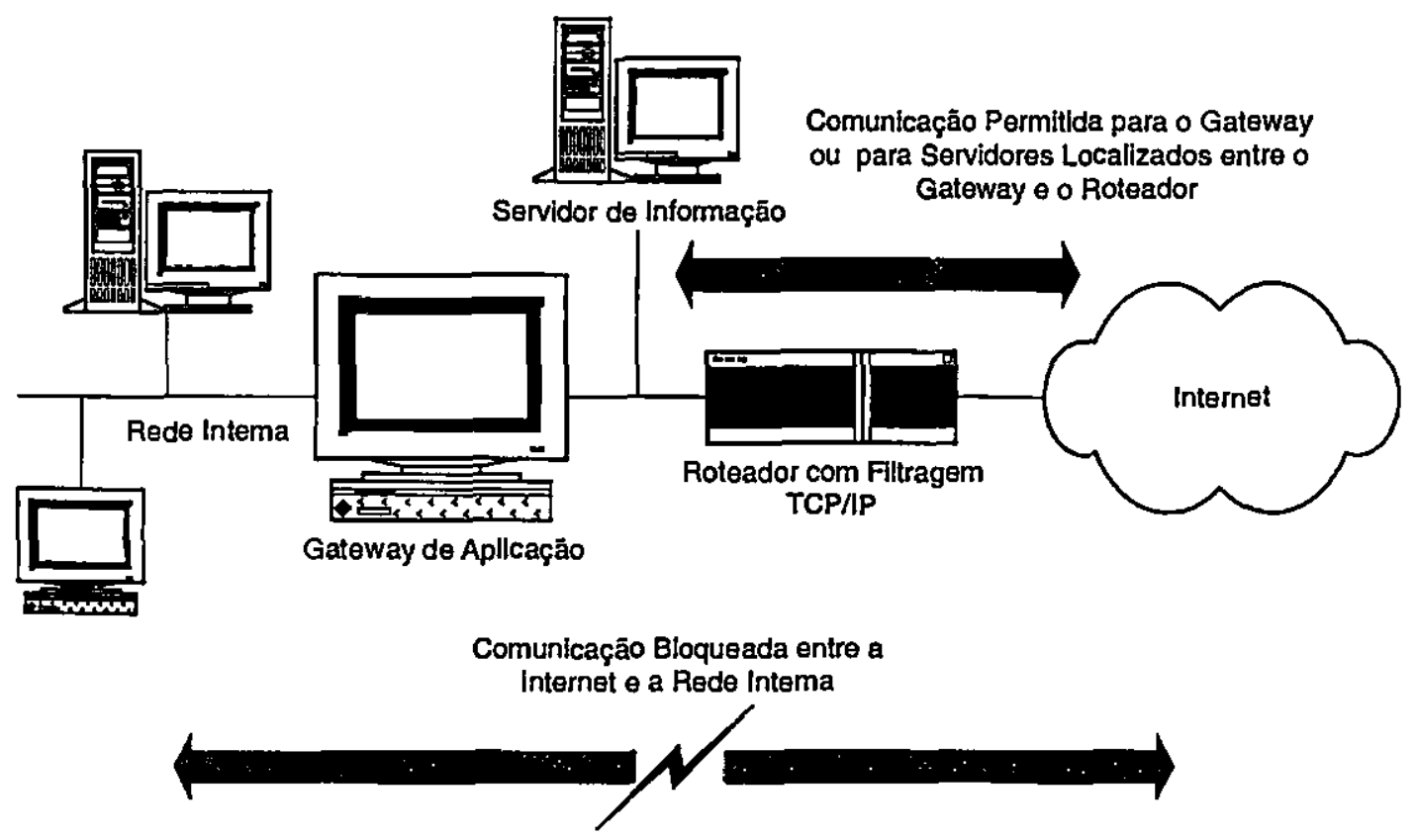

Figura 6-Dual-Homed gateway

Esta configuração é bem parecida com a dual-homed gateway, mas não existe uma subrede entre o roteador que faz a filtragem dos pacotes e o gateway, alem do fato de que o gateway tem apenas uma interface de rede. Apesar de ser mais flexível, ela pode se tornar uma solução menos segura. Todo o tráfego direcionado à rede privada continua tendo de ser processado por um proxy situado no gateway, além de alguns serviços poderem ser configurados para passarem diretamente, sem a intervenção do gateway. 


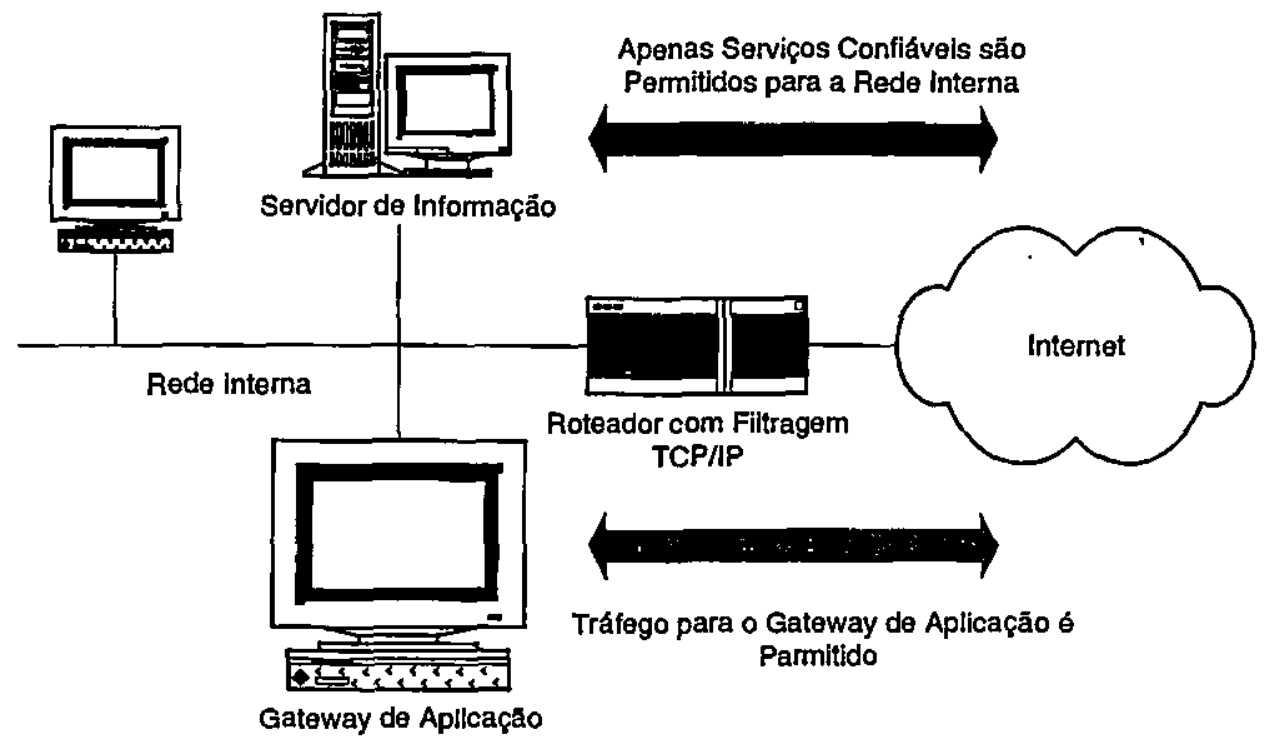

Figura 7 - Screened host firewall

Esta é uma variação do dual-homed gateway e do screened host firewall. Ela tem dois roteadores formando uma rede intermediária chamada de $\mathrm{DMZ}$, onde serão colocados os gateways de aplicação e servidores de informações. A rede interna e a rede DMZ também são referenciadas na literatura como sub-rede azul e sub-rede vermelha, respectivamente. Nesta configuração não há tráfego direto entre a rede interna e a Internet, apenas entre a rede interna e a $\mathrm{DMZ}$ e entre a $\mathrm{DMZ}$ e a Internet. Todos os serviços que necessariamente precisem estar conectados à Internet são colocados na rede DMZ, diminuindo assim o risco de que uma intrusão em um destes serviços venha a atingir a rede interna. Esta e uma configuração considerada bastante segura mas requer maiores preocupações quanto a sua configuração e manutenção. 


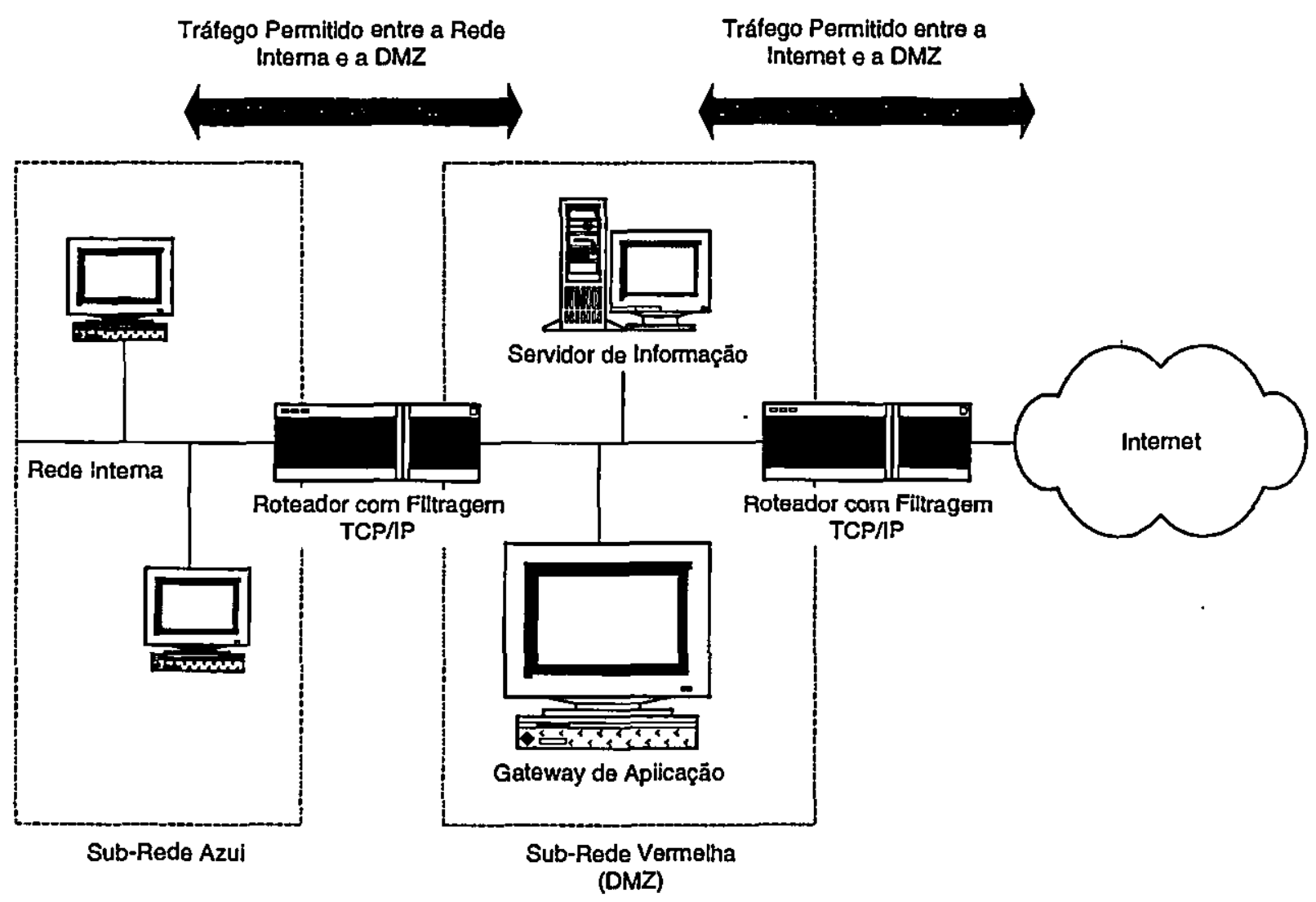

Figura 8 - Screened subnet firewall

Um firewall pode apresentar diversos problemas, basta uma pequena brecha na configuração, algum serviço que tenha sido esquecido ou que tenha sua importância negligenciada para que se tenha um furo na segurança que intrusos poderão explorar. Isto pode ser ainda mais perigoso uma vez que o administrador, ao usar um firewall, dará uma importância relativamente menor às configuraçōes das máquinas.

Outro grande problema com firewalls diz respeito à maus usuários (que tenham usernames e senhas válidas). Qualquer pessoa que queira abrir uma conexão "teoricamente" 
legal terá permissão, a não ser nos casos em que todas as conexões provenientes da máquina, ou do domínio, de origem tenham sido configuradas para serem filtradas pelo firewall. Um intruso, que consiga um username e uma senha, poderá abrir uma conexão de uma máquina externa e ter acesso à todo o sistema.. Uma vez dentro do sistema (mesmo com acesso comum, ou seja, não como root) ele poderá usar diversas técnicas disponíveis e bem conhecidas para então executar suas intenções e conseguir privilégios de root.

A obtenção de uma senha válida pode se dar de diversas formas. Dentre as mais comuns, estão os furos existentes nos sistemas que permitem à atacantes ter acesso ao arquivo de senhas (/etc/passwwd) e, através de técnicas de quebra de senhas por "força bruta", conseguir um usename e uma senha válida. Um dos exemplos clássicos deste tipo de furo foi o sendmail que permitia um usuário, conectado a porta 25 da máquina, enviar para algum endereço de e-mail o arquivo de senhas da máquina.

Outra grande preocupação é com respeito aos usuários, que frequentemente anotam suas senhas em locais impróprios ou as divulgam a estranhos, sem estarem cientes do perigo de tal ato, ou ainda, que são vítimas de engenharia social, caso em que um intruso engana um usuário dizendo ser, por exemplo, um administrador da rede ou um colega com problemas, e pede sua senha.

Outra abordagem de ataque é a de se atacar diretamente o firewall e deixá-lo inoperante de forma que não se tenha mais nenhuma barreira para a rede interna.

Qualquer ataque que se pareça com uma conexão normal, e que não possa ser detectado a não ser a partir da análise do conteúdo da conexão, será muito difícil de ser detectado por um firewall. A seguir são mostrados dois tipos de ataque ao serviço ftp que poderiam passar por um firewall. Estes ataques foram realizados pelo Internet Security Scanner, ISS.

O primeiro é talvez o tipo de ataque mais simples e comum. É chamado de doorknob e consiste basicamente em abrir uma conexão telnet ou ftp em alguma máquina e, pelo método de tentativa e erro, conseguir encontrar uma senha válida e consequentemente, acesso ao sistema. Apesar de parecer um método bastante ineficaz, muitas redes ainda são mal configuradas, possuem administradores negligentes e frequentemente tem contas com senhas simples, ou ainda sem senhas. Exemplos de senhas possíveis para a conta root seriam: root, toor, administrator, operator, rotarepo, secret, o nome do administrador, e diversos outras senhas comuns. Existem 
ainda outras contas no sistema que podem ser exploradas como: access, admin, archie, audit, backup, bulletin, demo, bbs, bin, diagnostic, ftp, games, gopher, help, guest, irc, lib, local, manager, news, etc.

No exemplo da Figura 9, o intruso atacando o servidor de ftp Vitima tenta três senhas para a conta root: root, toor e administrator.

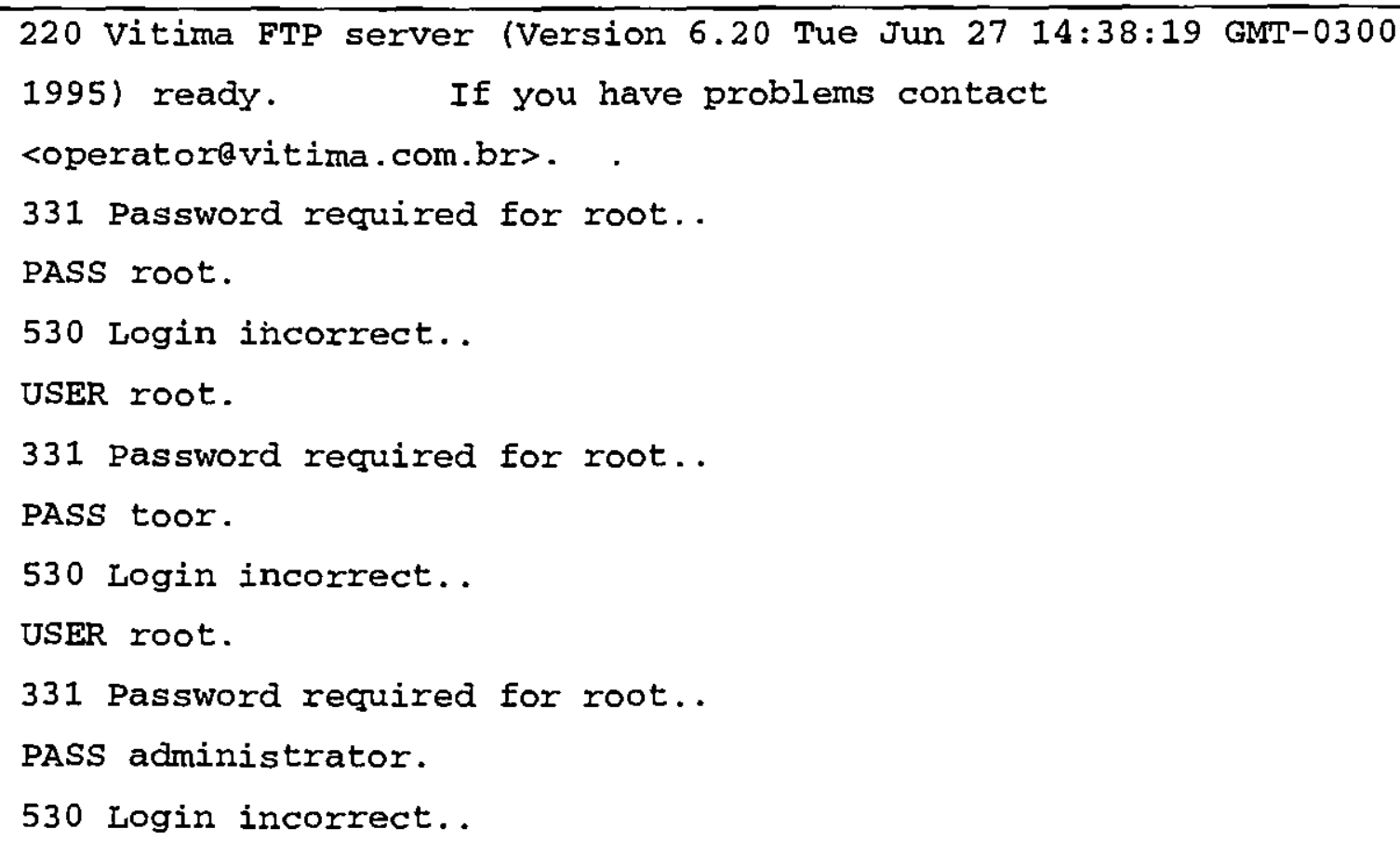

Figura 9 -Exemplo de ataque doorknob

No segundo exemplo de ataque (Figura 10), o intruso entra como anonymous em um servidor de ftp e tenta executar comandos como MKD e RMD para testar se os diretórios estão com permissão de escrita. Isto não constitui um ataque em si, mas para muitos outros tipos de ataque, é necessário que o atacante tenha algum arquivo dentro do site a ser atacado, e um dos possíveis lugares é dentro da conta de ftp anonymous. 


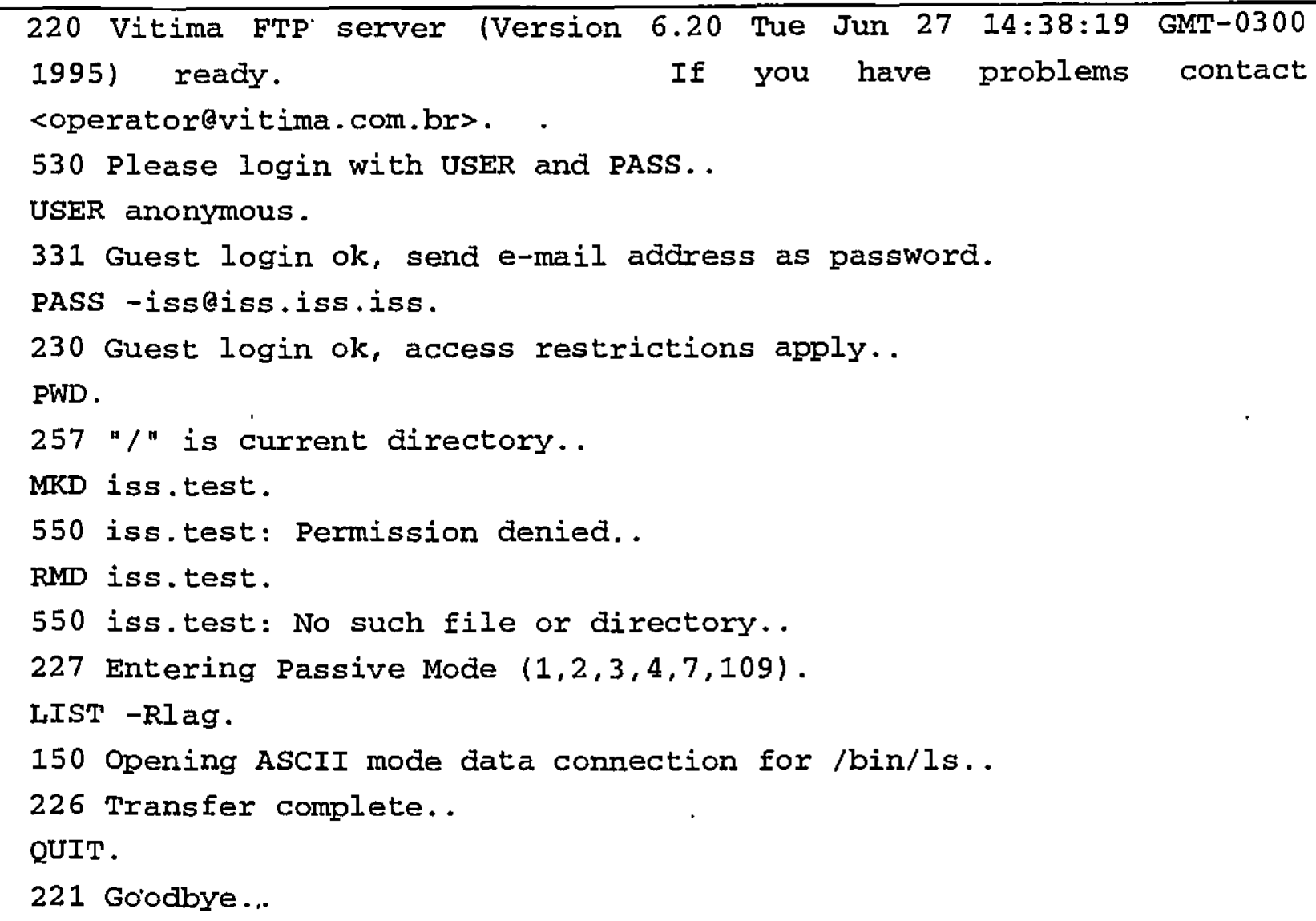

Figura $10-$ Exemplo de ataque usando $\mathrm{ftp}$

Ainda que firewalls sejam uma altemativa considerada segura e largamente utilizada, seu uso não implica em segurança total. É necessário o uso de outras tecnologias atuando em conjunto para se aumentar o nível de segurança provido por um firewall. 
Tentativas de ataque acontecem de acordo com algumas técnicas de acesso e frequentemente o invasor está fisicamente fora do sistema sob ataque. Os primeiros modelos de sistemas de detecção de intrusão, projetados para computadores isolados, usam algoritmos básicos que incluem análise de funções multinomiais e aproximação de matrizes covariantes para detectar desvio do comportamento normal, tão bem como sistemas especialistas para detectar violação de políticas de segurança. Os modelos mais modernos monitoram um grande número de redes de computadores e transferem a informação monitorada para ser processada em um equipamento central que emprega técnicas de sistemas distribuídos.

A maioria dos IDSs tem um processo auditor (daemon) em cada máquina, responsável por capturar ações de violação de segurança dentro da máquina. Sistemas baseados em redes, ao invés de utilizar pistas de auditoria, analisam o tráfego de pacotes dentro da rede para detectar comportamento intrusivo.

O objetivo de um sistema de deteç̧ão de intrusão neste projeto é prover capacidades extras a um firewall. Tal sistema deve observar as conexões consideradas seguras e permitidas pelo firewall procurando por um comportamento suspeito que indique uma possível intrusão ou tentativa de ataque. Como o firewall não tem meios de avaliar o conteúdo de tais conexões, ele se baseia apenas em suas regras de filtragem para decidir se uma conexão pode ou não ser aceita. Desta forma, as funcionalidades de um sistema de detecção se tornam de vital importância na medida em que provêem meios de inferir sobre o conteúdo das conexões permitidas e detectar as que apresentem um comportamento suspeito ou não condizente com a política de segurança implantada.

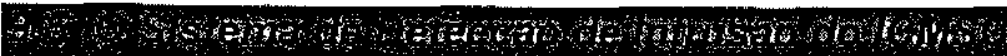

Uma das características inovadores deste sistema de detecção de intrusão consiste em introduzir um agente de segurança capaz de detectar comportamento intrusivo em conexões estabelecidas. Este agente atua capturando e decifrando pacotes que são transmitidos através da rede sobre monitoramento. Para fazer uma inferência sobre a condição de segurança das conexões, o agente emprega um sistema especialista e uma rede neural que irá prover um 
coeficiente de suspeita, o qual, baseado em informaçōes intrusivas previamente registradas, dará uma idéia a respeito da severidade do ataque ou o grau de suspeita das atividades naquela conexão.

O sistema se baseia no fato de que uma intrusão pode ser detectada a partir de uma análise de modelos predeterminados, que são anômalos se comparados com ações normais. A grande maioria dos ataques são resultado de um pequeno número de ataques conhecidos, como relatados por equipes como o CERT.

O uso de redes neurais pode fornecer mecanismos para o reconhecimento de ataques, tão bem quanto uma capacidade de adaptação em resposta a mudanças nas técnicas de intrusão.

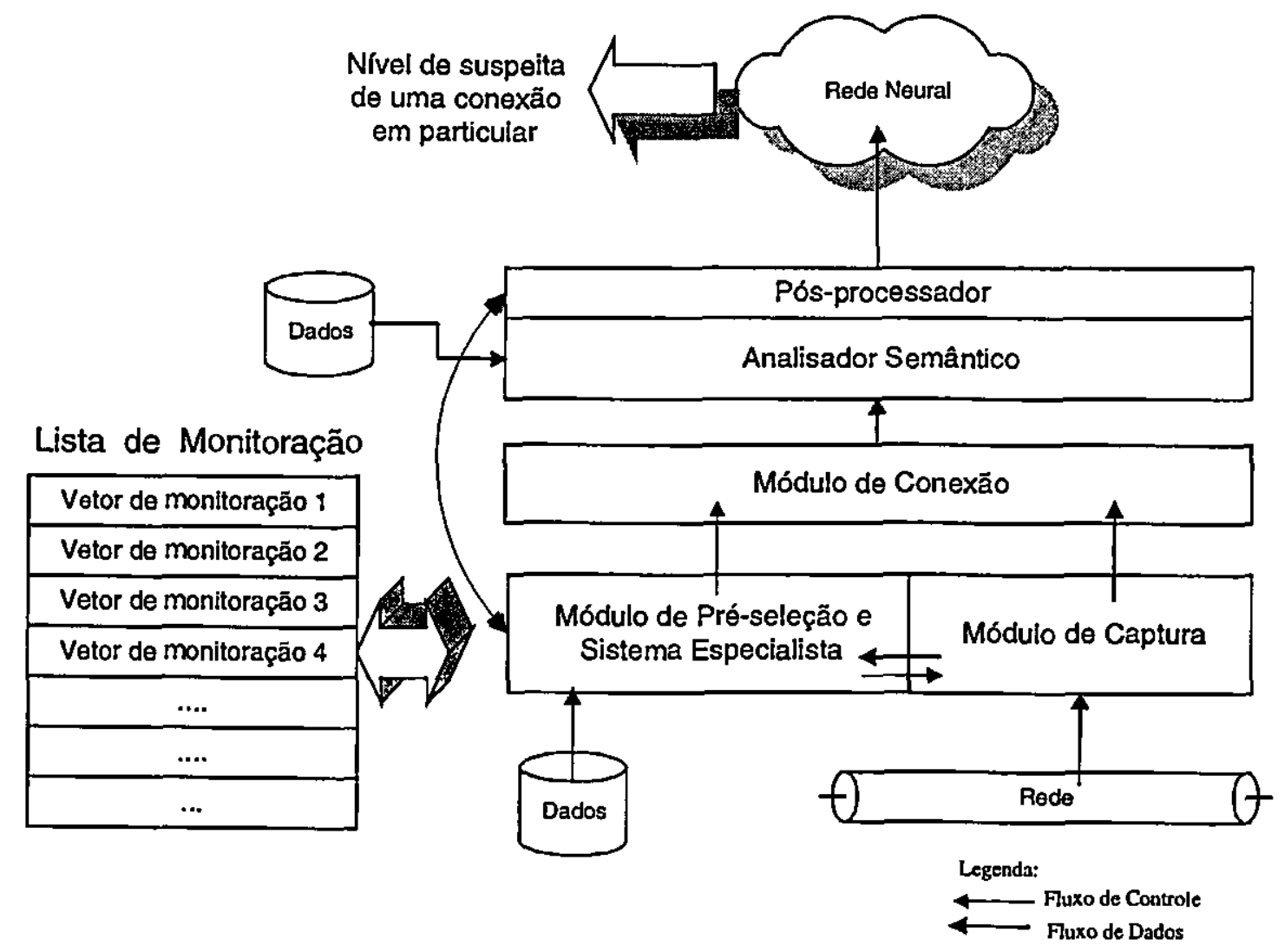

Figura 11 - Estrutura modular do sistema de detecção de intrusão 
O agente é organizado em quatro módulos (Figura I1). Os módulos gerenciam o fluxo de pacotes e fornecem um vetor de estímulo para a rede neural. O nível mais baixo apenas captura um fluxo de dados na rede e passa os pacotes ordenados ao segundo módulo. O módulo seguinte consiste de 2 sub-módulos: módulo de pré-seleção de pacotes, e módulo do sistema especialista. O módulo de pré-seleção faz a monitoração e filtragem iniciais dos pacotes, que possam representar eventos de interesse, tais como que tipo de protocolo será monitorado ou que origens e destinos devem ser considerados. Os pacotes previamente filtrados então passam através de uma análise feita pelo sistema especialista. O sistema especialista usa as seguintes informações ao tomar decisões de quais conexões terão seus conteúdos monitorados: Quais os caminhos esperados de conexões: origem e destino (quais podem ser perigosos) e portas de origem e destino envolvidas; sensibilidade das máquinas e confiabilidade dos domínios; capacidades dos serviços e autenticação do nível de segurança. O sistema especialista ainda mantém registro de eventos passados que influenciarão em sua decisão. Eventos previamente registrados de um mesmo par origem-destino irão conferir um maior grau de severidade a novos eventos.

O terceiro módulo é baseado no modelo hierárquico do Monitor de Segurança de Redes (MSR). Ele recebe os pacotes e organiza-os em uma relação de causa-efeito, identificando um fluxo de dados unidirecional. Isto é feito através da análise dos campos de origem e destino, portas, e número de sequência dos pacotes, solucionando então o problema da fragmentação. Este procedimento pode ser feito no nível de IP ou TCP. Este fluxo de dados representa a transcrição dos dados de uma particular conexão, que são então mandados para serem processados pelo Analisador Semântico.

O Analisador Semântico atua sobre o fluxo de dados da conexão, buscando por perfís de ataque que poderiam aparecer nos dados. Estes perfis são assinaturas de ataque e contém informações de como uma sessão suspeita se comporta. O Analisador Semântico irá procurar por strings suspeitas (login root, access denied, etc). Estas informações são enviadas para o último módulo de pós-processamento, que as unifica com as informações do sistema especialista (sensibilidade dos serviços e conexões) e à sua base de dados, para formar o vetor de estímulo para a rede neural. Estas informações são codificadas de forma binária para facilitar o treinamento e uso da rede neural, cada string suspeita tem um código binário diferente.

$\mathrm{Na}$ atual fase de implementaçāo do protótipo do sistema de detecção, o vetor de estímulo contém apenas o código binário da porta utilizada na conexão (ou seja, o serviço: ftp, telnet, 
sendmail, etc) seguido pelos códigos binários das strings suspeitas encontradas na conexão. Futuramente estão previstas a adição de informações como: capacidade e nível de autenticação do serviço, nível de segurança das máquinas envolvidas, quantidade de dados transferida e horário da conexão.

A rede neural analisa o vetor de estímulo, e tenta atribuir um grau de suspeita, que representa o estado de suspeita de uma conexão em particular. Antes que a rede neural possa identificar ataques potenciais, ela deve ser treinada com um significativo e suficientemente grande número de vetores de estímulo, que representem o comportamento de conexões suspeitas e legítimas. Uma vez treinada, a rede deve usar suas características de generalização para identificar corretamente os usuários que mostrem características similares às contidas nas ações de intrusão utilizadas em seu treinamento.

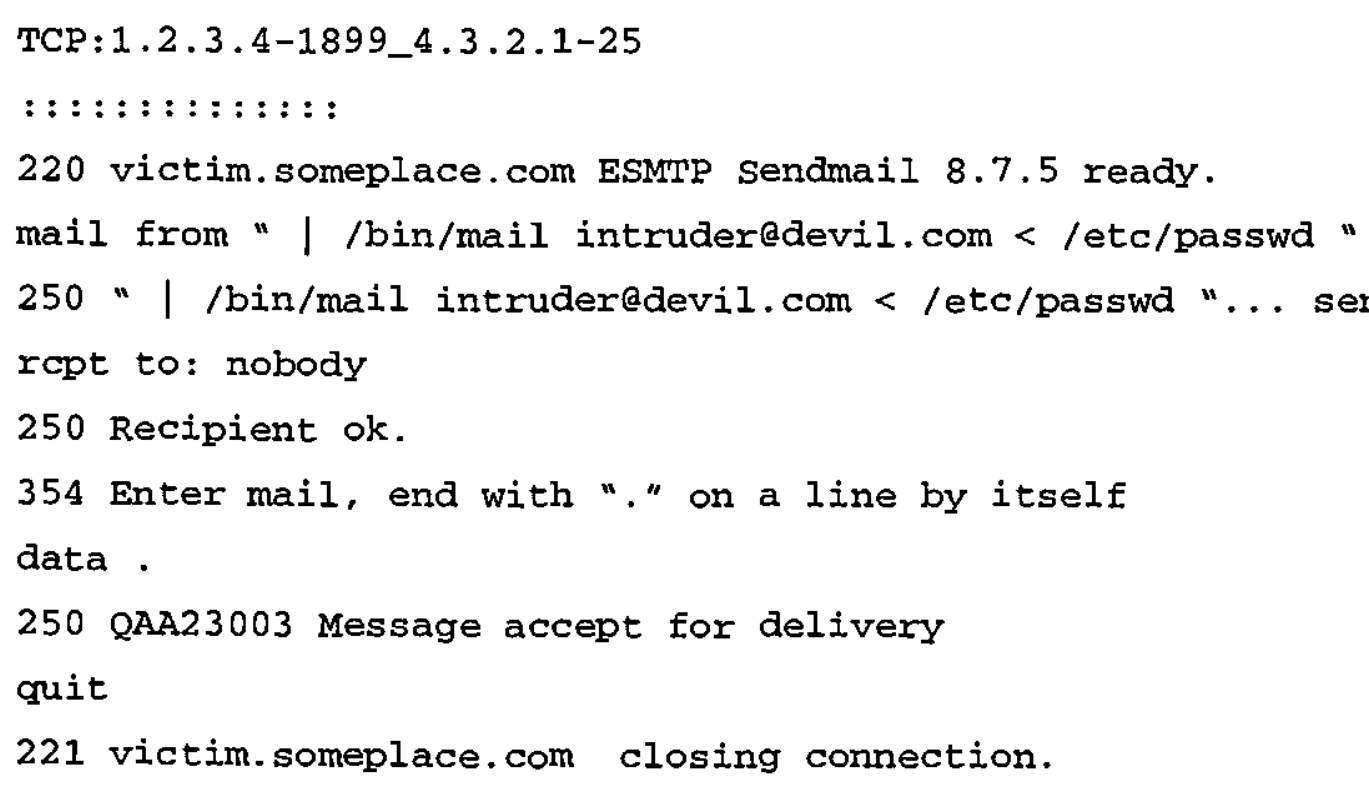

Figura 12 - Exemplo de ataque ao SendMail

A Figura 12 mostra um exemplo de ataque ao sendmail. As três primeiras linhas são geradas pelo Módulo de Conexão e representam as portas e endereços IP de origem e destino. A 
conexão (TCP) foi originada do host fictício 1.2.3.4 (porta de usuário 1899) para a porta 25 do host 4.3.2.1. Os dados restantes são o conteúdo da conexão, capturados pelo Módulo de Captura.

Este registro é uma assinatura de ataque e guarda o comportamento de uma conexão suspeita. Como há muitas informações desnecessárias, o Analisador Semântico irá filtrar os dados procurando pelos componentes principais de uma assinatura de ataque.

Com base nesta conexão, o Analisador Semântico irá produzir o vetor de estímulo como entrada para a rede neural mostrado na Tabela 2.

\begin{tabular}{|llllllll|l|}
\hline 0 & 0 & 0 & 1 & 0 & 0 & & &
\end{tabular}

Tabela 2 - Vetor de estímulo produzido pelo analisador semântico

O vetor de estímulo é composto por duas partes:

A primeira parte identifica a porta destino da conexão, isto é, o serviço utilizado. Esta parte tem 6 bits onde cada bit identifica uma porta e o código 000000 identifica as demais portas menos importantes.

\section{Porta}

$$
\text { String Suspeita \#1 }
$$$$
\text { String Suspeita \#2 }
$$ 
Figura 13 - Vetor de estímulo

A segunda parte corresponde às strings suspeitas. $O$ vetor de estímulo pode conter até 10 strings suspeitas. Caso haja menos de 10 strings, os slots restantes são preenchidos com 0 . Se forem encontradas mais de 10 strings na conexão, as outras serão ignoradas. Alternativamente, pode-se usar técnicas como janelas, correspondendo aos diferentes subconjuntos de strings encontradas como mostrado na Figura 14.

String String String String String String String String String String String String

$\begin{array}{llllllllllll}\# 1 & \# 2 & \# 3 & \# 4 & \# 5 & \# 6 & \# 7 & \# 8 & \# 9 & \# 10 & \# 11 & \# 12\end{array}$

\begin{tabular}{|c|c|c|c|c|c|c|c|c|c|c|c|c|}
\hline 1 & 2 & 3 & 4 & 5 & 6 & 7 & 8 & 9 & 10 & & & Vetor de Estímulo \#1 \\
\hline & 2 & 3 & 4 & 5 & 6 & 7 & 8 & 9 & 10 & 11 & & Vetor de Estímulo \#2 \\
\hline & & 3 & 4 & 5 & 6 & 7 & 8 & 9 & 10 & 11 & 12 & Vetor de Estímulo \#3 \\
\hline
\end{tabular}

Figura 14 - Vetores de estímulo gerados pela técnica de janelas

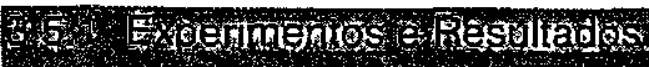

2.

Os experimentos apresentados aqui usam redes neurais MLP (Rumelhart \& McClelland, 1986). Estas redes são geralmente treinadas pelo algoritmo backpropagation. Este algoritmo usa uma generalização da regra delta rule para treinar uma rede com várias camadas começando na camada de saída e voltando camada por camada. Geralmente, este treinamento requer diversos passos. Como o algoritmo backpropagation requer um longo tempo para treinar a rede, algumas modificações foram utilizadas que aceleram o processo de treinamento. As variações do backpropagation que foram usadas são Quickprop e Rprop. 
As redes neurais usadas nestes experimentos tem 126 neurônios na camada de entrada correspondentes aos 126 bits do vetor de estímulo. Diversas configurações diferentes foram testadas para identificar a que apresenta o melhor desempenho para este problema.

Os testes foram realizados com o simulador SNNS (Sttutgart Neural Network Simulator) ${ }^{6}$. Foram feitos testes com 8 topologias diferentes, todas com 126 neurônios na camada de entrada e um na camada de saída. As topologias usadas foram: 126-1 (126 neurônios de entrada e 1 de saída, sem camadas intermediárias), 126-5-1, 126-10-1, 126-20-1, 126-40-1, 126-60-1 (com uma camada intermediária, onde o segundo número indica o número de neurônios nesta camada), 126-20-1-1 e 126-20-5-1 (com duas camadas intermediárias). Foi usada uma segunda camada intermediária na tentativa de se aumentar o desempenho. Nos testes, foi verificado que a rede com o melhor desempenho foi a 126-20-1, então foi decidido inserir a segunda camada intermediária nesta topologia, com 1 e 5 neurônios. Todas as topologias utilizadas são completamente conectadas, isto é, todos os neurônios em uma camada estão conectadas a todos os neurônios da camada seguinte.

Foram usados 3 algoritmos de treinamento, cada um com parâmetros diferentes mostrados na Tabela 3.

Cada uma das 8 topologias foram testadas utilizando-se todos os algoritmos com todos os respectivos possíveis parâmetros. Para cada possível configuração (topologia, algoritmo de treinamento e parâmetros) foi verificado que valores diferentes nos pesos iniciais dos neurônios causaram grandes diferenças na saída da rede. Para conseguir um resultado confiável, foram feitos 20 treinamentos diferentes para cada configuração possível e foi usado o valor médio como um valor de comparação adequado. Foram feitos 1440 treinamentos diferentes ao todo e os resultados agrupados em 3 gráficos (Figura 15, 16 e 17) correspondentes aos três algoritmos: Backpropagation, Rprop e QuickProp. O eixo X representa as topologias usadas, o eixo Y, o erro médio e as barras em cada topologia representam os parâmetros usados indicados nas caixas à direita do gráfico.

${ }^{6}$ O site do SNNS pode ser encontrado em http://www.informatik.uni-stuttgart.de/ipvrb/bv/projekte/snns/snns.html 


\begin{tabular}{|l|l|}
\hline Algoritmo de Treinamento & \multicolumn{1}{|c|}{ Parâmetros } \\
\hline \multirow{3}{*}{ BackPropagation } & $\mathrm{n}: 1$ delta: 0.5 \\
& $\mathrm{n}: 1$ delta:0.1 \\
& $\mathrm{n}: 0.1$ delta:0.1 \\
& $\mathrm{n}: 0.2$ delta: 0.5 \\
\hline \multirow{2}{*}{ RPROP } & delta $_{0}: 0.1$ delta $_{\max }: 50 \mathrm{a}: 2$ \\
& delta $_{0}: 0.1$ delta $_{\max }: 50 \mathrm{a}: 0.1$ \\
& delta $_{0}: 0.1$ delta $_{\max }: 50 \mathrm{a}: 0.001$ \\
\hline QuickProp & $\mathrm{n}: 0.2 \mathrm{u}: 2.25 \mathrm{v}: 0.0001$ delta: 0.1 \\
& $\mathrm{n}: 0.2 \mathrm{u}: 1.75 \mathrm{v}: 0.0001$ delta:0.1 \\
\hline
\end{tabular}

Tabela 3 - Algoritmos de treinamento e parâmetros

Foram usados três conjuntos de dados para realizar os testes: treinamento, validação e teste, com 120, 56 e 56 padrões respectivamente; e todos os conjuntos contendo $50 \%$ de padrões de comportamento intrusivo e 50\% de não intrusivo, para garantir um resultado não tendencioso da rede neural. Foram adicionados ruídos em alguns padrões de todos os conjuntos.

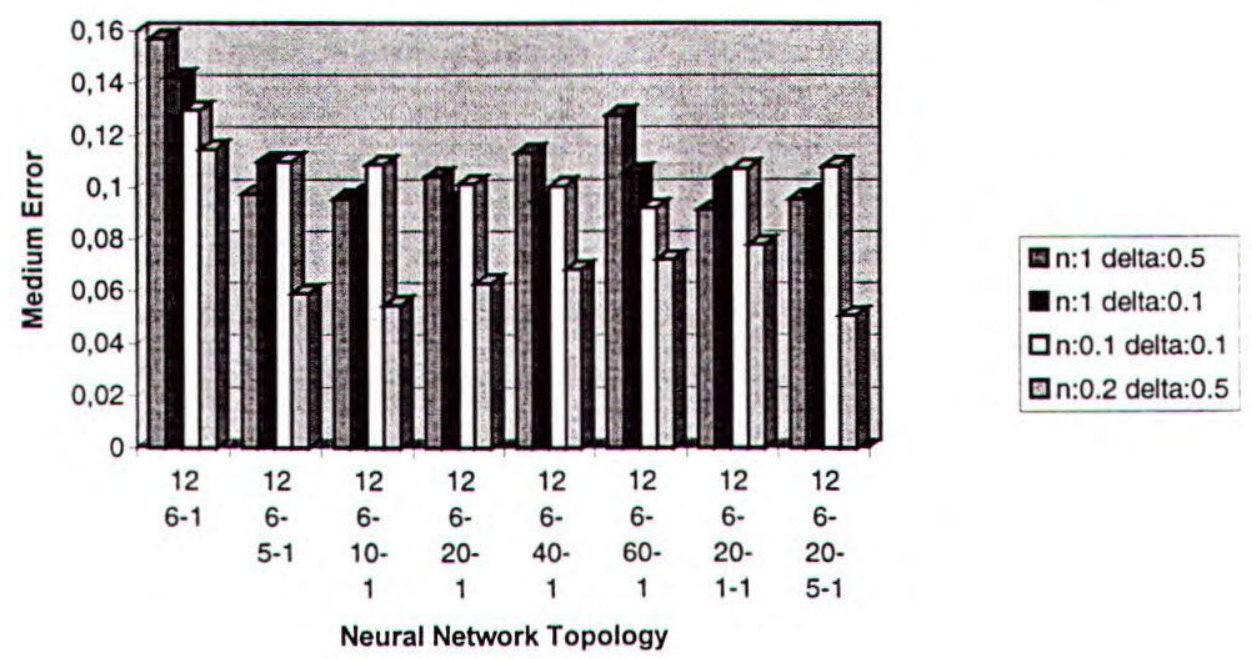

Figura 15 - Resultados do algoritmo Backpropagation 
Para o treinamento, foram usados 500 ciclos de treinamento e uma validação a cada 10 ciclos. Após o treinamento, foi feito o teste com o terceiro padrão (teste).

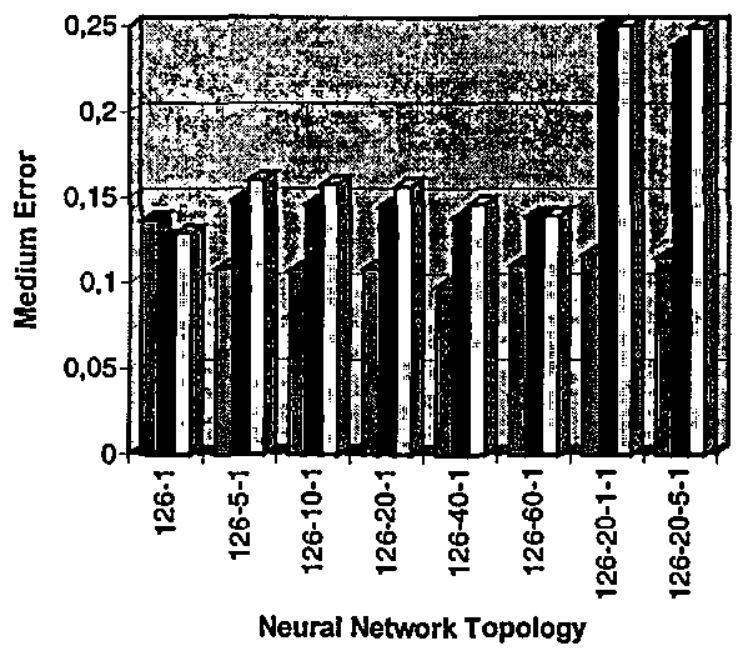

Figura 16 - Resultados do algoritmo Rprop

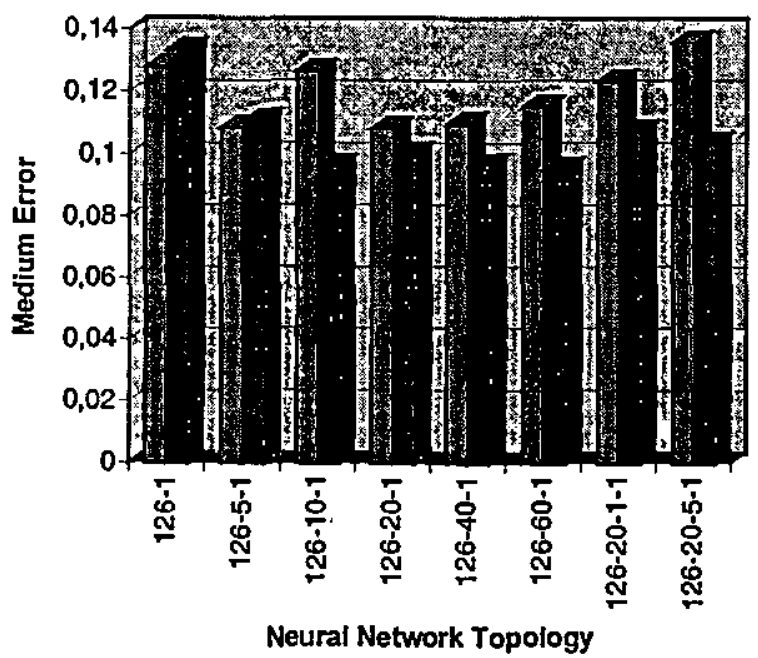

n:0.2 u:2.25 v:0.0001 delta:0.1

an:0.2 u:1.75 v:0.0001 delta:0.1

Figura 17 - Resultados do algoritmo QuickProp

Os padrões de ataque e não-ataque foram capturados em um ambiente de rede controlado por simulações de ataque e comportamentos normais. As simulações de ataque foram feitas manualmente usando-se técnicas de intrusão conhecidas e por sistemas como SATAN e ISS. 
Com estes métodos, foi conseguido um bom conjunto de assinaturas para treinar as redes neurais.

A análise dos resultados mostra que a rede neural com a melhor performance foi a 12620-5-1, com duas camadas intermediárias, algoritmo de treinamento e parâmetros n igual a 0.2 e delta igual a 0.5 , apresentando uma taxa média de erro de $5.067 \%$. É interessante notar também que este algoritmo de treinamento com estes parâmetros teve os melhores resultados, e nas topologias com apenas uma camada intermediária, os melhores resultados situaram-se entre as topologias 126-5-1 e 126-20-1, tornando-se pior com mais ou menos neurônios na camada intermediária.

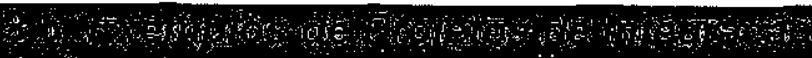

O Darpa (Defense Advanced Research Projects Agency), subordinado ao DoD (Department of Defense), tem um projeto chamado "Survivability of Large Scale Systems" relacionado à segurança de informações. O Darpa se baseia na premissa de que mesmo com os melhores mecanismos de segurança, pode-se esperar que um intruso será capaz de penetrar suas defesas. As pesquisas deste projeto se destinam principalmente à sistemas que fazem parte da infra-estrutura crítica de informações nacionais e de defesa como telecomunicações, sistemas de controle de geração e distribuição de energia, sistemas financeiros e de defesa, entre outros.

Este programa tem as seguintes metas:

- Desenvolver tecnologias para detecção de intrusões e eventos suspeitos.

- Permitir que elementos de infra-estrutura (como firewalls) reajam à eventos detectados.

- Permitir que sistemas danificados possam redirecionar recursos para as tarefas consideradas mais importantes.

\footnotetext{
${ }^{7}$ O site do DARPA pode ser encontrado em htlp://www.darpa.mil
} 
- Permitir que os sistemas comprometidos sejam reconfigurados para um estado não suscetível ao ataque original.

Neste sentido, vários projetos estão em andamento, como sistemas de detecçāo de intrusão, protocolos para comunicação dos vários elementos que compõem a infra-estrutura de segurança: elementos de proteção (firewalls), elementos de análise, elementos geradores de informação (sistemas auditores) e outros. Esta integração visa uma detecção coordenada e ações de resposta automática, além da criação de padrões de tal forma que produtos fomecidos por diferentes fabricantes possam se comunicar.

Todos os projetos em desenvolvimento tem forte participação de grandes empresas e universidades como Boeing, TIS, Carnegie Mellon University, Comell University, Columbia University, SRI Intemational, etc.

A seguir serão detalhados dois dos projetos. Infelizmente, projetos como IDIP ainda não tem artigos publicados e existe pouca informação disponível na Intemet.

\section{5}

IDIP (Intrusion Detection and Isolation Protocol) é um protocolo que éstá sendo desenvolvido em conjunto pela Boeing Corporation, Trusted Information Systems (TIS) e pela Universidade da Califórnia em Davis para detectar e isolar intrusos uma vez que estes tenham penetrado em alguma parte do sistema.

O objetivo deste protocolo é combinar sistemas de detecção de intrusão com firewalls e roteadores inteligentes para formar um sistema de defesa automático. Isto é feito configurando-se estes componentes em uma "rede de segurança virtual" na qual eles possam se comunicar.

Em um caso de ataque em andamento, os componentes de segurança irão alertar um ao outro e será selecionado um para iniciar uma resposta automática.

No atual estágio de desenvol vimento, já foram desenvolvidos:

- uma primeira definição do protocolo. 
- a camada de transporte IDIP (implementada em Sun Solaris, BSDI BSDOS e Boeing Secure Network Server).

- a camada de aplicação para o Firewall toolkit (TIS) rodando em BSDOS, para o Master Intrusion Detection System (UC Davis) rodando em Sun Solaris e para o roteador inteligente da Boeing dentro do Secure Network Server, além da integração desta camada com a camada de transporte.

O desenvolvimento deste protocolo segue os mesmos princípios deste projeto de mestrado. Para se aumentar a segurança de um sistema computacional, é necessário que vários elementos de segurança estejam trabalhando em conjunto, pois cada um deles tem uma funçăo específica. Sua integração cria um sistema em que as deficiências são mutuamente preenchidas, além de permitir respostas automáticas em casos de intrusão.

\section{(3)}

O CIDF (Common Intrusion Detection Framework) (Staniford-Chen, Tung \& Schnackenberg, 1998) é um projeto que visa o desenvolvimento de protocolos e APIs ${ }^{8}$ para que projetos de deteç̧ão de intrusão possam interoperar, e que seus componentes possam ser reusados em outros sistemas.

${ }^{8}$ Do inglês: Application Programming Interface 


\section{Sistema de Segurança Distribuído}

"Geralmente, aquele que ocupa primeito o campo de batalha e espera seu inimigo está em vantagem"-Sun Tzu

Tendo em vista as constantes mudanças pelas quais as redes e todas as aplicações e serviços que dela se utilizam estão passando, nota-se o crescimento de preocupações com seu correto e bom funcionamento. Ferramentas de gerenciamento e administração de redes cada vez se tomam mais um requisito básico para qualquer administrador de redes. Vê-se também que tais ferramentas visam incorporar cada vez mais funcionalidades, para poder fornecer melhores e mais poderosos recursos para o administrador de rede. Neste sentido, pode-se considerar que segurança é um item de fundamental importância no que se refere ao gerenciamento de redes. Uma ferramenta de gerenciamento que também tenha funcionalidades de segurança torna-se uma solução bastante poderosa e abrangente.

Neste contexto, este trabalho apresenta um sistema de segurança distribuído para adicionar características de segurança para um sistema de gerenciamento, o NetTracker. Foi feita uma análise de quais requisitos um sistema de segurança deveria ter para torná-lo o mais robusto e flexível possível. Tal análise de requisitos levou fortemente em conta a preferência por padrões abertos e consolidados em sua implementação.

Comparado a outras soluções mais complexas e completas como o IDIP, que define todo um protocolo de interação de tecnologias de segurança, esta solução é focada em um nicho de ambientes mais simples, que não requerem um alto nível de sofisticação, mas que precisam de soluções integradas que lhes forneçam um maior grau de segurança do que o encontrado em soluçōes isoladas.

Para a implementação, foram usadas várias técnicas e conceitos de estruturas de dados, engenharia de software, objetos distribuídos e tecnologias de redes para modelagem das estruturas de dados e arquiteturas de comunicação.

O sistema de segurança distribuído foi construído com base em duas tecnologias principais: 
- O gerenciamento dos objetos do sistema de forma distribuída é realizado através do padrão CORBA (Common Object Request Broker) de comunicação de objetos distribuídos, que provê uma plataforma simples de desenvolvimento para aplicações distribuídas.

- O sistema foi criado como uma aplicação da ferramenta de gerenciamento NetTracker.

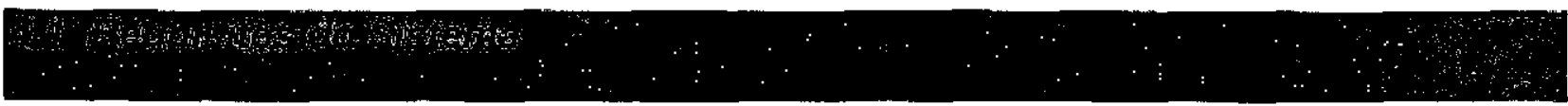

Ao invés de todos os componentes do sistema estarem em uma única máquina dedicada, a arquitetura e projeto do sistema foram feitos de tal forma a aproveitar toda a gama de recursos computacionais já existentes para a execução distribuída das diversas partes do sistema, além de apresentarem diversas outras vantagens e capacidades. Este ambiente distribuído é a base para a integração do firewall com o sistema de detecção ACME!, que são duas aplicações subordinadas ao sistema.

Desta forma, o sistema foi desenvolvido com as seguintes características:

- Modular: é formado por módulos pequenos que realizam tarefas específicas. Essa estrutura permite que mudanças, inserções e remoções de módulos sejam simples, sem a necessidade de grandes alterações no restante do sistema. A tecnologia de orientação à objetos fornece essa capacidade uma vez que o sistema é estruturado como um conjunto de objetos com comportamentos e estados bem definidos e encapsulados dos demais objetos do sistema.

- Processamento Distribuído: os módulos podem estar em uma ou várias máquinas de forma transparente. Este recurso visa aproveitar a capacidade computacional ociosa da rede. A comunicação entre os módulos é realizada através de CORBA, o que permite que todos os objetos possam se comunicar transparentemente, que módulos possam ser movidos de uma máquina para outra e trabalharem em plataformas diferentes de hardware e software. 
- Gerenciamento Remoto: é disponibilizado ao administrador uma interface de gerenciamento remota do sistema via um Web Browser padrão (Netscape Navigator e Internet Explorer, por exemplo) com suporte à linguagem Java, uma vez que a interface é um applet Java. Com isto, em qualquer parte da rede, ou até mesmo fora dela, o administrador pode se comunicar com o sistema sem a necessidade de estar fisicamente presente em um determinado ponto da rede. Com o crescimento das redes, recursos de administração remota têm se tornado cada vez mais desejados em aplicações que tratam de gerenciamento da rede.

- Tolerância a Falhas: deverá ter recursos que permitam que diversas máquinas possam executar a mesma tarefa de forma que caso ocorra algum problema com um dos módulos, outro módulo idêntico em outra máquina assuma seu lugar, mantendo a operacionalidade do sistema como um todo. Este recurso é particularmente interessante, pois dá ao sistema a característica de não ter pontos críticos nos quais um ataque comprometeria todo o sistema. O padrão CORBA incorpora definições neste sentido e uma vez que a implementação de CORBA utilizada para o desenvolvimento tenha estas características implementadas, este recurso é automaticamente utilizado.

- Escalabilidade: deve ser possível a inserção de módulos de forma a aumentar os recursos disponíveis no sistema, ou seja, a inclusão de uma aplicação ou recurso ao sistema deve se dar de forma simples e rápida.

- Portabilidade: os diversos modulos do sistema devem ser capazes de serem executados na maior gama de plataformas diferentes. Para isso, a linguagem Java fornece uma ambiente independente de plataforma de hardware e software sobre os quais os módulos podem ser executados.

- Segurança nas Comunicações: as comunicações entre módulos devem se dar de forma segura através de criptografia. Para prover este requisito, a implementação de CORBA usada possibilita que todas as comunicações sejam feitas usando-se o protocolo SSL (Secure Sockets Layer). O SSL é um protocolo aberto desenvolvido pela Netscape Communications que permite encriptação de dados, autenticidade das partes comunicantes e verificação de integridade das mensagens utilizando diversos algoritmos criptográficos. Ele trabalha entre a camada de transporte e as aplicações. 
Aqui serão abordadas as principais tecnologias empregadas na construção do sistema de segurança distribuído: NetTracker, CORBA e Java.

O NetTracker é uma ferramenta de gerenciamento de redes que utiliza o protocolo SNMP (Simple Network Management Protocol) (Schoffstall, 1990). Uma análise sobre este protocolo pode ser vistas em (Morishita, 1997).

A estrutura do gerenciador (Mouro, 1997; Mouro, Morishita \& Moreira 1997) é a mais modular possível, de forma que partes possam ser inseridas e ou removidas sem a necessidade de grandes alterações no sistema, facilitando a manutenção do código fonte.

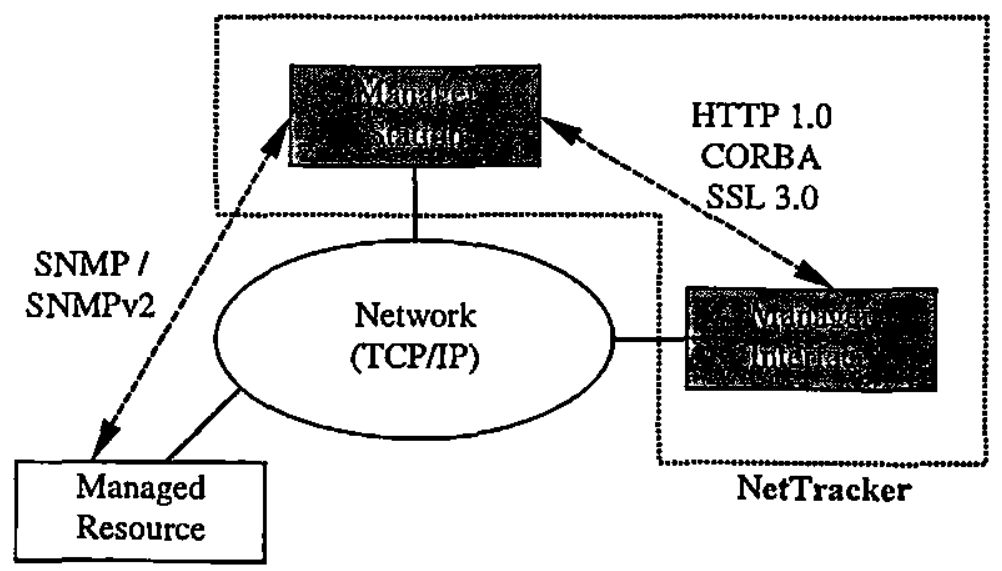

Figura 18 - Relacionamento de comunicação intramódulos 
A Figura 18 sintetiza o relacionamento de comunicação entre os três principais elementos que compõem o ambiente gerenciado pela ferramenta NetTracker.

Manager Resources são os elementos que compõem a rede e que sejam providos de capacidades de gerenciamento. Manager Station é o centralizador das informações, provê as funções de controle e monitoramento ao administrador. Manager Interface é a interface do sistema, disponibilizada ao administrador como um código transportável (Applet Java).

A Figura 19 mostra a arquitetura do sistema, composto por cinco camadas interdependentes: Módulos de Programas de Aplicação (NAPM), Interface de Extensão de Aplicações (NEAPI), Módulos de Extensão (NEM), Biblioteca de Objetos Java e Máquina Virtual Java.

\section{NetTracker}

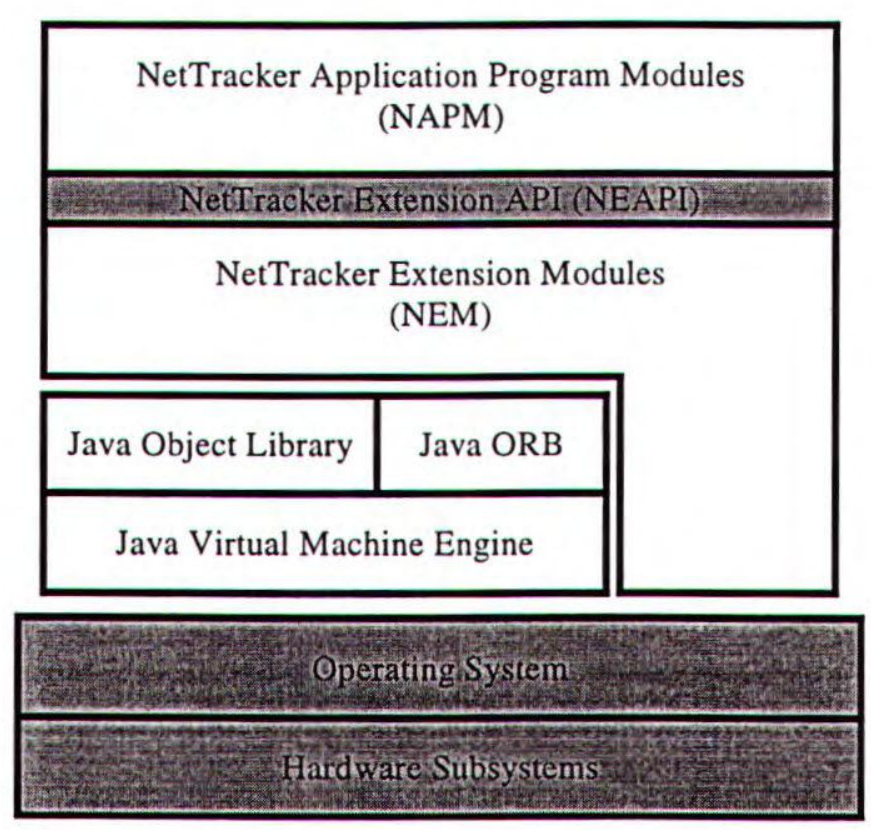

Figura 19 - Arquitetura do sistema NetTracker

A camada NAPM trata dos aspectos funcionais agregados ao sistema NetTracker, incorporando as aplicações responsáveis por proverem as funções de gerenciamento e de comunicação com o administrador. Como exemplos de elementos componentes desta camada, podemos citar uma aplicação de Filtragem de Traps, juntamente com aplicações de gerenciamento de trigger e de busca e reconhecimento automático da topologia. 
Na camada NEAPI, encontram-se disponíveis as interfaces de programação que fornecem acesso às funções implementadas pelos Módulos de Extensão. No contexto da tecnologia de objetos, que é amplamente empregada neste projeto, esta camada é composta por todas as interfaces dos objetos codificados na camada NEM.

Todos os objetos responsáveis por proverem funções básicas de apoio às funçðes de gerenciamento serão integrados à camada NEM. Tais funçð̋es desempenham o papel de alicerce para os programas de aplicações que se encontram na camada superior. Basicamente, esta é composta pelos sub-módulos: HTTPServer, Iṇterface, Database, SNMP e Segurança.

O NetTracker é composto por duas categorias principais de objetos: Objetos de Sistema e Objetos de Aplicação. Os primeiros definem os objetos que integram o ambiente básico de execução do sistema, efetuando a carga dinâmica e posterior ativação dos Objetos de Aplicação. Estes últimos, por sua vez, definem de fato as aplicações do sistema NetTracker. Os objetos de Aplicação devem necessariamente herdar os atributos e métodos da classe MVApplication.

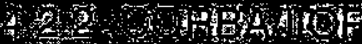

Devido ao atual cenário de plataformas de hardware e software incompatíveis e da necessidade por aplicações distribuídas que pudessem ser construídas com um alto grau de facilidade e flexibilidade, a OMG (Object Management Group) ${ }^{9}$ criou em 1991 um padrão chamado de CORBA (Common Object Request Broker Architecture) (Schimidt \& Vinoski, 1995; Vinoski, 1997) para solucionar os problemas de interoperabilidade em ambientes distribuídos heterogêneos. A especificação de CORBA se encontra atualmente na versão 2.0 (OMG, 1995).

A base da arquitetura CORBA é o ORB (Object Request Broker) que permite o uso de relações cliente-servidor entre diversos objetos.

\footnotetext{
${ }^{9} \mathrm{O}$ site da OMG se encontra em http://www.omg.org
} 
Um ORB é o middleware que permite que um objeto acesse um serviço implementado por outro objeto, na mesma máquina ou remotamente pela rede. Toda chamada de métodos é feita de forma completamente transparente aos dois objetos com relação à interface de chamada do método, à linguagem de programação utilizada e sua localização. O ORB intercepta a chamada à função e a partir disto, ele procura onde está a implementação da função requisitada e cuida da comunicação e da resposta da função.

As interfaces dos objetos podem ser definidas via um stub-skeleton IDL (Interface Definition Language). IDL é uma especificação independente de linguagem para criar as interfaces cliente-servidor.

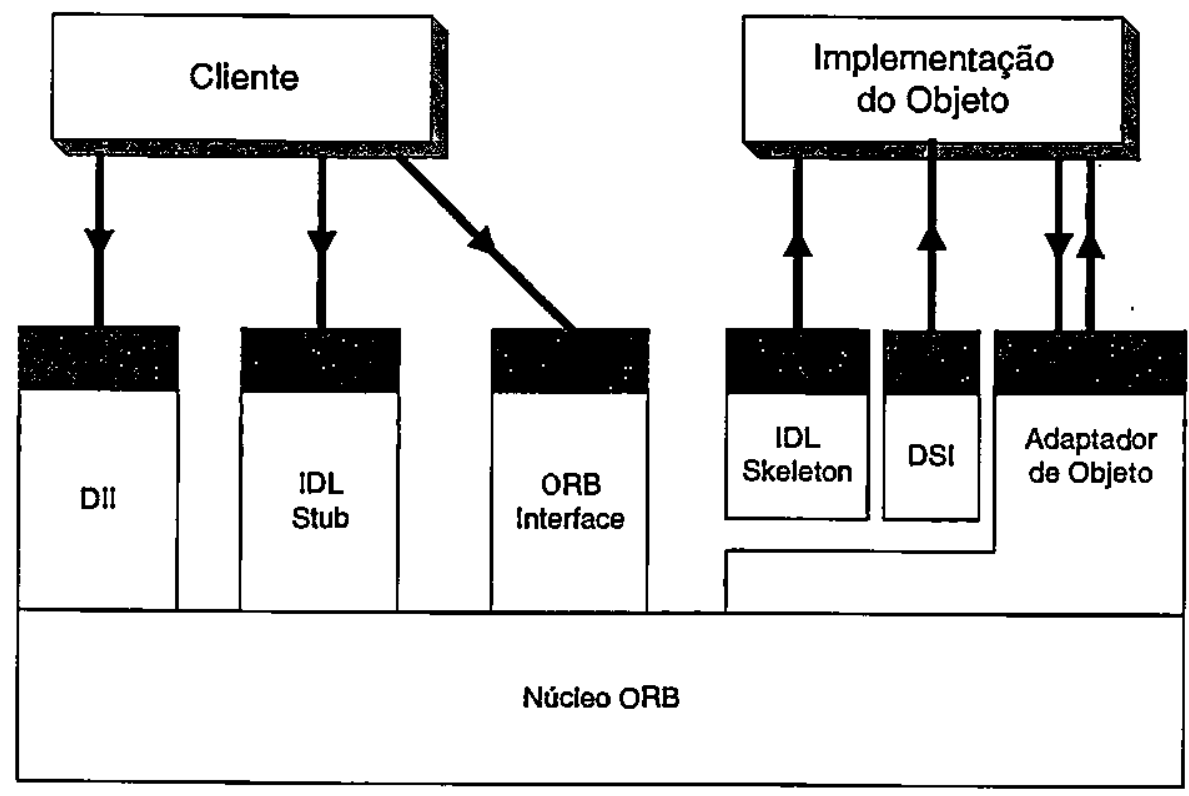

Figura 20 - Arquitetura CORBA

Uma requisição é feita a partir da referência de um objeto por um método stub (IDL) ou construindo-se a requisição dinamicamente (DDI). O ORB então, irá localizar onde está a implementação correspondente e passará os parâmetros via um IDL Skeleton ou um skeleton dinâmico (DSI). Após o servidor realizar a requisição, os valores de retorno são transmitidos de volta ao cliente. 
Antes da versão 2.0 do CORBA, uma das maiores reclamações sobre produtos comerciais ORB era que eles não "interoperavam". 'A falta de interoperabilidade era causada pelo fato de que a especificação do CORBA não continha nenhum protocolo ou formato de dados para a comunicação entre ORB's. CORBA 2.0 introduziu uma arquitetura geral que provê uma interoperabilidade ORB-para-ORB e uma baseada em ponte (bridge-based).

Interoperabilidade direta é possível quando dois ORB's residem em um mesmo domínio, ou seja, eles entendem as mesmas referências a objetos, o mesmo sistema de tipos IDL, etc. Bridge-based é necessária quando ORB's de diferentes domínios devem comunicar. O papel da ponte é mapear informação específica sobre o ORB de um domínio para o outro.

A arquitetura geral de interoperabilidade de um ORB é baseada em um GIOP (General Inter-ORB Protocol), que especifica a sintaxe de transferência e um conjunto padrão de formatos de mensagens para interoperação de ORB's sobre qualquer transporte orientado a conexão. GIOP foi desenvolvido para ser simples e fácil de implementar e permite escalabilidade e desempenho razoáveis.

O IIOP (Internet Inter-ORB Protocol) especifica como o GIOP é construído sobre TCP/IP.

\section{6.}

A linguagem Java ${ }^{10}$ (Gosling, Joy \& Steele, 1996), desenvolvida pela Sun Microsystems tornou-se um dos grandes padrões da Internet tendo como principal marketing ser uma linguagem independente de plataforma, "Write Once, Run Anywhere".

Dentre as diversas características que fizeram de Java a principal linguagem utilizada em aplicações Web/Internet/Intranet pode-se destacar:

- Independência de Plataforma: Java é uma linguagem interpretada a partir de um bytecode que é executado por uma Máquina Virtual Java (Lindholm et al., 1997).

${ }^{10} \mathrm{O}$ site da linguagem Java pode ser encontrado em $\mathrm{htt}$ : $/ /$ java.sun.com 
Desta forma, apenas a $\mathrm{JVM}^{11}$ necessita ser portada para diferentes plataformas, o bytecode é único.

- Portável: Por não ter qualquer aspecto de implementação dependente de plataforma, o bytecode pode ser executado em qualquer plataforma que tenha suporte a JVM. Um cenário muito utilizado é a execução de códigos no lado do cliente em browsers Web que tenham uma JVM incorporada.

- Orientada a objetos: Usa o paradigma de programação orientada a objetos, o que lhe confere a característica de ser possível produzir software reusável e criação de interfaces de modo simples. A especificação da linguagem procurou torná-la bastante parecida com a linguagem $\mathrm{C}++$, o que facilita em muito sua aprendizagem por programadores que já conheçam $\mathrm{C}++$.

- Fortemente Tipada: Por realizar uma alta checagem de tipos e ter um modelo de ponteiros diferente de $\mathrm{C} / \mathrm{C}+$, Java é mais robusta e elimina problemas como escrever em posiçōes de memória indevidas.

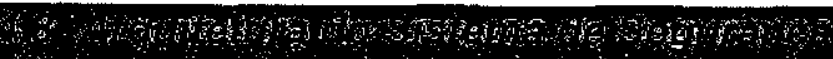

Atualmente, o sistema de segurança é composto basicamente por quatro módulos: Manager, Interface de Gerenciamento, Gerenciador do Firewall e Gerenciador do ACME!. A

Figura 21 mostra a arquitetura do sistema.

Pela arquitetura do sistema é possível observar que não existe comunicação direta entre dois módulos, todos se comunicam através de ORBs, os quais cuidarão de localizar o objeto correspondente e realizar a comunicação de baixo nível.

\footnotetext{
${ }^{11}$ Do inglês, Java Virtual Machine
} 


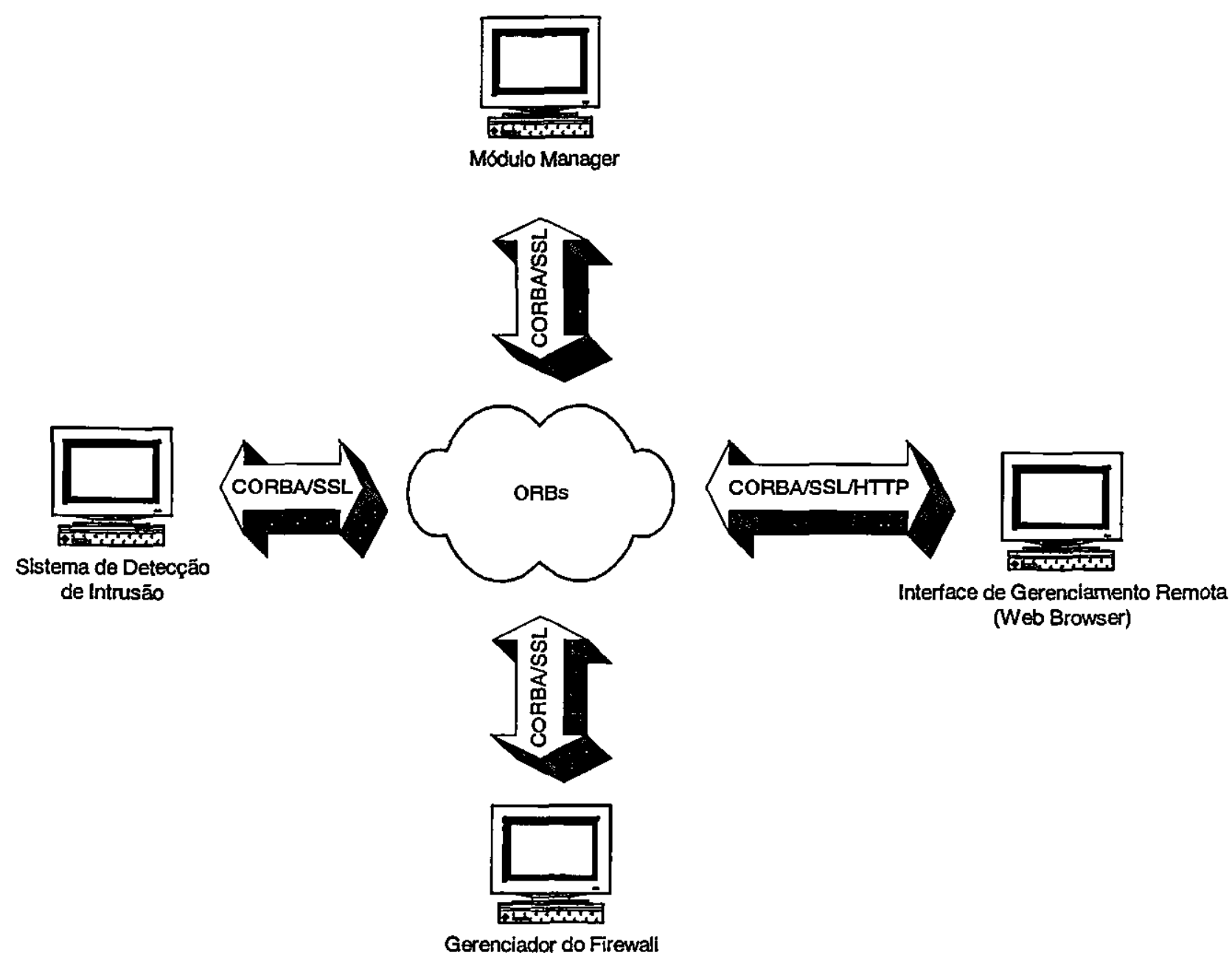

Figura 21 - Arquitetura do sistema de segurança distribuído

O módulo Manager é o gerenciador de informaçōes. É ele quem recebe informações do sistema de detecção ACME! e realiza os procedimentos necessários que são:

- Atualizar a interface de gerenciamento de forma que o administrador tenha uma visão em tempo real da situação de segurança da rede.

- Caso o índice de suspeita fornecido pela rede neural esteja acima de um threshold previamente definido, enviar instruções para o módulo gerenciador do firewall para que a conexão em questāo seja bloqueada imediatamente. 
Este threshold deve ser escolhido de acordo com a política de segurança vigente, pois ele tem uma importante implicação no sistema. Um threshold baixo irá fazer com que qualquer conexão que tenha um mínimo comportamento suspeito seja classificada como intrusiva e bloqueada, o que pode levar ao bloqueio de várias conexões normais por apresentarem algum traço que a rede neural identificou como intrusivo, situação conhecida por falso positivo. Em contrapartida, um threshold alto poderá permitir que conexões realmente intrusivas não sejam bloqueadas (falso negativo), apenas apresentadas ao administrador, e este então deverá bloqueála manualmente. As duas alternativas são opostas e refletem políticas diferentes. A primeira deve ser empregada apenas em conjunto com uma política de segurança bastante rígida, ao passo que a segunda é mais flexível e permite um maior grau de liberdade aos usuários.

Além destas funcionalidades, o Manager também poderia acionar um sistema de contramedidas automático ou ativar sistemas de logs adicionais para que se possa fazer uma melhor análise acerca da possível intrusão, ou mesmo para colher mais evidências para uso ern futuros processos legais.

O módulo Manager é um objeto derivado da classe MVApplication do NetTracker, que é a classe base para todas as aplicações subordinadas ao NetTracker.

O módulo da Interface de Gerenciamento é um applet Java que se comunica com o usuário mostrando o estado de suspeita das conexões em tempo real e permite a configuração remota do firewall.

O módulo Gerenciador do Firewall realiza a configuração do firewall pelo módulo Manager, e o Gerenciador do ACME! de enviar informações das conexões suspeitas para o módulo Manager.

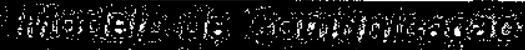

O sistema de segurança tem um modelo de comunicação independente dos módulos, ou seja, são objetos que se comunicam entre si através de CORBA e que interagem com os módulos através de uma API de acesso. 


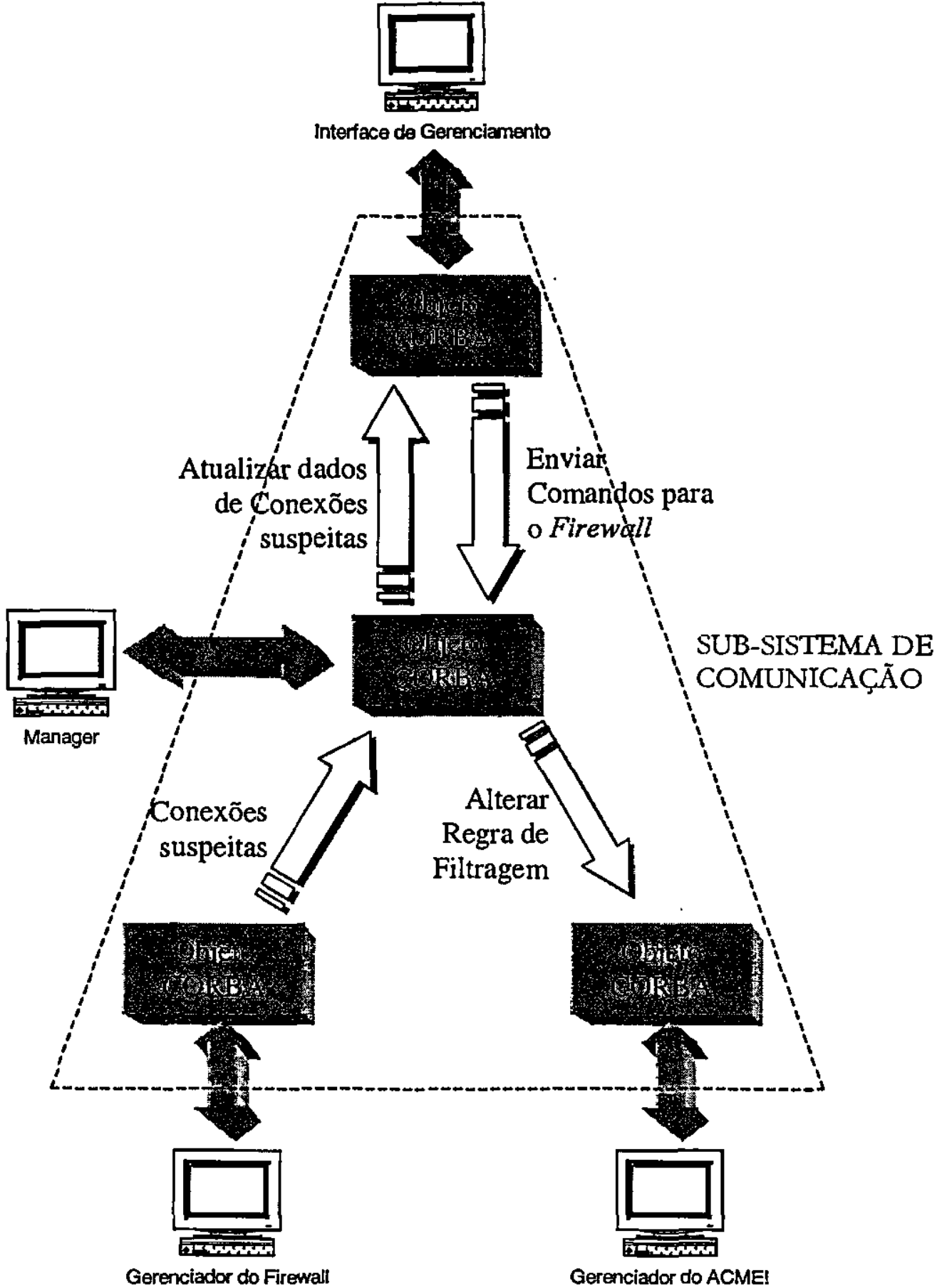

Figura 22 - Modelo de comunicação do sistema de segurança

Este modelo de comunicação, mostrado na Figura 22, cria um subsistema de comunicação independente do restante do sistema mostrado dentro da linha tracejada. 


\section{Th W}

A implementação de CORBA utilizada para desenvolver o sistema de segurança foi o Visibroker $^{12} 3.2$ for Java, uma solução comercial para plataforma Windows NT x86. Porém, o sistema de detecção e o firewall estão ambos em plataforma Linux x86. A solução encontrada foi utilizar outra implementação de CORBA para esta plataforma. Dentre as implementações disponíveis para. Linux, foi escolhido o MICO (Mico Is COrba) ${ }^{13}$. O MICO é uma implementação gratuita de CORBA em C++ para Unix (Linux, Solaris, Digital Unix, HP-UX, AIX, IRIX, Ultrix) e Windows 95/NT. MICO foi desenvolvido na Universidade de Frankfurt e os códigos fontes são disponíveis de acordo com o copyright da GNU.

A comunicação entre um objeto MICO e um Visibroker é gerenciada automaticamente e transparentemente pelas duas implementações através do protocolo IIOP para interações de ORBs de diferentes fabricantes.

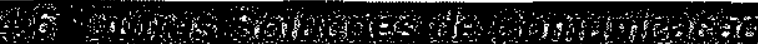

Uma vez que o subsistema de comunicação foi implementado de forma independente do restante dos objetos do sistema, temos uma nítida separação entre os objetos da aplicação e dos objetos de comunicação.

Esta é uma característica interessante sob o ponto de vista de portabilidade. Supondo um caso hipotético onde o firewall ou o sistema de deteç̧ão tenham de ser executados em uma plataforma que não tenha suporte ao padrão CORBA, ou ainda nos casos em que estas soluções não sejam softwares, mas sim hardwares especializados, seria necessária uma remodelação da arquitetura de comunicação de forma a se adaptar este novo cenário.

\footnotetext{
${ }^{12} \mathrm{O}$ site do Visibroker se encontra em http://www.inprise.com/visibroker

${ }^{13} \mathrm{O}$ site do MICO se encontra em http://diamant-atm.vsb.cs.uni-frankfurt.de/ -mico
} 
Como o subsistema de comunicação é independente, ele pode ser trocado por outra solução sem necessidade de alteraçōes drásticas no restante dos códigos. A principal mudança é se rescrever os objetos de comunicações usando outra tecnologia. É também possível ter um ambiente misto, onde diversas soluções são usadas ao mesmo tempo.

Outras soluçōes viáveis podem ser RMI (Remote Method Invocation) (SUN, 1998), um padrão de invocação remota de métodos e serialização de objetos para a linguagem Java ou ainda sockets (Leffler, 1986).

Para atuar como firewall, a solução escolhida foi utilizar uma máquina Intel Pentium 200MHz com $64 \mathrm{MB}$ de memória e com duas placas de rede com o sistema operacional Linux (distribuição RedHat 5). O Linux tem suporte para funcionalidades de firewall, sem a necessidade de se instalar softwares adicionais. Uma solução mais bem elaborada é a utilização do TIS Firewall, gratuito para a plataforma Linux.

No laboratório Intermídia foi criada uma sub-rede interna com duas máquinas, o Linux firewall e uma máquina que fica na sub-rede interna para demonstração das funcionalidades do sistema de segurança. A única alteração feita na rede do Intermídia foi a inserção de rotas estáticas para esta máquina. E ela foi configurada para ter o Linux firewall como seu gateway default.

A configuração das regras de filtragem no Linux pode ser feita basicamente através de dois programas: ifpwadm e ipchains. Através destes programas é possível inserir e retirar regras de filtragem.

Para controlar o firewall através do sistema de segurança, foi desenvolvido um módulo para ser executado na máquina do firewall que recebe os comandos do sistema de segurança e configura o firewall através do ipfwadm. 
O sistema de detecção de intrusão ACME! é um projeto que vem sendo desenvolvido em conjunto pela USP-São Carlos e UNESP-Rio Preto.

No Instituto de Biociências, Letras e Ciências Exatas (IBILCE) ${ }^{14}$ da UNESP foram desenvolvidos os módulos de captura, pré-seleção e conexão do ACME!, além das simulações de comportamentos intrusivos e não intrusivos para treinamento e teste da rede neural.

No Instituto de Ciências Matemáticas e de Computação (ICMC) ${ }^{15}$ da USP foram desenvolvidos os módulos de análise semântica, pós-processador e rede neural.

É importante frisar que o projeto ACME! está em constante desenvolvimento e melhoria de seus recursos e funcionalidades como: desempenho dos módulos, comunicação entre módulos, desempenho da rede neural, novas simulaçőes de comportamentos intrusivos, etc.

No início deste projeto de mestrado, o ACME! encontrava-se no seguinte estágio de desenvolvimento:

- Os módulos de captura, pré-seleção e conexão implementados.

- Comportamentos intrusivos e não intrusivos simulados e guardados em um arquivo.

- Módulo de análise semântica e pós-processamento implementados de forma autônoma (não integrado com os outros módulos), ele apenas processa o arquivo com as simulações e gera como saída os vetores para a rede neural.

- Rede neural treinada e testada a partir do arquivo de saída do módulo de análise semântica através do simulador SNNS.

Tendo-se em vista este cenário, para tornar o ACME! completamente funcional e operacional de forma a todos os módulo operarem integrados sem necessidade de intervenção humana, as seguintes tarefas tiveram de ser realizadas:

\footnotetext{
${ }^{14} \mathrm{O}$ site do IBILCE pode ser encontrado em http://www.ibilce.unesp.br

${ }^{15} \mathrm{O}$ site do ICMC pode ser encontrado em http://www.icmc.sc.usp.br
} 
- Adaptação do módulo de análise semântica para ser integrado com os outros módulos e para trabalhar de forma interativa, ou seja, os dados serem tratados à medida que chegam e não mais lidos já completos de um arquivo.

- Desenvolvimento de estruturas de dados para serem usadas no módulo de análise semântica para aumento de desempenho e tratamento das conexões.

- Geração do código da rede neural em linguagem $\mathrm{C}$ e sua posterior incorporação ao ACME!.

- Desenvolvimento do módulo de comunicação com o sistema de segurança em CORBA.

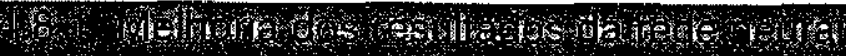

A primeira fase deste projeto foi a melhoria dos resultados da rede neural. Os resultados dos treinamentos estão detalhados na seção 3.5.1. Nos experimentos anteriores, foi conseguida uma rede neural que apresentava uma taxa de erros em torno de $15 \%$. Com os novos treinamentos, esta taxa de erro foi reduzida para valores em torno de $5 \%$, o que significa um aumento considerável de desempenho.

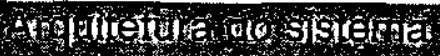

A Figura 23 mostra a arquitetura do sistema ACME! sob a ótica de seus arquivos, como se relacionam e dos fluxos de dados.

Cada módulo está separado por uma linha tracejada e é executado como um processo independente. 


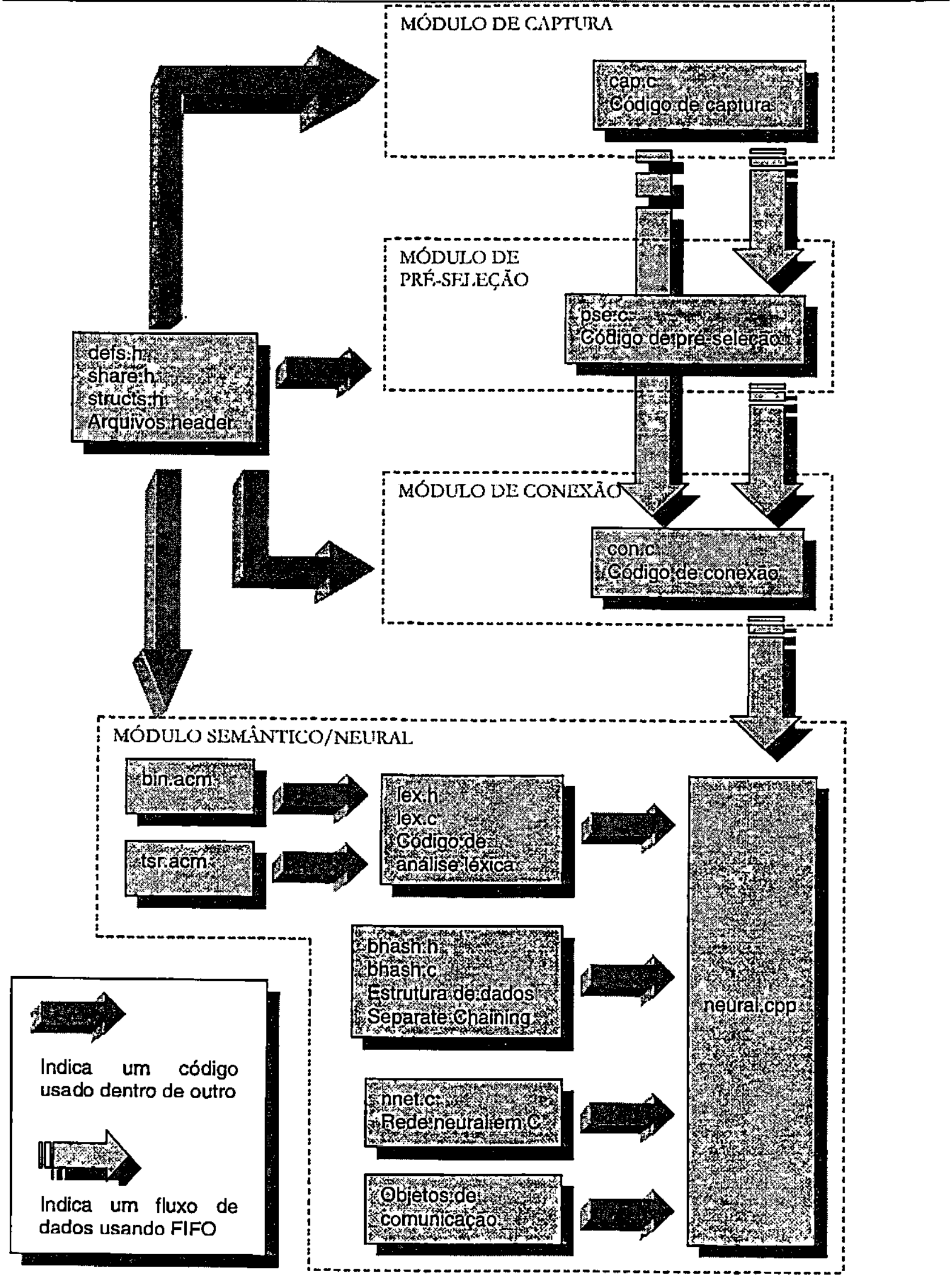

Figura 23 - Arquitetura de arquivos e comunicação do ACME! 
Conforme a legenda, existem dois tipos de setas, as que indicam os fluxos de dados entre os módulos e as que indicam como os arquivos se relacionam. Os fluxos de dados são "named pipes" (arquivos FIFO) pelos quais um módulo escreve dados e o outro lê seguindo a política "First In, First Out". As outras setas representam ou arquivos que são usados em tempo de execução, como no caso dos arquivos bin.acm e tsr.acm, ou de arquivos que foram criados para fins de facilidade de implementaçăo mas que são "linkados" junto com outro arquivo, constituindo um só programa executável.

Os arquivos de header são utilizados em todos os módulos por conterem conteúdo comum:

- defs.h: definições e constantes gerais.

- share.h: códigos para trabalhar com FIFOs e estruturas de dados TCP/IP.

- structs.h: estruturas de cabeçalhos TCP, UDP, IP, de conexão e de monitoração.

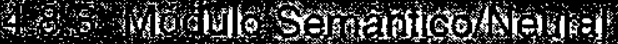

Para efeitos de desempenho e de se evitar o uso de mais um FIFO, foi decidido a implementação dos módulos de análise semântica, pós-processamento e rede neural em um único executável. Deve-se notar que ainda que seja um único executável, os módulos foram implementados separadamente. Mais adiante será apresentada uma análise de desempenho do sistema como um todo.

O arquivo neural.cpp é o responsável pelo tratamento e gerenciamento dos dados. Ele os recebe do módulo de conexão através de um FIFO e armazena-os em uma estrutura de dados junto com os dados de todas as outras conexões monitoradas (a seção seguinte trata desta estrutura de dados).

Os dados monitorados são então analisados pelo analisador léxico que buscará pelas strings suspeitas dentro da conexão. As strings suspeitas que devem ser procuradas ficam armazenadas dentro do arquivo tsr.acm (tabela de símbolos reservados) associadas a um código numérico inteiro. Um exemplo de entradas deste arquivo seria: 


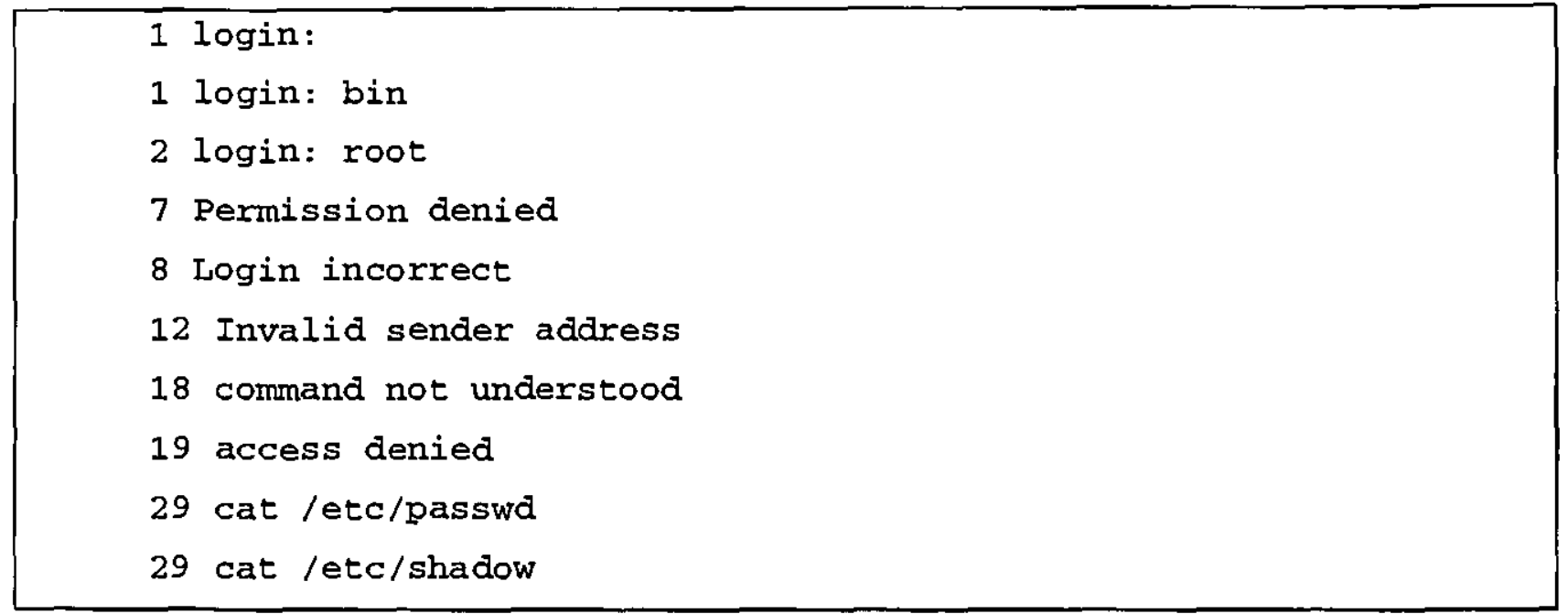

Figura 24 - Exemplo do arquivo tsr.acm

Como várias strings podem ter o mesmo significado, elas são primeiro convertidas em um código inteiro para posteriormente serem convertidas em binário para formarem o vetor de conexão da rede neural. Desta forma, strings com mesmo significado tem o mesmo código inteiro.

A tradução do código inteiro para binário é feita pelo arquivo bin.acm:

$\begin{array}{llllllllllll}1 & 0 & 0 & 1 & 1 & 1 & 0 & 0 & 0 & 1 & 1 & 1 \\ 2 & 0 & 0 & 0 & 1 & 0 & 0 & 0 & 1 & 0 & 0 & 0 \\ 3 & 1 & 1 & 1 & 1 & 0 & 0 & 0 & 0 & 0 & 1 & 1 \\ 4 & 1 & 1 & 0 & 1 & 0 & 1 & 0 & 0 & 1 & 1 & 0 \\ 5 & 1 & 1 & 1 & 0 & 0 & 0 & 1 & 1 & 0 & 0 & 1\end{array}$

Figura 25 - Exemplo do arquivo bin.acm

O analisador léxico é um autômato finito que faz busca e comparação de strings dentro dos dados da conexão com as strings do arquivo tsr.acm e retorna o código binário das strings encontradas. 
Esses códigos binários, mais o código binário da porta utilizada na conexão são reunidos no vetor de estímulo da rede neural e posteriormente analisados.

\subsubsection{Implementação das estruturas de dados}

Neste módulo, não é necessário estarem armazenados todos os dados da conexão, apenas informações relevantes à conexão como portas, endereços IP e tipo da conexão, e as strings suspeitas encontradas dentro da conexão. A solução lógica $\epsilon$, à medida que chegarem novos dados, fazer a busca pelas strings suspeitas e discartar os demais dados, que agora são irrelevantes.

Contudo, ainda é interessante que se tenha toda a conexão guardada para que se possa fazer uma análise do que realmente aconteceu, uma vez que apenas a sequência das strings suspeitas pode não fornecer muitas informações sobre o modo como o ataque foi efetuado. $O$ módulo de Conexão salva todos os dados das conexões monitoradas em arquivos para que possam ser analisados pelo administrador do sistema. Tais arquivos são separados em diretórios cujo nome é o endereço da sub-rede da qual se originava a conexão e os nomes dos arquivos são compostos pelo tipo do pacote (TCP ou UDP), portas e endereços IP de origem e destino.

Em uma rede com alto tráfego, muitas informações estarão chegando ao módulo de análise semântica para serem processadas e enviadas à rede neural, de forma que estes dados devem ser guardados em uma estrutura de dados na memória principal que seja de rápido acesso. Outro problema neste processo é que o módulo recebe os dados à medida que eles são capturados da rede pelo módulo de captura, o que faz com que os dados cheguem geralmente em pequenos grupos de bytes, isto se considerando uma conexão telnet, por exemplo, em que os comandos são digitados interativamente pelo usuário. E cada pequeno grupo de bytes deve ser tratado independentemente, o que também causa um acesso muito grande à estrutura de dados que mantém as conexões.

A escolha da estrutura de dados levou em conta alguns requisitos desejáveis:

- Velocidade de busca.

- Velocidade de operações de inserção. 
- Não ter restrições quanto ao número máximo de elementos armazenados.

- Trabalhar razoavelmente bem em casos extremos (estrutura altamente carregada).

Diante destes requisitos, a estrutura de dados escolhida é uma tabela hash modificada chamada de Separate Chaining. Ela tem várias vantagens em relação a uma tabela hash convencional. Neste tipo de estrutura existe uma tabela hash onde cada posição guarda uma lista encadeada dinâmica na qual cada nó representa uma determinada conexão. A chave de busca é uma string contendo o tipo da conexão (TCP ou UDP), as portas e os endereços IP de origem e destino. A função hash soma o código ASC de cada caracter desta string e faz uma divisão inteira com o número total de posições da tabela hash. Tendo-se este índice, a conexão será representada por um nó na lista encadeada daquela posição do vetor. Neste tịpo de estrutura, não existe o conceito de re-hash.

Esta estrutura é capaz de armazenar dados mesmo quando o número de elementos for maior que o número total de posições alocadas da tabela hash. Em uma tabela hash convencional, quando o número de elementos cresce além do previsto pelo programador, o número de cálculos da função re-hash torna-se altamente proibitivo em termos de desempenho, além de suportar apenas um número máximo de elementos. Com a estrutura escolhida, o número de elementos pode crescer sem perda considerável de desempenho. Ela ainda apresenta um desempenho razoável em situações que tenham muitos elementos inseridos.

A Figura 26 exemplifica uma estrutura deste tipo em que são mostradas três posições da tabela hash e três conexões sendo monitoradas, a primeira parte do nó que guarda a conexão contém a chave, que é o tipo da conexão, o endereço IP e a porta de origem e o endereço IP e a porta de destino. A segunda parte guarda as informações relativas à conexão, como a lista de strings suspeitas encontradas, nível de segurança fornecido pela rede neural e outras coisas. E por fim, um ponteiro para o próximo nó. 


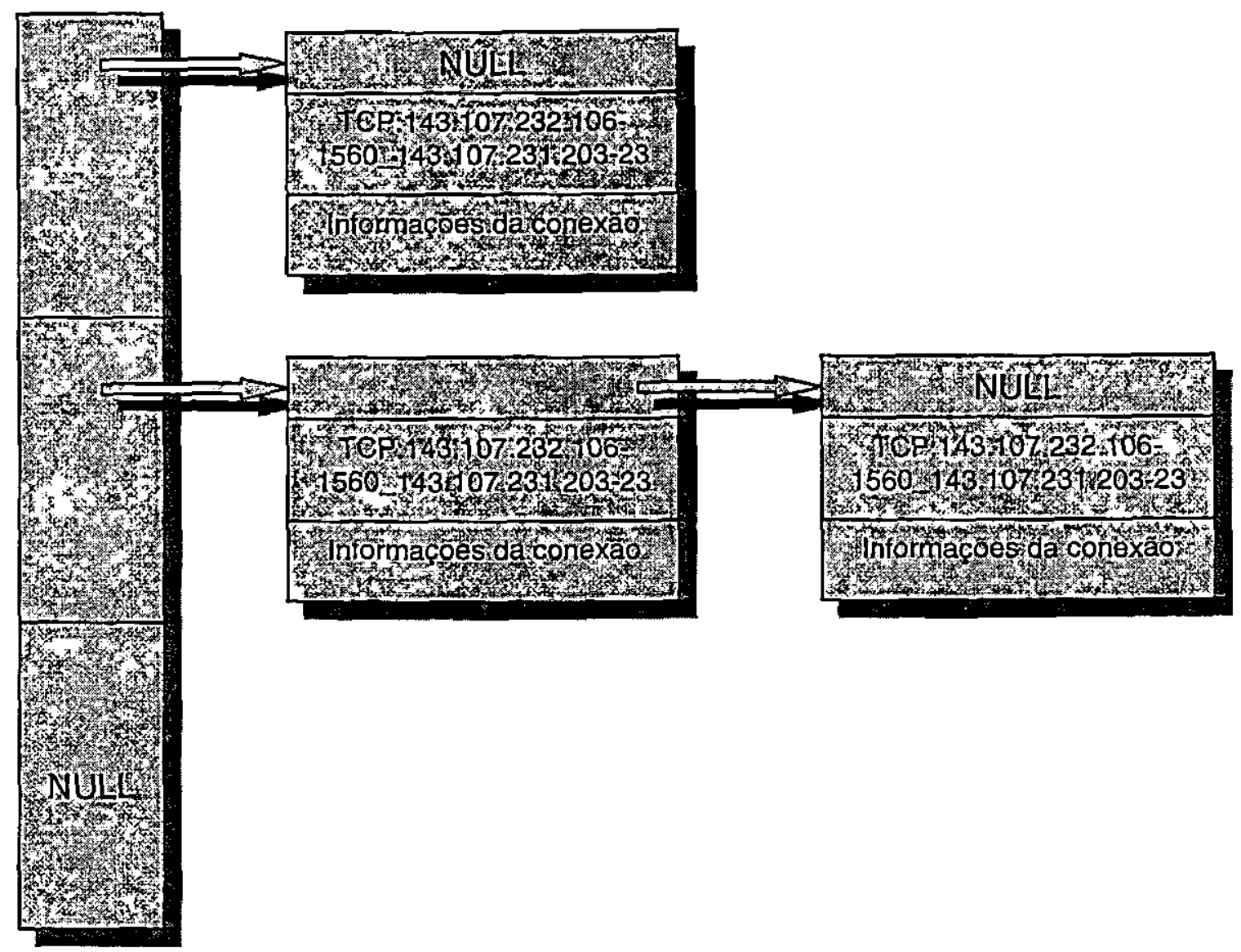

Figura 26 - Estrutura de dados Separate Chaining

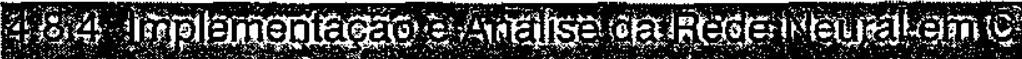

A rede neural foi primeiramente treinada e simulada através do simulador SNNS. Este simulador permite criar uma rede, definindo-se quantas e de que forma são as camadas de neurônios que a rede terá e também treiná-la através de arquivos de padrões de treinamento e validação. Tais arquivos contêm as entradas para a rede e o valor de resposta esperado. Ela é treinada até que se consiga um bom nível de acerto nas respostas.

Feito o treinamento, ela é testada com um outro arquivo, o de teste, nos mesmos moldes dos anteriores. É com base na porcentagem de acertos que a rede tem com este arquivo que definimos sua eficiência. Nos testes, foi conseguido um grau de acerto em torno de $95 \%$. 
Cada arquivo não contém exemplos iguais e possui em igual número exemplos de comportamentos intrusivos e não-intrusivos para que a rede não fique "viciada".

A Figura 27 mostra a janela de treinamento da rede, indicando a diminuição do erro médio à medida que o treinamento prossegue.

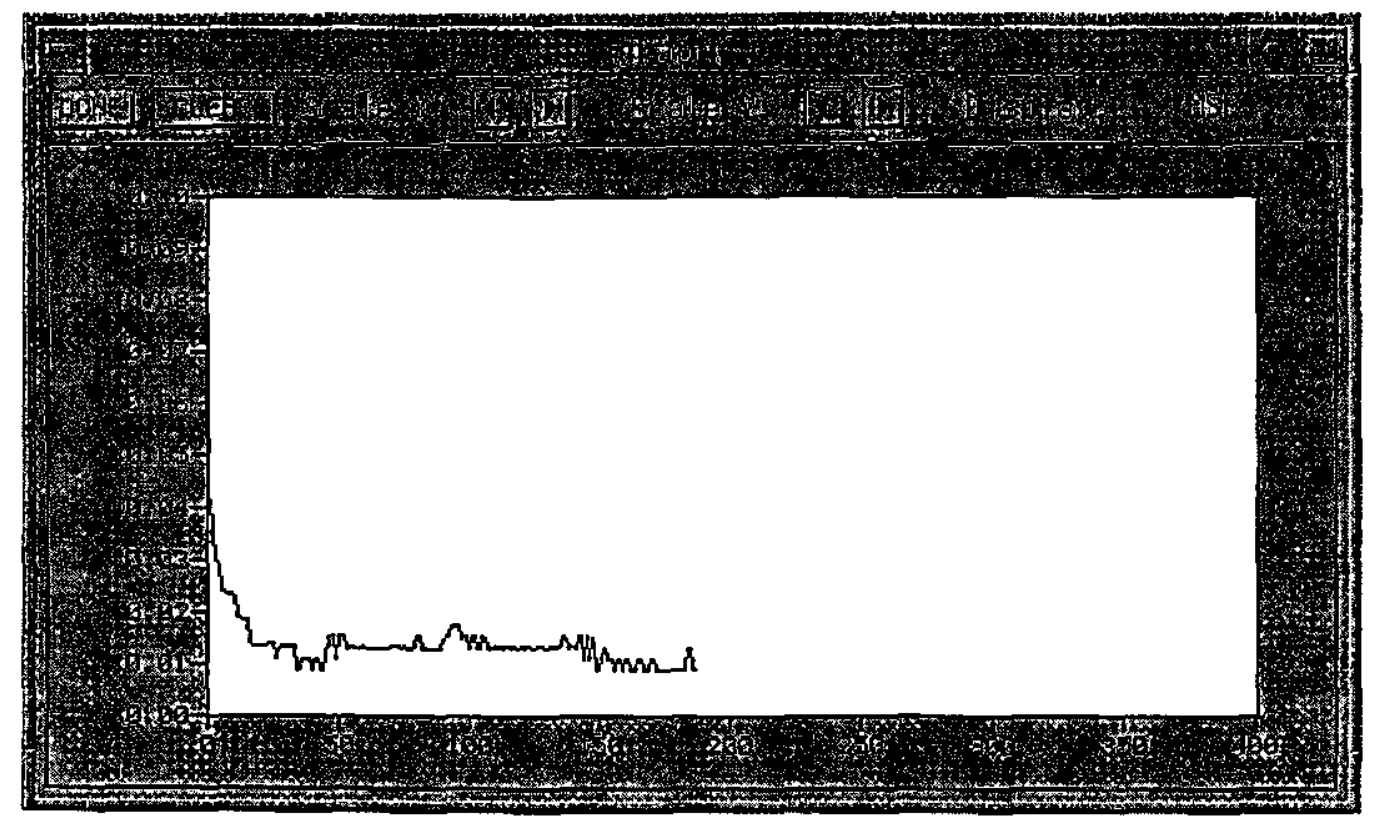

Figura 27 - Janela indicando a diminuição do erro da rede neural

Para realizar a adaptação ao novo cenário, o pacote SNNS vem com um utilitário chamado snns $2 c$ que gera um código $C$ a partir de uma rede neural previamente treinada.

O treinamento ainda tem de continuar sendo feito através do SNNS, mas uma vez que se tenha uma rede treinada, ela é salva em um arquivo com a extensão .net. Este arquivo guarda informações referentes à arquitetura da rede, números de neurônios, conexões, algoritmos de treinamento e outras informações importantes.

O snnc2c cria um arquivo .c e um .h que contém as estruturas de dados necessárias e a função que calculará a saída da rede neural com base em um vetor de entrada. A função que implementa a rede neural é chamada diretamente dentro do código do módulo Semântico/Neural. $\dot{O}$ arquivo $h$ pode ser visto na Figura 28 , mostrando a função neuralnet. 


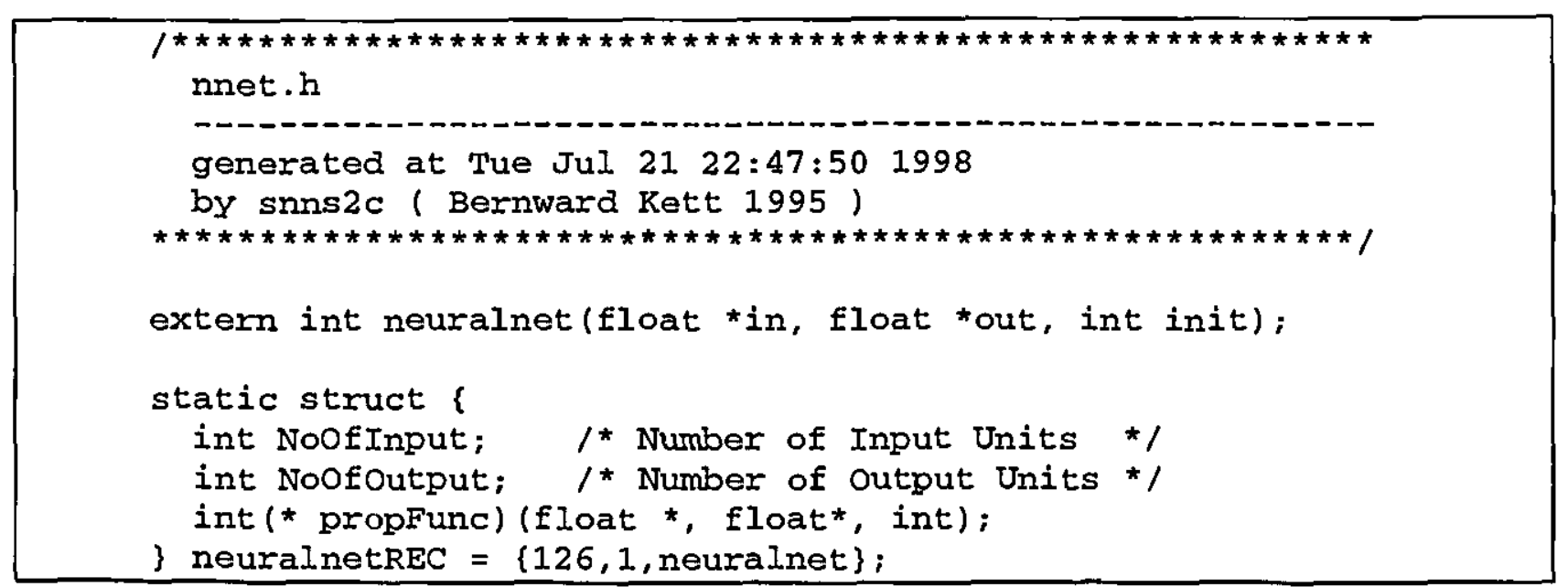

Figura 28 - Arquivo nnet.h mostrando a função que implementa a rede neual

Esta solução tem um ponto falho no que se refere a novos treinamentos da rede. O código C gerado corresponde apenas a uma determinada rede já treinada. Caso novos treinamentos sejam necessários, deve ser novamente utilizado o SNNS. Ele não provê nenhum recurso de se gerar um código que incorpore também funcionalidades de treinamento. Outros simuladores possuem esta funcionalidade e deveräo ser pesquisados em trabalhos futuros para este sistema.

A rede neural que foi utilizada aqui tem quatro camadas onde a primeira, a de entrada, possui 126 neurônios correspondentes aos 126 bits do vetor de estímulo (6 bits para codificar a porta da conexão mais 10 códigos de 12 bits para cada string suspeita encontrada); a segunda camada tem 20 neurônios; a terceira 5 e a quarta, a camada de saída tem apenas um neurônio. Esta camada fornece como resposta um número real que varia de 0 a 1 , indicando o nível de suspeita da conexão. Quanto mais próximo de 1 for este número, mais suspeita a conexão, e quanto mais próximo de 0 , menos suspeita.

A rede usada é uma rede do tipo full connected, ou seja, todos os neurônios de uma camada se ligam a todos os neurônios da camada seguinte. Existem métodos para se extrair conhecimento a partir dos valores das conexões e para diminuir o número de conexões, deixando apenas as conexões realmente necessárias. Isto visa diminuir o tempo que a rede neural leva para fornecer um resultado na medida que diminui o número de cálculos necessários. Isto também 
deverá ser feito em trabalhos futuros neste sistema. O uso de código de treinamento e de estudos mais aprofundados sobre a rede neural utilizada fogem do escopo deste projeto atual.

A rede neural pode ser vista na Figura 29. As linhas entre os neurônios indicam as conexões entre eles. 


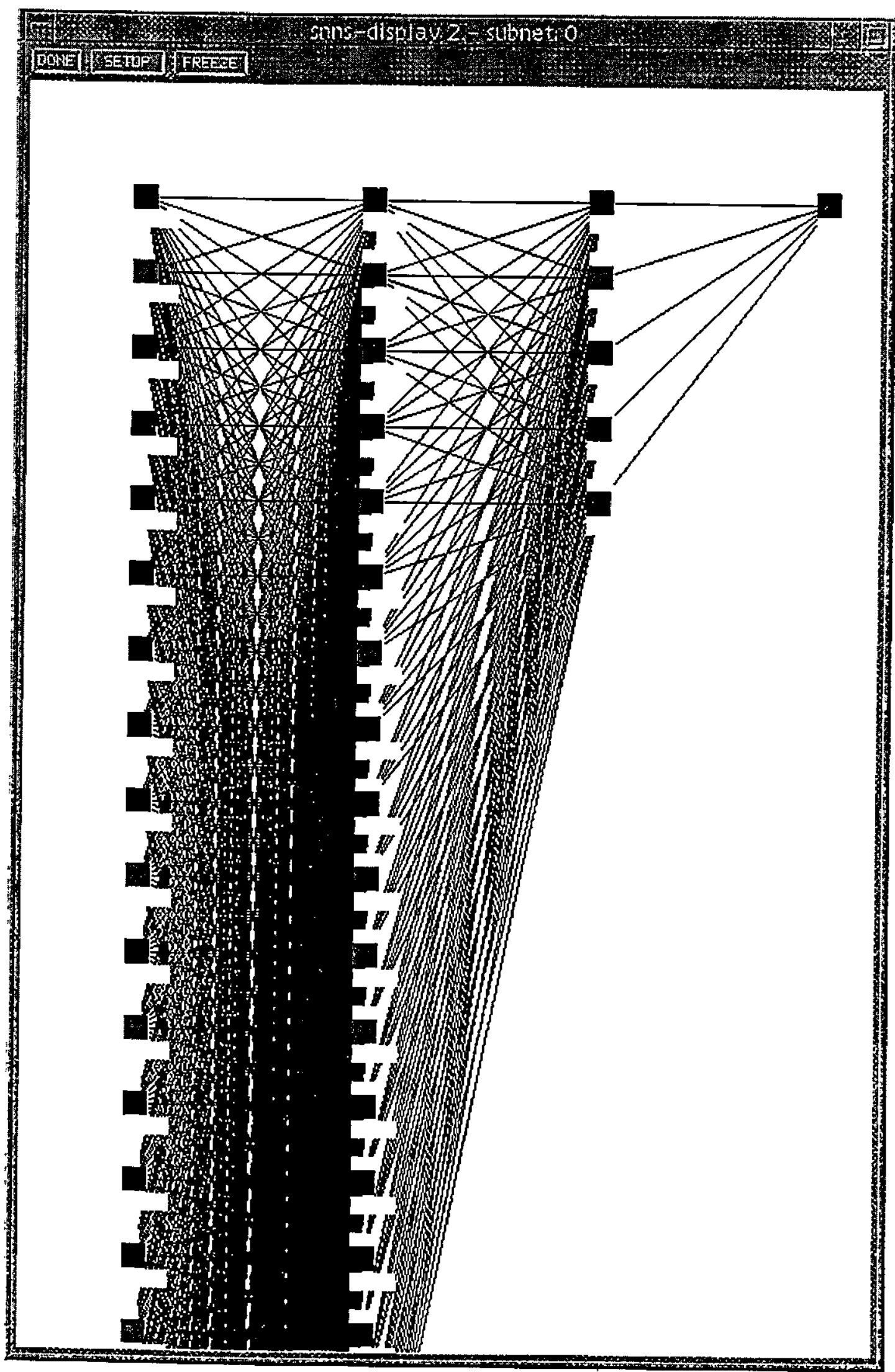

Figura 29 - Visualização gráfica da rede neural no SNNS 
A implementação dos novos módulos e sua integração com os demais já implementados neste protótipo, permite que algumas consideraçōes e análises sejam realizadas. Este ítem trata de duas questões importantes quanto ao sistema: seu uso em ambientes baseados em switch e da análise de desempenho do sistema como um todo.

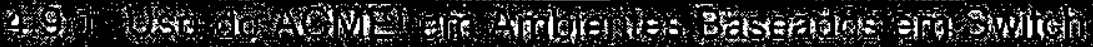

Como o ACME! é um sistema que passivamente monitora a rede em modo promíscuo, e da mesma forma que outros sistemas de detecção de intrusão semelhantes, ele encontra um grave problema para trabalhar em ambientes com grande uso de switches.

Como o switch isola o tráfego entre suas portas, o sistema de detecção não terá acesso aos pacotes que estejam trafegando pelas outras portas, apenas os que forem originados ou destinados à porta em que ele se encontra.

Neste cenário, pode-se citar três alternativas principais:

- Colocar um ou vários sistemas nos pontos críticos da rede, por exemplo no(s) link(s) externo(s). É também interessante colocar junto a servidores e máquinas consideradas críticas, de forma que todo o tráfego que envolva estas máquinas possa ser monitorado.

- Usar switches com capacidades de fazer cópias de pacotes para uma porta específica ou que tenham recursos específicos de monitoração.

- Implementar o sistema de detecção em hardware e inseri-lo dentro do switch, de forma que ele tenha acesso, em nível de hardware, a todo o tráfego que está atravessando o switch. 


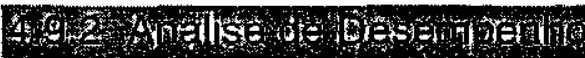

Considerando-se um ambiente de rede altamente carregado ou com tecnologias de 100 Mbits por segundo ou maior, vemos que o desempenho é um fator crítico para um sistema de detecção de intrusão baseado em rede. Ele deve ser capaz de não perder pacotes na rede, pois pode ser que dados importantes que identifiquem um comportamento intrusivo estejam justamente nos pacotes perdidos, o que afetaria diretamente o nível de acerto das inferências da rede neural.

A primeira consideração a ser feita ao desempenho do sistema ACME! é com relação ao modo como os módulos se comunicam. $\mathrm{Na}$ implementação atual, os módulos (captura, préseleção, conexão e semântico/neural) comunicam-se através de "named pipes", que são arquivos especiais em disco que devem ser escritos e lidos, o que leva uma considerável perda de tempo em acessos a disco.

Apesar de deixar o sistema como um todo mais simples de se gerenciar e enfatizar sua característica de modularidade, a implementação de processos independentes comunicando-se através de "named pipes" não é eficiente.

Neste contexto, duas alternativas principais podem ser consideradas. Uma alternativa é a implementação de cada módulo em arquivos separados, mas que são "linkados" e usados dentro de um único processo. A outra alternativa é usar memória compartilhada para realizar a troca de informações entre os módulos.

Como a implementação dos três primeiros módulos já estava feita usando-se "named pipes", foi decidido não alterar-se todo o código já pronto e manter esta política principalmente por questões de tempo de desenvolvimento.

Quanto ao módulo Semântico/Neural que foi inteiramente implementado, essas preocupações foram levadas em consideração. Em vez de criar mais dois módulos (Análise Semântica e Rede Neural) foi decidido colocá-los em um único módulo. Vale lembrar que as implementações estão separadas em arquivos distintos para manter a modularidade do sistema. 
Considerações sobre desempenho também foram feitas quanto às estruturas de dados usadas neste módulo. Diversas estruturas foram analisadas e escolhida a que melhor atendia aos requisitos do sistema, a Separate Chaining, que foi implementada. 


\section{Conclusão} "Quando o inimigo se encontra em uma posiçāo diffcil, nāo deixe-o
olhar ao redor"-Miyamoto Musashi

O crescimento e interligação das redes de computadores traz consigo mudanças radicais nos mais variados setores da sociedade moderna. Mudanças profundas estão ocorrendo em áreas de marketing, negócios, pesquisa, bancárias e muitas outras. Tais mudanças são seguidas de prós e contras. Na mesma medida que possibilitaram o comércio eletrônico, onde uma pessoa no Brasil pode comprar um livro em uma livraria americana (que, interessantemente, não tem uma loja real) sem sair de sua cadeira, também inseriu preocupações com a segurança de tais transações.

É neste cenáriơ que segurança de redes tem se tornado um assunto de crescente importância, e diversas tecnologias foram criadas para esta finalidade. Porém, nenhuma tecnologia ou ferramenta que tenha sido desenvolvida é suficientemente abrangente ou que possa ser considerada o estado-da-arte. Em consequência disso, a integração de diferentes tecnologias, cada qual suprindo as deficiências umas das outras e atuando em conjunto é de extrema importância para se atingir níveis de segurança cada vez maiores.

Neste contexto, o sistema de segurança distribuído foi idealizado e implementado de forma a integrar duas das principais tecnologias de segurança usadas atualmente, um firewall e um sistema de detecção de intrusão. Esta integração uniu um sistema sensor (detecção) com um sistema atuador (firewall) de forma a possibilitar respostas rápidas e automáticas do sistema frente a uma intrusão que esteja ocorrendo sem necessidade de intervenção humana. Ainda com relação à integração de tecnologias, a insersão do sistema de segurança no ambiente de gerenciamento NetTracker possibilitou que um mesmo ambiente tenha funcionalidades de gerenciamento dos recursos da rede e da segurança dos mesmo, sob uma interface única e remota.

Comparado à outras soluções de integração de tecnologias de segurança, como o protocolo IDIP, este sistema de segurança pode ser considerado 
O uso de CORBA e da linguagem Java para a implementação forneceram ao sistema várias características importantes como independência de plataforma, tanto para execução dos objetos do sistema, como para a comunicação com objetos escritos em diferentes linguagens. Isto possibilitou que os objetos do sistema de segurança escritos em Java/Windows NT se comunicassem com os objetos para controle do firewall e do ACME! escritos em C++/Linux.

Paralelamente, a implementação dos módulos restantes e a integração do ACME! permitiu ao sistema fornecer informações a respeito do estado de suspeita das conexões ativas em tempo real para o sistema de segurança.

- Com a grande velocidade com que surgem a cada dia novidades no cenário de técnicas de intrusão, é necessário que se realize frequentemente simulações de conexões com comportamentos suspeitos que exemplifiquem tais técnicas para se manter a rede neural sempre atualizada. Dentre as novas técnicas de intrusão que tem surgido atualmente, pode-se citar o BackOrifice e furos de segurança em tecnologias Internet como activeX e applets.

- Além de inclusão de novas técnicas de intrusão, é interessante também que se faça um estudo mais aprofundado da rede neural, existem técnicas que permitem realizar extração de conhecimento de uma rede treinada para melhorar seu desempenho. Técnicas como esta ainda permitem descobrir quais conexões entre os neurônios são realmente úteis e descartar as demais. Isto diminui o tempo que a rede leva para fornecer uma resposta.

- Para que o ACME! possa operar em redes de alta velocidade, é necessário um esforço no sentido de otimizar todo o código escrito, principalmente no que diz respeito a cornunicação entre os rnodulos, que usa named pipes.

- Para arnbientes corn switches, a solução ideal é sua irnplernentação corno urn módulo de hardware inserido dentro do próprio switch de forma a ter acesso fácil a todos os pacotes que trafegam pelo switch, não importando por quais portas. Esta solução 
ainda tem a vantagem de permitir que o ACME! possa ter um desempenho superior ao de sua versão em software.

- Uma vez que o sistema de segurança foi desenvolvido para dar suporte a integração de diferentes tecnologias de segurança, a integração de novas ferramentas, é de fundamental importância para que se aumente ainda mais as funcionalidades do sistema. Dentre as ferramentas que podem ser incluídas se encontram sistemas de auditoria, analisadores de audit trails para reconhecimento de ataques e outras.

- Uma solução bastante interessante a se integrar dentro do sistema de segurança é o Shogun, um sistema de segurança baseado em agentes móveis desenvolvido no ICMC/USP. Este sistema pode fornecer informações para auxf́lio na inferência sobre o estado de segurança da rede, bem como poder enviar agentes para as máquinas sob ataque. Tais agentes podem realizar diversas funções como uma melhor monitoração e auditoria da máquina em questão ou realizar configurações de software.

- Com a definição de protocolos como o IDIP, é interessante que o sistema como um todo possa, no futuro, ter suporte a este protocolo. 


\section{Referências}

(Bellovin, 1989) BELLOVIN, S. M. Security Problems in the TCP/IP Protocol Suite. Computer Communications Review, 9(2), p.32-48, Abril, 1989. http://www.raptor.com/lib/ipext.pdf.

(Bellovin, 1992) BELLOVIN, S. M. There Be Dragons. In: III USENIX SECURITY SYMPOSIUM, Proceedings, p.1-16, 1992 USENIX Association.

(Bonifácio et al., 1998a) BONIFÁCIO Jr, J. M. et al. Neural Networks Applied in Intrusion Detection Systems. In: THE IEEE INTERNATIONAL JOINT CONFERENCE ON NEURAL NETWORKS IJCNN '98, Proceedings. Anchorage, Alaska, Maio, 1998.

(Bonifácio et al., 1998b) BONIFÁCIO Jr, J. M. et al. Um Ambiente de Segurança Distribuído para a Integração de Firewalls com Sistemas de Detecção de Intrusão. In: XVI BRAZILIAN SYMPOSIUM ON COMPUTER NETWORKS SBRC'98, Anais. Rio de Janeiro, Maio. 1998.

(Bonifácio et al., 1998c) BONIFÄCIO Jr., J. M. et al. Ạ Adaptive Intrusion Detection System Using Neural Networks. In: 14TH INTERNATIONAL INFORMATION SECURITY CONFERENCE SEC'98, PART OF 15TH IFIP WORLD COMPUTER CONGRESS, Proceedings. Viena, Austria, Agosto/Setembro, 1998.

(Cansian, 1997) CANSIAN, A.M. Desenvolvimento de um Sistema Adaptativo de Detecção de Intrusos em Redes de Computadores. São Carlos, 1997. 153p. Tese (Doutorado) - Instituto de Física de São Carlos, Universidade de São Paulo.

(Cansian et. al., 1997a) CANSIAN, A. M. et al. Network Intrusion Detection Using Neural Networks. In: INTERNATIONAL CONFERENCE ON COMPUTATIONAL INTELIGENCE AND MULTIMEDIA APPLICATIONS, ICCMMA'97, Proceedings. Gold Coast, Australia, Fevereiro, 1997. p276-280.

(Cansian et al., 1997b) CANSIAN, A. M. et al. An Adaptative System for Detecting Intrusion in Networks. In: III INTERNATIONAL CONGRESS ON INFORMATION ENGINEERING. Proceedings. Buenos Aires, Argentina, Abril, 1997. p96-105. 
(Cansian et al., 1997c) CANSIAN, A. M. et al. Modelo Adaptativo para Deteç̧ão de Comportamento Suspeito em Redes de Computadores. In: XV BRAZILIAN SYMPOSIUM ON COMPUTER NETWORKS, SBRC'97. Anais. São Carlos, Maio, 1997. p51-60.

(Chapman, 1992) CHAPMAN, D. B. Network (In)Security Through IP Packet Filtering. In: III USENIX SECURITY SIMPOSYUM. Proceedings. Setembro, 1992. p63-76. WWW: http://www.cert.lu/security/documents.html

(Chapman \& Zwicky, 1995) CHAPMAN, D. B.; ZWICKY, E. D. Building Internet Firewalls. O'Reilly \& Associates, 1995.

(Cheswick, 1991) CHESWICK, B. (1991). An Evening with Berferd In Wich a Cracker is Lured, Endured, and Studied. AT\&T Bell Laboratories, 1991 WWW: http://www.raptor.com/lib/berferd.pdf.

(Cheswick \& Bellovin, 1994) CHESWICK W. R.; Bellovin, S. M. Firewalls and Internet Security: Repelling the Wily Hacker. Addison-Wesley, 1994.

(Farmer \& Venema) FARMER, D.; VENEMA, W. Improving The Security of Your System by Breaking Into It. WWW: http://www.rootshell.com/docs/improve_by_breakin.txt.

(Freier, Karlton \& Kocher, 1996) FREIER, A. O.; KARLTON, P.; Kocher, P. C. The SSL Protocol Version 3.0. Internet Draft. Netscape Communications, 1996 WWW: http://home.netscape.com/eng/ssl3

(Garfinkel \& Spafford, 1996) Garfinkel, S.; Spafford, G. Practical Unix and Internet Security. 2.ed. O'Reilly \& Associates, 1996.

(Gosling, Joy \& Steele, 1996) GOSLING, J.; JOY, B.; STEELE, G. The Java Language Specification. Addison-Wesley, 1996.

(Howard, 1997) Howard, J. D. An Analysis Of Security Incidents On The Internet. Pittsburgh, 1997. Tese (Doutorado) - Carneguie Mellon University. http://www.cert.org/research/JHThesis/Start.html.

(Leffler, 1986) LEFFLER, S. J. et al. An Advanced 4.4BSD Interprocess Communication Tutorial, Berkeley. CA: Computer Systems Research Group, Department of Electrical Engineering and Computer Science, University of California, Berkeley, 1986. pl-46. 
(Lindholm et al., 1997) LINDHOLM, T. et al. The Java Virtual Machine Specification. AddisonWesley, 1997.

(Morishita, 1997) MORISHITA, F.T. Uma Avaliação Evolutiva dos Protocolos de Gerenciamento da Internet: SNMPv1, SNMPv2 e SNMPv3. São Carlos, 1997. 68p. Dissertação (Mestrado) - Instituto de Ciências Matemáticas e de Computação, Universidade de São Paulo.

(Mouro, 1997) MOURO, R. B. Uma Arquitetura Operacional Extensível para Ferramentas de Gerenciamento de Redes. São Carlos, 1997.60p. Dissertação (Mestrado) - Instituto de Ciềncias Matemáticas de São Carlos, Universidade de São Paulo.

(Mouro, Morishita \& Moreira 1997) MOURO, R. B., MORISHITA, F. T. e MOREIRA, E. S. NetTracker: Uma Arquitetura Operacional Extensível para Ferramentas de Gerenciamento de Redes. In: XV BRAZULIAN SYMPOSIUM ON COMPUTER NETWORKS SBRC'97. Anais. São Carlos, Maio, 1997. p 164-174.

(Mukherjee, 1994) MUKHERJEE, B. Network Intrusion Detection, IEEE Network, May/June, v.8, 1994.

(Vinoski, 1997) VINOSKI, S. CORBA: Integrating Diverse Applications Within Distributed Heterogeneous Environments. IEEE Communications Magazine, v.14, n.2, 1997.

(OMG, 1995) OMG (Object Management Group). The Comom Object Request Broker: Architecture and Specification. Julho, 1995. WWW:

http://www.cs.wustl.edu/ schimidt/CORBA-docs/corba2.0.ps.gz.

(Pabrai \& Gurbani, 1996) PABRAI, U. O.; GURBANI, V. K. Internet \& TCP/IP Network Security: Securing Protocols and Applications. McGraw Hill, 1996.

(Ranum, 1992) RANUM M. J. An Internet Firewall. In: WORLD CONFERENCE ON SYSTEMS MANAGEMENT AND SECURITY. Proceedings. 1992. FTP: ftp://decuac.dec.com/pub/docs/firewall.ps.

(Ranum, 1993) RANUM, M. J. Thinking About Firewalls. In: SANS II CONFERENCE. Proceedings. Abril, 1993. WWW: http://www.cert.lu/security/documents.html

(Rumelhart \& McClelland, 1986) RUMELHART, D.E., MCCLELLAND, J.L. Parallel Distributed Processing: Exploration in the Microstructure of Cognition, MIT Press, 1986. 
(Schimidt \& Vinoski, 1995) SCHIMIDT, D.; Vinoski, S., Object Interconections, Introduction to distributed object computing. C++ Report Magazine. Jan, 1995.

(Schneider, 1995) SCHNEIDER, B. Applied Cryptography: Protocols, Algorithms and Source Code in C. 2.ed. John Wiley, 1995.

(Schoffstall, 1990) SCHOFFSTALL, M. et al. A Simple Network Management Protocol (SNMP). Request for Comment 1157. DSS Network Information Center, SRI International, 1991.

(Siyan \& Hare, 1996) SIYAN, K.; HARE, C. Internet Firewalls and Network Security.2.ed. New Riders Publishing, 1996.

(Snapp, 1991) SNAPP, S. R. et al. Intrusion Detection Systems (IDS): A Survey of Existing Systems and a Proposed Distributed IDS Architecture, Technical Report CSE-91-7, Division of Computer Science, University of California, Davis, Fevereiro, 1991. WWW: http://www.jump.net/ snapp/papers.html.

(Spafford, 1988) SPAFFORD, E. H., The Internet Worm Program: An Analysis. Purdue Technical Report CSD-TR-823, Department of Computer Sciences, Purdue University, 1988.

(Staniford-Chen, Tung \& Schnackenberg, 1998) STANIFORD-CHEN, S.;TUNG, B.;

SCHNACKENBERG, D. The Commom Intrusion Detection Framework (CIDF).

INFORMATION SURVIVABILITY WORKSHOP. Proceedings. Orlando, Outtubro, 1998.

(Position Paper) WWW: http://seclab.cs.ucdavis.edu/cidf/papers/isw.txt.

(SUN, 1998) SUN MICROSYSTEMS. Java Method Remote Invocation Specification. Outubro, 1998. WWW: http://java.sun.com/products/jdk/1.2/docs/guide/rmi/spec/rmiTOC.doc.html.

(Tanenbaum, 1997) TANENBAUM, A. S. Redes de Computadores. 3.ed. Rio de Janeiro, Campus, Rio de Janeiro, 1997. p.657-709.

(Vaccaro \& Liepins, 1989) VACCARO, H. S.; LIEPINS, G. E.; Detection of Anomalous Computer Session Activity. In: IEEE COMPUTER SOCIETY SYMPOSIUM ON SECURITY AND PRIVACY. Proceedings. Maio, 1989. p280-289.

(Venema, 1992) VENEMA, W. TCP Wrapper: Network Monitoring, Access Control and Booby Traps. In USEṄIX Security Symposium III. Proceedings. USENIX Association, Setembro, 1992. p85-92. 
(Wack, 1997) WACK, J. P.; CARNAHAN, L. Keeping Your Site Comfortably Secure: An Introduction to Internet Firewalls. NIST Special Publication 800-10, U.S. Department of Commerce. 1997. WWW: http://www.raptor.com/lib/intro-fw-draft.ps.

(Wagner \& Shneider, 1996) WAGNER, D.; SHNEIDER, B. Analysis of the SSL 3.0 Protocol. In: SECOND USENIX WORKSHOP ON ELECTRONIC COMMERCE. Proceedings. Oakland, California, Novembro, 1996. 


\section{Apêndice A - Site ACME!}

Para realizar uma melhor divulgação da pesquisa e resultados do projeto ACME!, foi criado um site. Neste site estão todos os artigos publicados pelo grupo em formato PostScript, uma breve descrição de cada membro do grupo e a página inicial com dados sobre as instituições de pesquisa envolvidas e outros dados importantes. $O$ site pode ser encontrado em http://www.intermidia.icmc.sc.usp.br

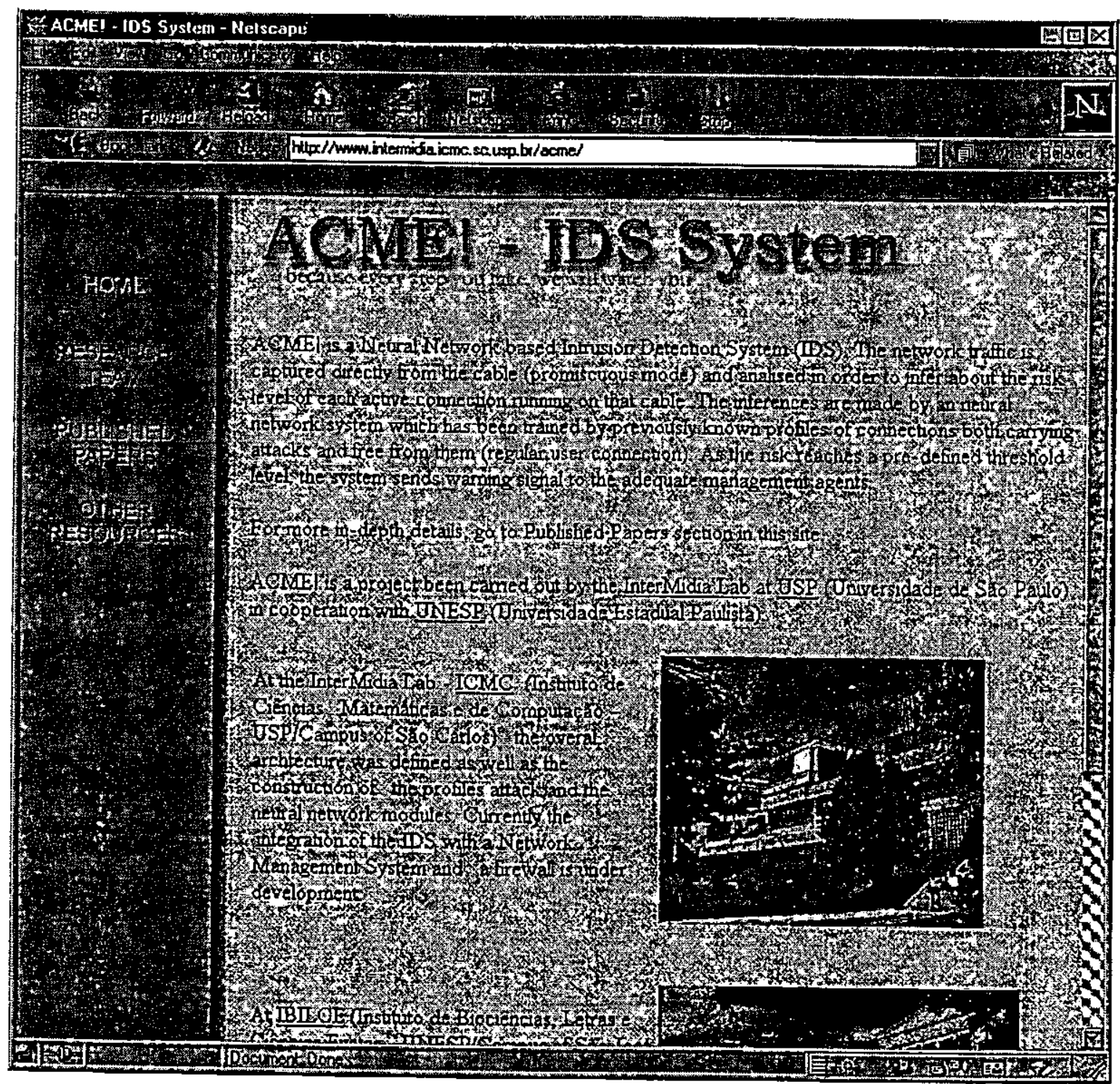

Figura 30 - Página principal do site ACME! 


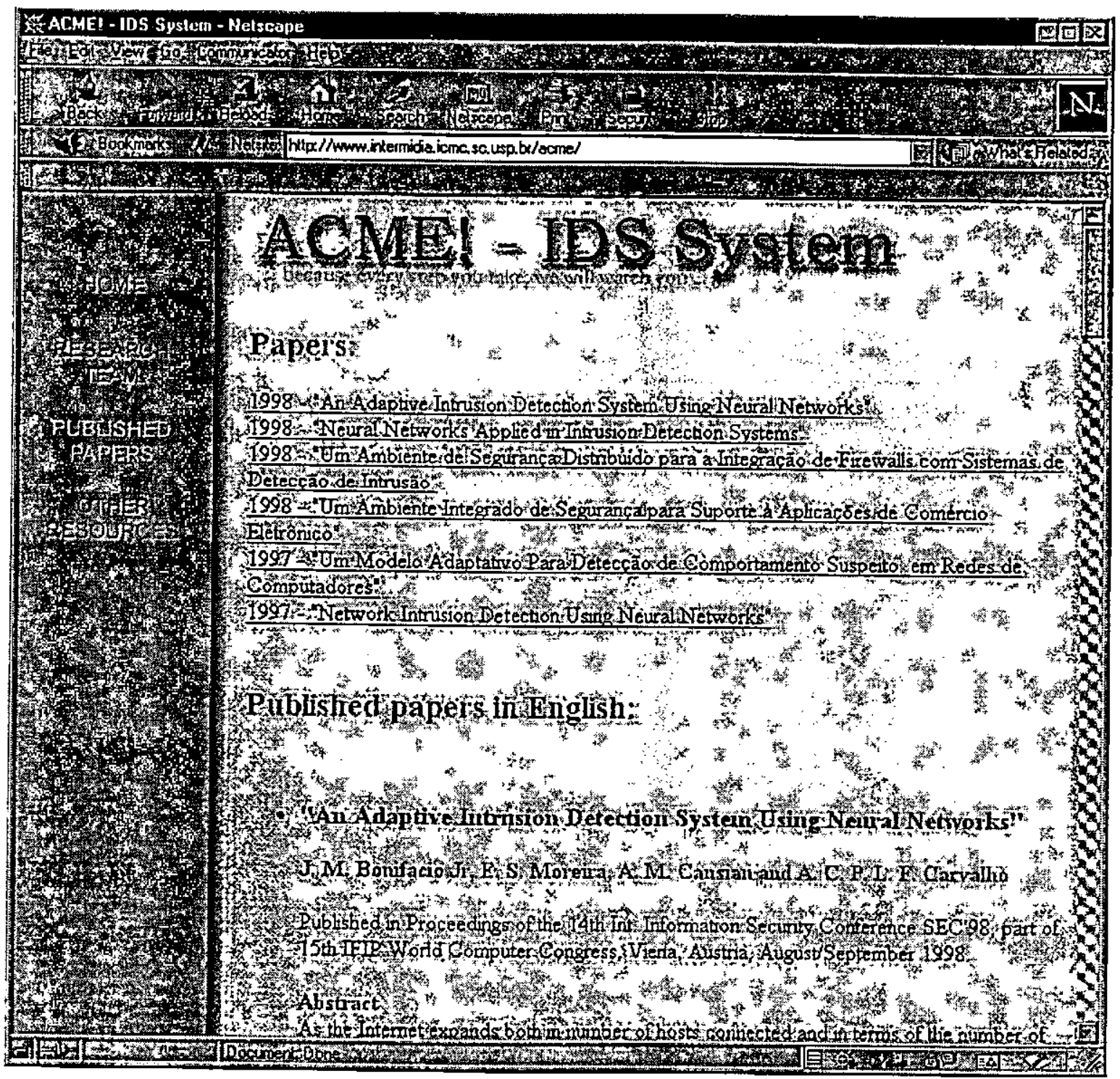

Figura 31 - Página com os artigos publicados 


\section{Apêndice B - Artigos Publicados}

Ao longo deste projeto de mestrado foram submetidos 8 artigos para congressos nacionais e internacionais, dos quais 6 foram aceitos. Nas próximas páginas serão apresentadas a primeira página de cada um dos artigos e, respectivamente, o congresso em que ele foi publicado.

Pelo número de artigos publicados, podemos ver a boa aceitação desta linha de pesquisa perante a comunidade acadêmica internacional, tanto na área de redes neurais como de redes de computadores e segurança. 


\title{
An Adaptive Intrusion Detection System Using Neural Networks
}

\author{
J. M. Bonifácio Jr', E. S. Moreira', A. M. Cansian ${ }^{2}$ and A. C. P. L. F. \\ Carvalho' \\ '\{boni, edson, andre\}@icmsc.sc.usp.br \\ Instituto de Ciências Matemáticas de São Carlos ICMSC/USP \\ Po Box 668 - CEP 13560-970 - São Carlos - SP - Brazil \\ 2adriano@unesp.br \\ UNESP - Universidade Estadual Paulista IBILCE/S.J.Rio Preto \\ Po Box 136 CEP 15970-001 - São José do Rio Preto - SP - Brazil
}

\begin{abstract}
As the Internet expands both in number of hosts connected and in terms of the number of services provided, security has become a key issue for the technology developers. This work presents and analyses a prototype of an intrusion detection system. This system, positioned at key points of the network, will keep looking at the passing packets, in search of suspicious connections. The system provides a list of such connections for the administrator, enabling him/her to take the proper action at an early stage of the intrusion. Neural Networks are used to look for profiles of intrusion within the analysed data streams. The assessment is done through comparison with well-known profiles of intrusion. The system is highly adaptive, since new profiles can be added to the database and the Neural Network re-trained to consider them.
\end{abstract}

Key Words

Intrusion Detection System, Network Security, Neural Networks

\section{INTRODUCTION}

The security, possession and handing of information have become an aspect of crucial importance for the whole society. On the other hand, piracy acts, intrusion attempts, consummate invasions and break-in actions are becoming frequent and involve an increasingly high number of computers (Bace, 1994)(Neumann, 1989). This scenario brings up the need for special security techniques in modern computer systems; ones that go beyond the traditional "locking up the doors" practice.

Various Intrusion Detection Systems (IDS) (Lunt, 1993) have been developed and some of them have been introduced experimentally. These systems are divided into host-based (Javitz, 1991)(Winkler, 1990)(Lunt, 1990) and network-based (Heberlein, 1990, 199I)(Spirakis, 1994). Host-based systems use audit trails (which 
Artigo publicado nos proceedings do IEEE International Joint

Conference on Neural Networks, IJCNN'98. Anchorage, Alaska,

Maio, 1998

\title{
Neural Networks Applied in Intrusion Detection Systems
}

\author{
José Maurício Bonifácio $\mathrm{Jr}^{1}$, Adriano M. Cansian ${ }^{2}$, André C. P. L. F. de Carvalho ${ }^{3}$, Edson S. Moreira ${ }^{4}$ \\ ${ }^{13 t}$ Instituto de Ciências Matemáticas de São Carlos - Universidade de São Paulo \\ Cx Postal 668, 13560-970 São Carlos SP - Brasil \\ \{boni, andre,edson\}@icmsc.sc.usp.br \\ ${ }^{2}$ UNESP Rua Cristóvão Colombo, 226, 515055-000 São José do Rio Preto SP - Brasil \\ adriano@reitoria.unesp.br
}

\begin{abstract}
Information is one of the most valuable possessions today. As the Internet expands both in number of hosts connected and number of services provided, security has become a key issue for the technology developers. This work presents a prototype of a intrusion detection system for TCP/IP networks. The system works by capturing packets and using a neural network to identify an intrusive behavior within the analyzed data stream. The identification is based on previous well know intrusion profiles. The system is adaptive, since new profiles can be added to the data base and the neural network retrained to consider them. It will be presented a proposed model, the results achieved and the analysis of an implemented prototype.
\end{abstract}

\section{Introduction}

An ever-increasing number of essential activities are performed through networks (especially over the Internet) and a correct and reliable operation is vital. On the other hand, piracy acts, intrusion attempts, consummate invasions and break-in actions are becoming frequent and involve an increasingly high number of computers [1][2]. This scenario brings up the need for special security techniques in modern computer systems; ones which go beyond the traditional "locking-up-the-doors" practice.

Various Intrusion Detection Systems (IDS) have been developed and some of them have been introduced experimentally. These systems are divided into host-based and network-based. Host-based systems use audit trails (which are usually daemons) as the main action to detect intrusions, while network-based systems build up their own set of information using the network traffic "sniffed" from the communication medium.

This paper describes the model and a prototype of a network-based security system [18] that uses Neural Networks to find out intruders, to register and learn about their mode of operation and then, to provide elements that can help the system administrator to take action against them.

\section{Detecting suspect conduct}

Attack attempts take place according to some access techniques. In most cases and environments, the intruder is physically away from the system under attack [2]. The early IDS models, designed for isolated computers, use basic algorithms which include multinomial functions evaluation and covariant matrixes approximation in order to detect deviation from normal user behavior [3], as well as expert systems to detect security policy violation [4]. The latest models monitor a large number of network computers and transfer monitored information to be processed by a central equipment for such, that employ distributed systems techniques. These models also have the traffic over network [5] as part of their detection algorithms. Most of the IDS have an auditor process (daemon) in each machine, responsible for capturing security violation actions within that machine. Networkbased systems rather than using audit trails, analyze the traffic of packets within the network to detect intrusive behavior [7].

One of the proposals for innovating our management system consists of introducing a security agent able to detect intrusive behavior in established connections. This agent acts by capturing and deciphering packets which are transmitted through the network under monitoring. In order to make inference about the security condition of the connections, the agent will employ an Expert System and a Neural Network that will provide a number, which, based on previously recorded intrusive information, can give an idea about the severity of attack or the degree of suspicion of the activities in that connection.

The system is based on the fact that an intrusion can be detected from an analysis of predetermined models, which are anomalous compared with normal actions. The 
Artigo publicado nos anais do XVI Brazilian Symposium on Computer Networks, SBRC98. Rio de Janeiro, Brasil, Maio, 1998. p561-576.

\title{
Um Ambiente de Segurança Distribuído para a Integração de
} Firewalls com Sistemas de Detecção de Intrusão

\author{
José M. Bonifácio Jr${ }^{1}$, Edson S. Moreira ${ }^{1}$, Adriano M. Cansian ${ }^{2}$ e André C. P. L. F. de \\ Carvalho'. \\ ${ }^{1}\{$ boni, edson, andre\}@icmsc.sc.usp.br \\ Instituto de Ciências Matemáticas de São Carlos - ICMSC/USP \\ Po Box 668 - CEP 13560-970 - São Carlos - SP - Brasil \\ 2adriano@ibilce.unesp.br \\ UNESP - Universidade Estadual Paulista - IBILCE / S.J.Rio Preto \\ Po Box 136 - CEP 15970-00I - São José do Rio Preto - SP - Brasil
}

\section{Resumo}

Com o atual crescimento no uso de computadores e redes de computadores, aliado ao seu uso para atividades essenciais e comerciais, e a interligaçâo de redes corporativas à Internet, segurança de computadores se torna um assunto chave nas mais diversas áreas. Paralelamente a este crescimento, é também observado um aumento nas tentativas de intrusão e ataques à redes de computadores. Este trabalho mostra um sistema de deteç̧ão de intrusão baseado em redes neurais e os resultados obtidos de um protótipo implementado. Este sistema de detecção será integrado à um firewall dentro de um ambiente de segurança distribuido. Esta integração visa complementar o firewall com as capacidades do sistema de detecçäo de inferir sobre o conteúdo das conexões permitidas pelo firewall.

Abstract

With the current growing in the use of computers and networks, their use for essential and commercial activities, and the connection of the corporate networks with the Internet, computer security has become a key issue in several different areas. It is observed too an increasing rate in attack attempts to the computer networks. This work show a intrusion detection system based in neural networks, as well as the results obtained from an implemented prototype. This intrusion detection system will be integrated with a firewall in a distributed security environment. This integration intends for adding to the firewall the capabilities that the intrusion detection system has to make inferences about the content of the connections allowed by the firewall.

Keywords: Intrusion Detection System, Neural Network, Distributed System

\section{Introdução}

Uma das principais características da sociedade moderna é o reconhecimento de que o poder é derivado da posse de informações. Como resultado, a posse, o manuseio e a proteção da informação tem se tornado um aspecto de crucial importância para a sociedade em geral. Observa-se uma crescente expansāo do uso de computadores e sua utilização em redes. $\mathrm{O}$ armazenamento de informações sensíveis e sua transferência pela rede tornaram-se características primordiais em sistemas de computação modernos. 
Artigo publicado nos proceedings do V International Congress on Information Engineering, ICIE'98, Buenos Aires, Argentina, Março, 1998.

\title{
Um Ambiente Integrado de Segurança para Suporte à Aplicações de Comércio Eletrônico
}

\author{
José Maurício Bonifácio Júnior, Elderclei Regis Reami, Edson dos Santos Moreira \\ \{boni,reami,edson\} @icmsc.sc.usp.br \\ Instituto de Ciências Matemáticas de São Carlos - ICMSC/USP \\ Po Box 668 - CEP 13560-970 - São Carlos - SP - Brasil
}

\begin{abstract}
Resumo
Com o crescimento da Internet, cada vez mais aplicaçōes e serviços essenciais estāo sendo realizados pela rede. Por outro lado, também são crescentes as tentativas de fraude, ataques à redes privadas e invasões consumadas. Neste cenário, é vital o uso integrado de diversas tecnologias para diminuir a probabilidade de que tais açōes tenham sucesso. Atualmente, um número crescente de empresas estão direcionando seu foco de operações para a Internet, como uma forma rápida e barata de atrair consumidores e alavancar neg 6 cios. Porém, esforços neste sentido frequentemente esbarram em problemas relativos à segurança. Uma vez que se tenha estabelecido um conjunto de características e requisitos que garantam um alto grau de segurança, tanto aos recursos computacionais quanto às transações, uma nova gama de aplicaçōes envolvendo comércio eletrônico e envio de informaçōes sensíveis, terăo uma base sólida sobre a qual se apoiar. Este artigo propōe um ambiente de segurança que integra diversas tecnologias para criar um ambiente altamente seguro sobre o qual as demais aplicaçōes de comércio eletrônico, comunicaçōes seguras e mesmo criação de VPNs podem residir.
\end{abstract}

\begin{abstract}
As the Internet is growing, more and more applications and essential services will be developed to use the network. Accompanying this tendency, is the number of attacks to private networks, fraud attempts and invasions. In this scenario, it is extremely important to integrate different kinds of security technologies, so that the likelihood of those malicious actions having success is diminished. Currently, an increasing number of companies is focusing on Internet-based commercial transactions, as an inexpensive mean to attract more customers, and promote new business opportunities. However, such effort is often troubled by problems related to security. So, there is an urge to the establishment of requirements for applications which demands high-level of security warranty, including transactions and physical resources security. This paper aims to propose a security environment, based on the integration of a plethora of different technologies, that provides a highly secure platform which might be the support for several electronic commerce applications, secure communications, and VPN (virtual private networks) deployment, as well.
\end{abstract}

Keywords: network security, eletronic commerce, secure communications

\section{Introdução}

Uma das principais características da sociedade moderna é o reconhecimento de que o poder é derivado da posse de informações. Como resultado, a aquisição, manuseio e a manutenção da informação têm se tornado um aspecto de crucial importância para a sociedade em geral. Paralelamente, é observada uma crescente expansão do armazenamento e da distribuição, através de redes de computadores, de informações sensíveis.

Por outro lado, atos de pirataria, tentativas de ataque e invasões consumadas tem se tornado frequentes e envolvem um número crescente de computadores destinando-se 
Artigo publicado nos anais do XV Brazilian Symposium on Computer Networks, SBRC97. São Carlos, SP, Maio 1997. p51-60.

\title{
Um Modelo Adaptativo Para Deteç̧ão de Comportamento Suspeito em Redes de
} Computadores

\author{
Adriano M. Cansian \\ (adriano@ibilce.unesp.br) \\ UNESP - Universidade Estadual Paulista - IBILCE / S.J.Rio Preto \\ Po Box 136 - CEP 15970-001 - São José do Rio Preto - SP - Brasil
}
José M. Bonifácio Jr, Edson S. Moreira e André C. P. de L. F. de Carvalho.
(boni, edson, andre@icmsc.sc.usp.br)
Instituto de Ciências Matemáticas de São Carlos - ICMSC/USP
Po Box 668 - CEP 13560-970 - São Carlos - SP - Brasil

\begin{abstract}
Resumo
Todos os sistemas computacionais, notadamente aqueles ligados à Internet, são suscetiveis a ação de atacantes, sejam eles internos ou externos. Neste trabalho apresentamos um modelo de deteç̧ão de intrusos em redes de computadores que operam sobre protocolo TCP/IP. O sistema consiste do reconhecimento de assinaturas de ataque, baseando-se em captura de pacotes. A identificação do comportamento intrusivo é realizada por intermédio de uma rede neural, o que confere grande adaptabilidade $e$ permite acompanhar as modificações das técnicas de ataque. É descrito um modelo de detecção de intrusos, e apresentada a situação atual de implementação de um protótipo do sistema.
\end{abstract}

\begin{abstract}
All computer systems, mainly those connected to the Internet are vulnerable to attacking attempts, both from internal and external sources. In this work we present a TCP/IP based network intrusion detection model. The system consists of a pattern recognizer of attacks, based in capture of packets. The identification of intrusion behovior is realized by a neural network, that provides high adaptability and allows for following up modifications in the attacking techniques. We describe the intrusion detection model and present the current status of the implementation of a prototype.
\end{abstract}

\section{Introdução}

O recente aumento no uso de redes de computadores tem sido seguido por preocupações envolvendo segurança e abuso dos recursos computacionais. Além do mais, um crescente número de atividades essenciais são realizadas através de redes de computadores (especialmente sobre a Internet), e portanto uma correta e confiável operação é vital. Por outro lado, atos de pirataria, tentativas de intrusāo, invasões consumadas e ações de break-ins estão se tornando frequentes e envolvem um alto número de computadores [1-2]. Este cenário cria a necessidade de técnicas especiais de segurança em modernos sistemas de computadores; técnicas que vão além da prática tradicional de se trancar as portas.

Este artigo descreve o estado atual do projeto de um sistema de segurança baseado em redes que usa técnicas de filtro e captura de pacotes, e redes neurais para encontrar intrusos, para registrar e aprender sobre seu modo de operação e então fomecer elementos que ajudem o administrador de sistemas a tomar ações contra eles. O sistema de deteç̧āo é formado por um ou mais agentes de segurança, que são colocados em pontos estratégicos na rede e que fornecem informação ao pessoal ou sistema de gerenciamento.

\section{Deteç̧ão de Comportamento Suspeito}




\title{
Network Intrusion Detection Using Neural Networks
}

\author{
Adriano M. Cansian ${ }^{1}$ \\ (adriano@ibilce.unesp.br) \\ UNESP - Universidade Estadual Paulista - IBILCE / S.J.Rio Preto \\ Po Box 136 - CEP 15970-001 - São José do Rio Preto - SP - Brasil
}

\author{
Edson S.Moreira, André C.P. de L.F. de Carvalho e José M. Bonifácio Jr. \\ (edson, andre, boni@icmsc.sc.usp.br) \\ Instituto de Ciências Matemáticas de Sāo Carlos - ICMSC/USP \\ Po Box 668 - CEP 13560-970 - Sāo Carlos - SP - Brasil
}

\begin{abstract}
A significative number of network computer security intrusions can't be prevented or dealed with simple access control and auditing being executed at standalone computers. Therefore advanced and distributed intrusion detection techniques can play an important role, preventing abuses and protecting information over a networked environment. This work presents current development status of a system which, positioned at key points of the network, will keep looking at the passing packets, in search of suspicious connections. Neural Networks are used to look for profiles of intrusion within the analysed data streams. The assessment is done through comparison with well known profiles of intrusion. The system is highly adaptive, since new profiles can be added to the data base and the Neural Network retrained to consider them.
\end{abstract}

\section{Introduction}

The recent increase in the use of networks has been followed by concerns about computers misuse and security. Additionally, an ever-increasing number of essential activities are performed through neiworks (especially over the Internet), and hence a correct and reliable operation is vital. On the other hand, piracy acts, intrusion attempts, consummate invasions and break-in actions are becoming frequent and involve an increasingly high number of computers [1-2]. This scenario brings up the need for special security techniques in modern computer systems; ones which go beyond the traditional "locking up the doors" practice.

This paper describes the actual status project of a network-based security system that uses techniques of Packet Filtering and Capture and Neural Networks to find out intruders, to register and learn about their mode of operation and then to provide elements that help the system administrator take action against them. The detection system is formed by one or more security agents, which are placed at strategic points in the network and that provide information to the managing personnel or systems.

\section{Suspect Behaviour Detection}

Attack attempts take place according to some access techniques and frequently the intruder is physically away from the system under attack [2]. The early Intrusion Detection Systems (IDS) models, designed for isolated computers, use basic algorithmics which include multinomial functions evaluation and covariant matrixes approximation in order to detect deviation from normal user behaviour [3-4], as well as expert systems to detect security policy violation [7]. The latest models monitor a great number of network computers and transfer monitored information to be processed in a central equipment by employing distributed systems techniques. These models also have the traffic over network [8] as part of their detection algorithmics. Most of the IDS have an auditor process (daemon) in each machine, responsible for capturing security violation actions within that machine. Network-based systems rather than using audit trails, analyse the traffic of packets within the network to detect intrusive behaviour [5][11].

\footnotetext{
'also Instituto de Física de Sāo Carlos - IFSC/USP - Po Box 336 - CEP 13560-970 - Sāo Carlos, SP - Brasil
} 